\title{
Hydrogen Co-deposition Effects on the Structure of Electrodeposited Copper 3
}

\author{
Nebojša D. Nikolić ${ }^{1}$ and Konstantin I. Popov ${ }^{1,2} \quad 4$ \\ ${ }^{1}$ ICTM-Institute of Electrochemistry, University of Belgrade, Njegoševa 12, 5 \\ Belgrade, Serbia \\ ${ }^{2}$ Faculty of Technology and Metallurgy, University of Belgrade, Karnegijeva 4, \\ Belgrade, Serbia
}

\section{INTRODUCTION}

The creation of open porous structures with an extremely high 10 surface area is of great technological significance because such 11 structures are ideally suited for electrodes in many electrochemi- 12 cal devices, such as fuel cells, batteries, and chemical sensors. ${ }^{1}$ The 13 open porous structure enables the fast transport of gases and liquids, 14 while the extremely high surface area is desirable for the evalua- 15 tion of electrochemical reactions. The electrodeposition technique 16 is very suitable for the preparation of such structures because it is 17 possible to control the number, distribution, and pore size in these 18 $\begin{array}{ll}\text { structures by the choice of appropriate electrolysis parameters. } & 19\end{array}$

These metal structures can be formed in both potentiostatic and 20 galvanostatic regimes of electrolysis and their formation are always 21 accompanied by strong hydrogen co-deposition. Hydrogen evolution 22 is the second reaction which occurs at the cathode during electrode- 23 position processes from aqueous solutions; in some cases it can be 24

S.S. Djokić (ed.), Electrodeposition: Theory and Practice,

Modern Aspects of Electrochemistry 48, DOI 10.1007/978-1-4419-5589-0_1,

(c) Springer Science+Business Media, LLC 2010 
ignored while in other cases it cannot. ${ }^{2}$ Co-deposition of hydrogen 25 during chromium electroplating is the best documented system, ${ }^{3,4} 26$ because the cathode current efficiency for chromium electrodeposi- 27 tion is $10-25 \%$. Generally, the effect of hydrogen co-deposition dur- 28 ing metal electrodeposition processes can be manifested through: ${ }^{2} 29$

1. Hydrogen absorption which occurs in the substrate metal as $\mathrm{H} 30$ atoms, not $\mathrm{H}_{2}$ molecules, but may gather as molecule bubbles 31 in voids or vacancies, thus leading to hydrogen embrittlement. 32

2. Hydrogen bubbles which cling to the surface in an adsorbed 33 state; this leads to the growth of pores as the deposition con- 34 tinues around the bubbles before they are released. $\quad 35$

3. Hydrogen bubble evolution can provide a stirring effect and 36 lead to a substantial bubble raft at the free surface of the 37 solution.

The most often employed electrolytes for the electrodeposition 39 of copper are those based on aqueous solutions of sulfuric acid 40 $\left(\mathrm{H}_{2} \mathrm{SO}_{4}\right)$ and cupric sulfate $\left(\mathrm{CuSO}_{4}\right) .{ }^{5}$ The main species present in 41 aqueous sulfuric acid solutions containing $\mathrm{Cu}(\mathrm{II})$ are: bisulfate ions 42 $\left(\mathrm{HSO}_{4}{ }^{-}\right)$, cupric ions $\left(\mathrm{Cu}^{2+}\right)$, aqueous cupric sulfate $\left(\mathrm{CuSO}_{4(\mathrm{aq})}\right), 43$ hydrogen ions $\left(\mathrm{H}^{+}\right)$, and sulfate ions $\left(\mathrm{SO}_{4}{ }^{2}-\right){ }^{6-8} \mathrm{In}$ an aqueous 44 solution of sulfuric acid and cupric sulfate, two weak electrolytes, 45 $\mathrm{HSO}_{4}{ }^{-}$and $\mathrm{CuSO}_{4(\mathrm{aq})}$, are formed according to the following 46 reactions:

$$
\begin{aligned}
& \mathrm{H}^{+}+\mathrm{SO}_{4}^{2-} \rightleftarrows \mathrm{HSO}_{4}^{-} \\
& \mathrm{Cu}^{2+}+\mathrm{SO}_{4}^{2-} \rightleftarrows \mathrm{CuSO}_{4(\mathrm{aq})}
\end{aligned}
$$

Pitzer's model $^{9}$ was used to calculate the ionic equilib- 48 rium in the $\mathrm{CuSO}_{4}-\mathrm{H}_{2} \mathrm{SO}_{4}-\mathrm{H}_{2} \mathrm{O}$ system over a wide range 49 of concentrations and temperatures. ${ }^{8}$ Using Pitzer's model, the rela- 50 tive concentrations of hydrogen ions $\left(\mathrm{H}^{+}\right)$as a function of the total 51 copper concentration and solution acidity were calculated, and this 52 dependence is presented in Fig. 1. From Fig. 1 it can be clearly seen 53 that increasing the copper concentration produces a sharp decrease 54 in the hydrogen ion concentration, while increasing the concen- 55 tration of sulfuric acid produces an increase in the hydrogen ion 56 concentration.

According to (1) and (2), the addition of sulfuric acid to the so- 58 lution decreases the concentration of free sulfate ions due to the 


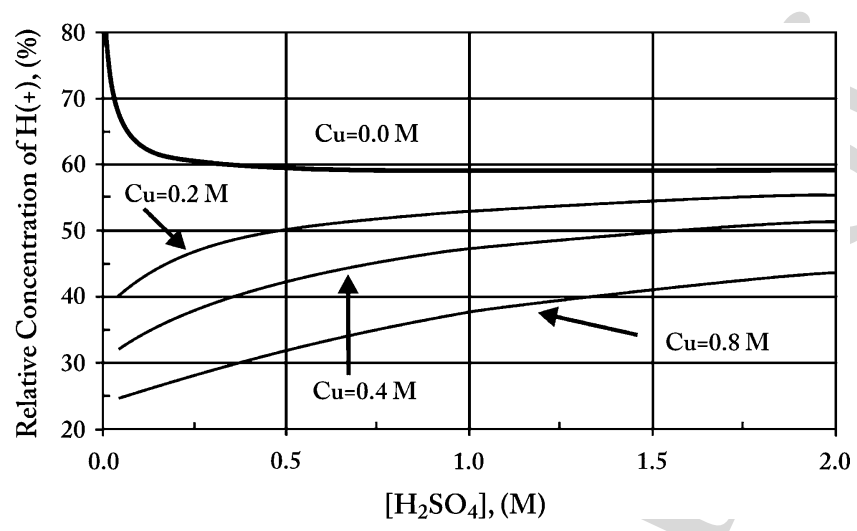

Figure 1. Relative concentration of hydrogen ions as function of sulfuric acid and total copper concentrations, at $25^{\circ} \mathrm{C}\left(C_{\mathrm{RH}}=\left[\mathrm{H}^{+}\right] /\left[\mathrm{H}_{\mathrm{T}}\right]\right)$. (Reprinted from Ref. ${ }^{8}$ with permission from Elsevier).

formation of bisulfate ions. The addition of cupric sulfate to the 59 solution increases the concentration of bisulfate ions and decreases 60 the concentration of hydrogen ions.

In the case of copper electrodeposition, ${ }^{10}$ as opposed to other 62 metals such as nickel and cobalt, ${ }^{11,12}$ there are well-defined ranges 63 of current densities and overpotentials without and with hydrogen 64 co-deposition. The beginning of the hydrogen evolution reaction, 65 as the second reaction, corresponds to some overpotential belong- 66 ing to the plateau of the limiting diffusion current density, being 67 higher than the critical overpotential for the initiation of dendritic 68 growth and lower than that for instantaneous dendritic growth. ${ }^{13}$ In- 69 creasing the overpotential intensifies the hydrogen evolution reaction 70 and at some overpotential outside the plateau of the limiting diffu- 71 sion current density, hydrogen evolution becomes vigorous enough 72 to change the hydrodynamic conditions in the near-electrode layer. 73 This offers the possibility of detailed investigations and comparison 74 of the morphologies of copper, and consequently, of any other met- 75 als, obtained without and with hydrogen co-deposition. 76

In the case of copper, electrodeposition at low overpotentials 77 produces large grains with relatively well-defined crystal shapes. 78 Further increasing the overpotential leads to the formation of 79 cauliflower-like and carrot-like protrusions, and finally, dendritic de- 80 posits are formed in the absence of strong hydrogen co-deposition. ${ }^{13} 81$ 
Strong hydrogen co-deposition leads to a mixing of the solution and 82 changes the mass transfer limitations at an electrode surface. At the 83 same time, the evolved hydrogen bubbles exert substantial effects 84 on mass and heat transfer, limiting current density and ohmic re- 85 sistance, ${ }^{14-16}$ as well as on the morphology of the deposit, leading 86 to the formation of open porous structures with an extremely high 87

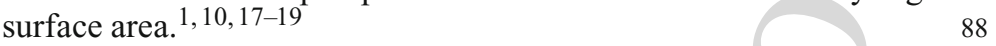

Electrodeposition of copper under conditions of a vigorous hy- 89 drogen co-deposition is of high technological significance, because 90 open porous structures of copper with an extremely high surface area 91 are suitable for the construction of nanocomposite anodes (consist- 92 ing of $\mathrm{Cu}$ and $\mathrm{CeO}_{2}$ ) for solid oxide fuel cells. ${ }^{1}$ Also, copper shows 93 a high activity for nitrate ion reduction, ${ }^{20}$ as well as for a reaction in 94 which nitrate is reduced to ammonia in high yield in aqueous acidic 95 perchlorate and sulfate media. ${ }^{21} 96$

Bearing in mind the great practical significance of copper de- 97 posits obtained under the conditions of hydrogen co-deposition, as 98 well as the fact that detailed investigations at high current densities 99 and overpotentials have been performed only from the point of view 100 of the formation of metal powders, ${ }^{13,22-25}$ a better understanding of 101 the effect of hydrogen evolution on the electrodeposition of copper 102 at high overpotentials is necessary.

The morphology of electrodeposited copper in the presence of 104 vigorous hydrogen evolution was described recently, ${ }^{1}$ and the mech- 105 anism of the formation of this type of morphology was established 106 by Nikolić et al. ${ }^{10}$

The aim of this chapter was to give comprehensive treatment of 108 the morphology of copper electrode posited at high overpotentials, 109 especially in the presence of hydrogen co-deposition, obtained in the 110 potentiostatic conditions from different electrolytes and at different 111 temperatures.

\section{THE CONCEPT OF "THE EFFECTIVE} OVERPOTENTIAL”

1. The Definition of the Concept and Mathematical Model

The polarization curve for copper electrodeposition from $0.15 \mathrm{M} 116$ $\mathrm{CuSO}_{4}$ in $0.50 \mathrm{M} \mathrm{H}_{2} \mathrm{SO}_{4}$ is shown in Fig. 2. The average current ef- 117 ficiencies for hydrogen evolution reaction, $\eta_{\mathrm{av}}\left(\mathrm{H}_{2}\right)$, in potentiostatic 118 
Hydrogen Co-deposition Effects on Copper Electrodeposition

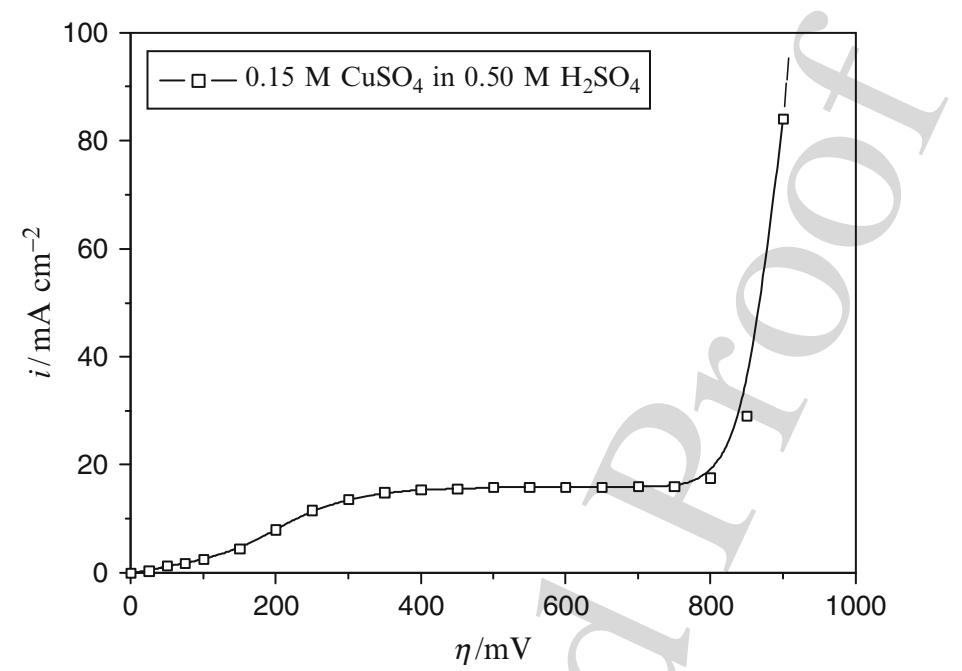

Figure 2. Polarization curve for the cathodic process of copper deposition from $0.15 \mathrm{M} \mathrm{CuSO}_{4}$ in $0.50 \mathrm{M} \mathrm{H}_{2} \mathrm{SO}_{4}$. Temperature: $18.0 \pm 1.0^{\circ} \mathrm{C}$. (Reprinted from Ref. ${ }^{10}$ with permission from Elsevier).

deposition are derived from the dependences of the current of copper 119 electrodeposition on time and the dependences of the volume of the 120 evolved hydrogen on time ${ }^{10}$ using procedure described in Ref. ${ }^{26} 121$

The average current efficiency for hydrogen evolution reaction 122 at an overpotential of $700 \mathrm{mV}$ was very small (near $2.0 \%$ ), ${ }^{10}$ and at 123 lower overpotentials it even cannot be observed. The average current 124 efficiency for the hydrogen evolution at an overpotential of $800 \mathrm{mV} 125$ was $10.8 \%$, while at an overpotential of $1,000 \mathrm{mV}$ was $30.0 \%{ }^{10}$ The 126 critical overpotential for the beginning of the hydrogen evolution can 127 be estimated to be about $680 \mathrm{mV} .^{10}$

The morphologies of copper electrodeposits obtained potentio- 129 statically, onto vertical stationary copper wire electrodes previously 130 covered by copper thin films ${ }^{10}$ from a copper solution containing 131 $0.15 \mathrm{M} \mathrm{CuSO}_{4}$ in $0.50 \mathrm{M} \mathrm{H}_{2} \mathrm{SO}_{4}$, at a temperature of $18.0 \pm 1.0^{\circ} \mathrm{C}$ in 132 different hydrogen co-deposition conditions are shown in Figs. 3-10. 133

The deposits obtained at an overpotential of $550 \mathrm{mV}$ with 134 different quantities of electricity are shown in Figs.3-6. At this 135 overpotential, there is no hydrogen co-deposition at all. The deposit 136 obtained with a quantity of electricity of $2.5 \mathrm{~mA} \mathrm{~h} \mathrm{~cm}^{-2}$ is shown 137 


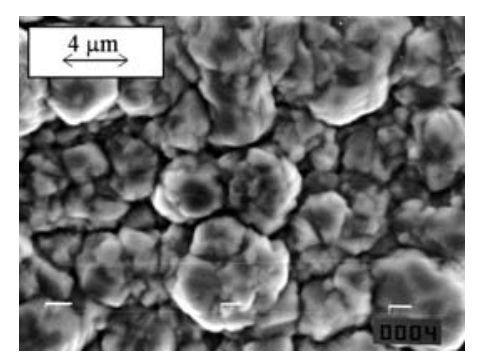

Figure 3. Copper deposit obtained at an overpotential of $550 \mathrm{mV}$. Quantity of electricity: $2.5 \mathrm{~mA} \mathrm{~h} \mathrm{~cm}^{-2}$. (Reprinted from Ref. ${ }^{10}$ with permission from Elsevier).

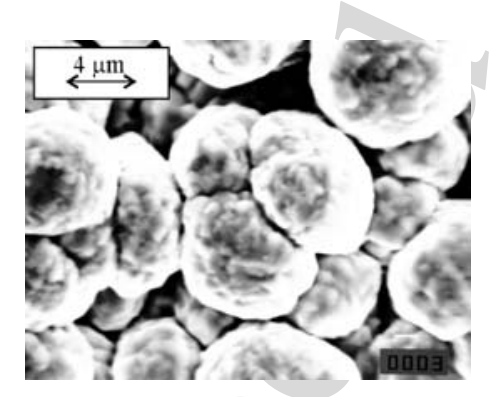

Figure 4. Copper deposit obtained at an overpotential of $550 \mathrm{mV}$. Quantity of electricity: $5.0 \mathrm{~mA} \mathrm{~h} \mathrm{~cm}^{-2}$. (Reprinted from Ref. 10 with permission from Elsevier).

in Fig. 3. The surface film is completed, the grains grown by elec- 138 trodeposition on the initially formed nuclei practically touch each 139 other and there is no new nucleation on already existing grains. 140 The difference in size between grains can also be observed. This 141 is due to the fact that the nucleation does not occur simultaneously 142 over the whole cathode surface, but it is a process extended in time, 143 so that crystals generated earlier may be considerably larger in the 144 size than ones generated later. These differences increase with an 145 increased quantity of electrodeposited metal, what can be seen from 146 Fig. 4 presenting the copper deposit obtained with a quantity of 147 
Hydrogen Co-deposition Effects on Copper Electrodeposition

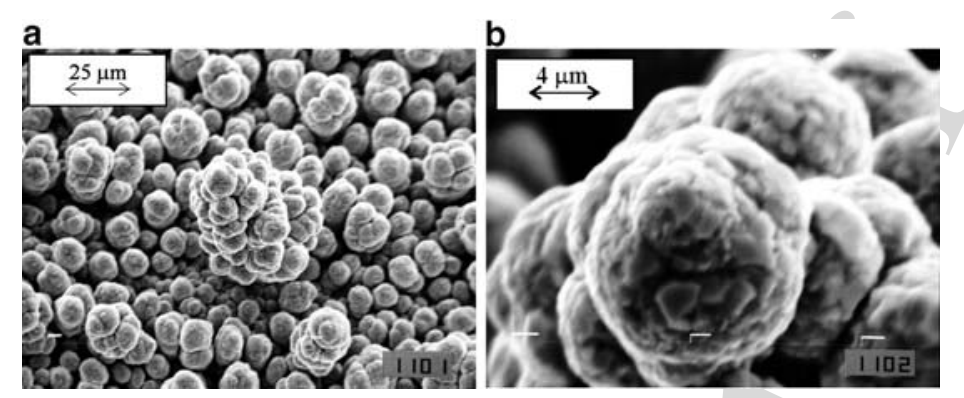

Figure 5. Copper deposit obtained at an overpotential of $550 \mathrm{mV}$. Quantity of electricity: $10 \mathrm{~mA} \mathrm{~h} \mathrm{~cm}{ }^{-2}$. (Reprinted from Ref. ${ }^{10}$ with permission from Elsevier).

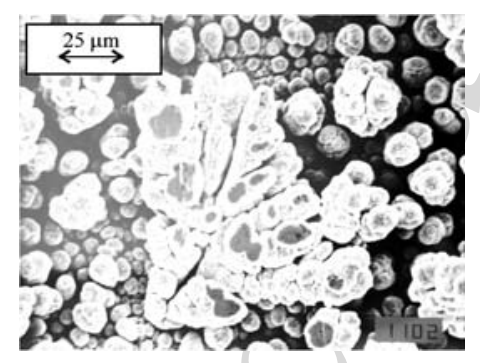

Figure 6. Copper deposit obtained at an overpotential of $550 \mathrm{mV}$. Quantity of electricity: $20 \mathrm{mAh} \mathrm{cm}^{-2}$. (Reprinted from Ref. ${ }^{17}$ with permission from Elsevier).

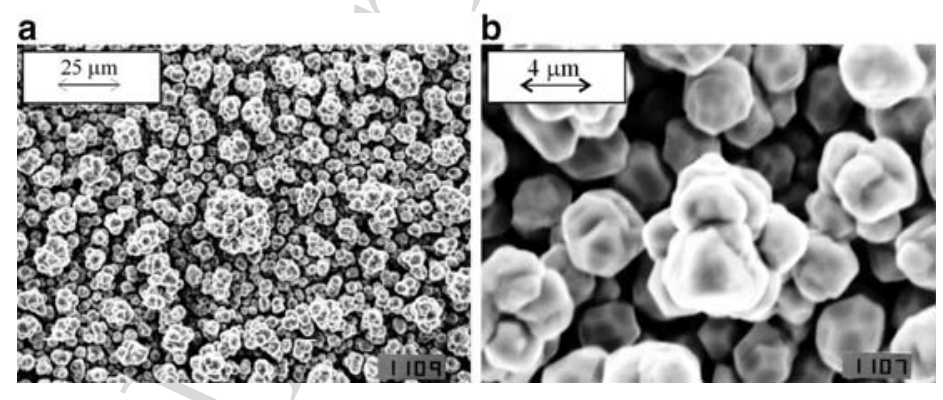

Figure 7. Copper deposit obtained at an overpotential of $700 \mathrm{mV}$. Quantity of electricity: $2.5 \mathrm{~mA} \mathrm{~h} \mathrm{~cm}^{-2}$. (Reprinted from Ref. ${ }^{10}$ with permission from Elsevier). 


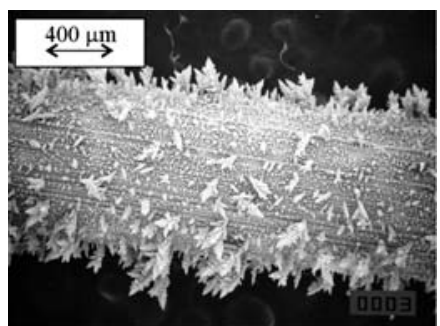

Figure 8. Copper deposit obtained at an overpotential of $700 \mathrm{mV}$. Quantity of electricity: $5.0 \mathrm{~mA} \mathrm{~h} \mathrm{~cm}^{-2}$. (Reprinted from Ref. ${ }^{10}$ with permission from Elsevier).
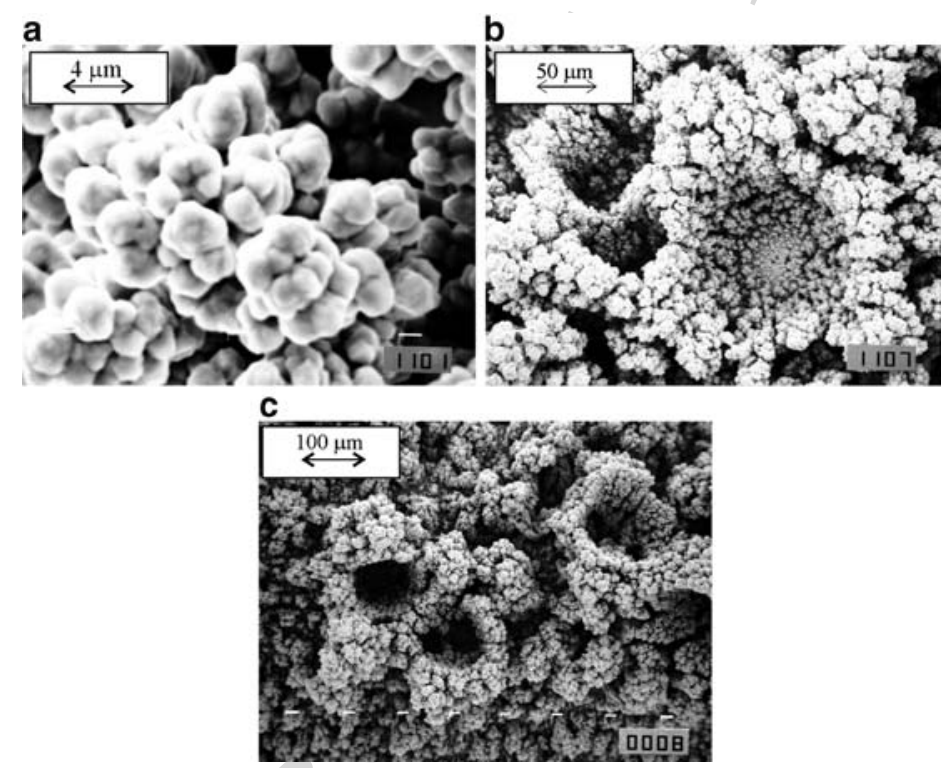

Figure 9. Copper deposit obtained at an overpotential of $800 \mathrm{mV}$. (a, b) quantity of electricity: $5.0 \mathrm{~mA} \mathrm{~h} \mathrm{~cm}^{-2}$ and (c) quantity of electricity: $10 \mathrm{~mA} \mathrm{~h} \mathrm{~cm}^{-2}$. (Reprinted from Ref. ${ }^{10}$ with permission from Elsevier).

electricity of $5.0 \mathrm{~mA} \mathrm{~h} \mathrm{~cm}^{-2}$. These enlarged differences are also 148 the consequence of the fact that some smaller grains are consumed 149 by the larger ones, ${ }^{27}$ as can be deduced from Figs. 3 and 4. This 150 is also illustrated by Fig. 5a. The increase of the quantity of the 151 


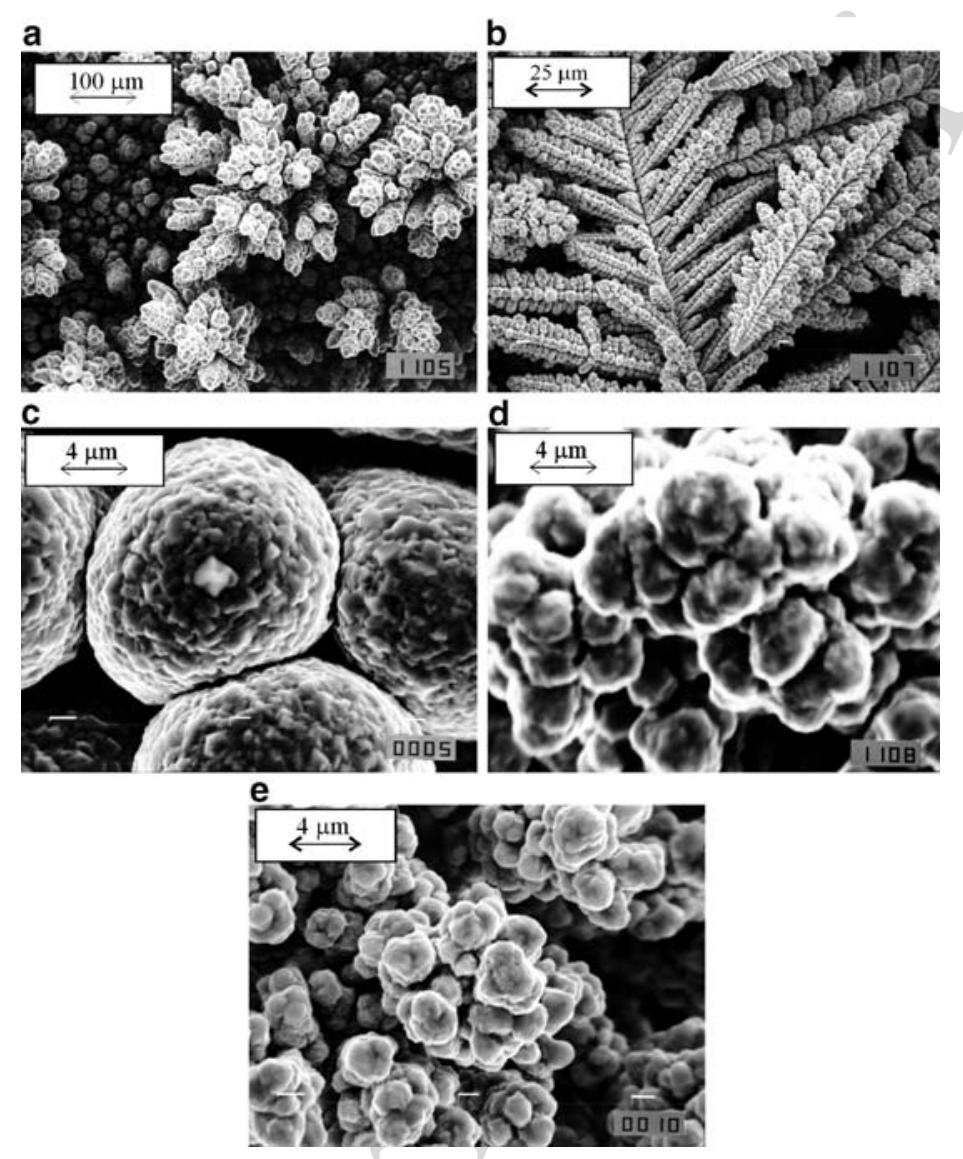

Figure 10. Copper deposits obtained with a quantity of the electricity of $20 \mathrm{mAh}$ $\mathrm{cm}^{-2}$ and at overpotentials of: (a) $550 \mathrm{mV}$, (b) $700 \mathrm{mV}$, (c) $450 \mathrm{mV}$, (d) $800 \mathrm{mV}$, and (e) $1,000 \mathrm{mV}$. (Reprinted from Ref. ${ }^{10}$ with permission from Elsevier).

electrodeposited metal led to the formation of a cauliflower-like 152 structure (Fig. 5a, b). Furthermore, from Fig. 5a it can be seen that 153 the spherical diffusion layers inside linear diffusion layer of the 154 macroelectrode are formed around these cauliflower-like particles. 155 Finally, further increase of the quantity of the electrodeposited metal 156 produces dendritic deposit (Fig. 6). 
On the other hand, it is well known that the induction time of 158 dendrite growth initiation strongly decreases with increasing overpo- 159 tential of electrodeposition. ${ }^{28}$ The situation on the electrode surface 160 after deposition with $2.5 \mathrm{~mA} \mathrm{~h} \mathrm{~cm}^{-2}$ at $700 \mathrm{mV}$ (Fig. 7) is very simi- 161 lar to the situation after $10 \mathrm{~mA} \mathrm{~h} \mathrm{~cm}^{-2}$ at $550 \mathrm{mV}$ (Fig. 5). The most 162 important difference is in the shape and size of growing grains, being 163 less globular and smaller in electrodeposition at $700 \mathrm{mV}$. Besides, 164 the interparticle distances are relatively equal which indicate that 165 these distances are not due to appearance of hydrogen co-deposition, 166 which is still very small at $700 \mathrm{mV}$. Dendrites appear at $700 \mathrm{mV}$ after 167 deposition with $5.0 \mathrm{~mA} \mathrm{~h} \mathrm{~cm}^{-2}$ (Fig. 8). ${ }^{10} 168$

The electrodeposition at $800 \mathrm{mV}$ with the quantity of the elec- 169 tricity of $5.0 \mathrm{~mA} \mathrm{~h} \mathrm{~cm}^{-2}$ (Fig. 9) did not lead to the formation of cop- 170 per dendrites as at previously analyzed overpotential of $700 \mathrm{mV}$. The 171 agglomerates of small copper grains become dominant form of the 172 copper morphology electrodeposited at this overpotential (Fig. 9a) 173 being similar to that from Fig. 7b. Also, there are large holes or 174 craters between the agglomerates of these grains, which is proba- 175 bly due to the hydrogen co-deposition (Fig. 9b). This copper deposit 176 is denoted as a honeycomb-like structure with craters as main char- 177 acteristic, ${ }^{10}$ as was shown earlier for copper and tin deposits in Ref. ${ }^{1} 178$ The honeycomb-like structure is formed at $800 \mathrm{mV}$ and with twice 179 the quantity of electricity (Fig. 9c), as well as at an overpotential of 180 $1,000 \mathrm{mV}^{10}$ (see also Sect. III).

It is known that the hydrogen evolution effects onto the hydro- 182 dynamic conditions inside electrochemical cell. ${ }^{29-31}$ The increase 183 in hydrogen evolution rate leads to the decrease of the diffusion 184 layer thickness and, hence, to the increase of limiting diffusion cur- 185 rent density of electrode processes. It was shown ${ }^{29}$ that if the rate 186 of gas evolution at the electrode is larger than $100 \mathrm{~cm}^{3} / \mathrm{cm}^{2} \min 187$ $\left(>5 \mathrm{~A} / \mathrm{cm}^{2}\right)$, the diffusion layer becomes only a few micrometers 188 thick. It is also shown ${ }^{29}$ that a coverage of an electrode surface with 189 gas bubbles can be about $30 \%$. If the thickness of the diffusion layer 190 in conditions of natural convection is $\sim 5 \times 10^{-2} \mathrm{~cm}$ and in strongly 191 stirred electrolyte $\sim 5 \times 10^{-3} \mathrm{~cm},{ }^{32}$ it is clear that gas evolution is the 192 most effective way to decrease mass transport limitations for electro- 193 chemical processes in mixed activation - diffusion control.

The overpotential $\eta$ and the current density $i$ are related by 195

$$
\eta=\frac{b_{\mathrm{c}}}{2.3} \ln \frac{i}{i_{\mathrm{o}}}+\frac{b_{\mathrm{c}}}{2.3} \ln \frac{1}{1-\left(i / i_{\mathrm{L}}\right)},
$$




\section{Hydrogen Co-deposition Effects on Copper Electrodeposition}

where $i_{\mathrm{o}}, i_{\mathrm{L}}$, and $b_{\mathrm{c}}$ are the exchange current density, the limiting 196 diffusion current density and cathodic Tafel slope for electrochemi- 197 cal process in mixed activation - diffusion control. ${ }^{13}$ The first term 198 in (3) corresponds to the activation part of deposition overpotential 199 and the second one is due to the mass transfer limitations. If one 200 and the same process takes place under two different hydrodynamic 201 conditions, characterized by two different values of the limiting 202 diffusion current densities $i_{\mathrm{L}, 1}$ and $i_{\mathrm{L}, 2}$, (3) can be rewritten in the 203 forms:

$$
\eta_{1}=\frac{b_{\mathrm{c}}}{2.3} \ln \frac{i_{1}}{i_{\mathrm{o}}}+\frac{b_{\mathrm{c}}}{2.3} \ln \frac{1}{1-\left(i_{1} / i_{\mathrm{L}, 1}\right)}
$$

and

$$
\eta_{2}=\frac{b_{\mathrm{c}}}{2.3} \ln \frac{i_{2}}{i_{\mathrm{o}}}+\frac{b_{\mathrm{c}}}{2.3} \ln \frac{1}{1-\left(i_{2} / i_{\mathrm{L}, 2}\right)},
$$

where $\eta_{1}$ and $\eta_{2}$ and $i_{1}$ and $i_{2}$ are the corresponding values of 206 overpotentials and current densities. The same degree of diffusion 207 control is obtained if

$$
\frac{i_{1}}{i_{\mathrm{L}, 1}}=\frac{i_{2}}{i_{\mathrm{L}, 2}}
$$

or,

$$
i_{2}=i_{1} \frac{i_{\mathrm{L}, 2}}{i_{\mathrm{L}, 1}}
$$

and substitution of $i_{2}$ from (7) in (5) and further rearranging gives

$$
\eta_{2}=\frac{b_{\mathrm{c}}}{2.3} \ln \frac{i_{1}}{i_{\mathrm{o}}}+\frac{b_{\mathrm{c}}}{2.3} \ln \frac{1}{1-\left(i_{1} / i_{\mathrm{L}, 1}\right)}+\frac{b_{\mathrm{c}}}{2.3} \ln \frac{i_{\mathrm{L}, 2}}{i_{\mathrm{L}, 1}}
$$

and

if (4) is taken into account:

$$
\eta_{2}=\eta_{1}+\frac{b_{\mathrm{c}}}{2.3} \ln \frac{i_{\mathrm{L}, 2}}{i_{\mathrm{L}, 1}}
$$

Hence, if

$$
i_{\mathrm{L}, 2}>i_{\mathrm{L}, 1}
$$

in order to obtain the same degree of diffusion control in two hydro- 214 dynamic conditions, (9) must be satisfied, meaning that

$$
\eta_{2}>\eta_{1} \text {. }
$$


The results presented here can be then explained as follows. In 216 the absence of strong hydrogen evolution, the diffusion layer is due 217 to the natural convection and does not depend on the overpotential 218 of electrodeposition. As excepted, for deposition times lower than 219 the induction time for dendritic growth initiation, the same type of 220 deposit at larger overpotential (Fig. 7) is obtained as at lower overpo- 221 tential (Fig. 5), being somewhat different in grain sizes and particle 222 shapes.

The vigorous hydrogen evolution changes the hydrodynamic 224 conditions and decreases the degree of diffusion control. Hence, (9) 225 should be rewritten in the form:

$$
\eta_{1}=\eta_{2}-\frac{b_{\mathrm{c}}}{2.3} \ln \frac{i_{\mathrm{L}, 2}}{i_{\mathrm{L}, 1}}
$$

where $\eta_{1}$ becomes the effective overpotential, $\eta_{1}=\eta_{\text {eff }}$, related 227 to conditions of natural convection at which there is the same de- 228 gree of diffusion control as at overpotential $\eta_{2}$ with the hydrogen 229 co-deposition. Hence, the dendritic growth can be delayed or com- 230 pletely avoided, as can be seen from Fig. 9c, meaning that there 231 is a really lower degree of diffusion control at an overpotential of 232 $800 \mathrm{mV}$ with the hydrogen co-deposition than at an overpotential of 233 $700 \mathrm{mV}$ where the hydrogen co-deposition is very small.

Hence, on the basis of presented results, we can propose a con- 235 cept of "effective overpotential" for a metal electrodeposition. This 236 concept is proposed - thanks to morphologies of copper deposits ob- 237 tained at high deposition overpotentials $(800 \mathrm{mV} \text { and more })^{10}$ where 238 the hydrogen evolution occurs. These copper deposits are probably 239 the consequence of the stirring of electrolyte in the near-electrode 240 layer by evolving hydrogen. This process leads to a decrease of the 241 thickness of diffusion layer, and consequently, up to an increase of 242 the limiting current density. According to (12), the increase of the 243 limiting current density leads to a metal deposition at an overpo- 244 tential, which is effectively lower than the specified one. Then, the 245 obtained morphologies of copper deposits become similar to the 246 ones obtained at some lower overpotential at which the hydrogen 247 co-deposition does not exist.

The better understanding of the concept "effective overpotential" 249 can be realized by taking into account the fact that the time of den- 250 dritic growth initiation depends on used deposition overpotentials. 251 Increasing deposition overpotentials lead to decreasing times for 252 


\section{Hydrogen Co-deposition Effects on Copper Electrodeposition}

the beginning of dendritic growth. ${ }^{28}$ Observing deposits obtained 253 at overpotentials belonging to the limiting diffusion current den- 254 sity plateau (550 and $700 \mathrm{mV}$ ), one can notice that cauliflower-like 255 forms are obtained at an overpotential of $550 \mathrm{mV}$ (Fig. 5a), and den- 256 dritic forms at an overpotential of $700 \mathrm{mV}$ (Fig. 8). Meanwhile, the 257 electrodeposition with a quantity of the electricity of $20 \mathrm{~mA} \mathrm{~h} \mathrm{~cm}^{-2} 258$ leads to the formation of degenerate dendritic structure at $550 \mathrm{mV} 259$ (Figs. 6 and 10a). Copper dendrites remain a main characteris- 260 tic of the electrodeposition at $700 \mathrm{mV}$ (Fig. 10b). On the other 261 hand, it can be shown that copper dendrites are not formed by the 262 electrodeposition at lower overpotential (for example, at $450 \mathrm{mV} 263$ where the hydrogen evolution was also zero) with a quantity of the 264 electricity of $20 \mathrm{~mA} \mathrm{~h} \mathrm{~cm}^{-2}$ (Fig. 10c). The main forms of the cop- 265 per deposit obtained at this overpotential are copper globules. Also, 266 dendritic forms are not formed with a quantity of the electricity 267 of $20 \mathrm{~mA} \mathrm{~h} \mathrm{~cm}^{-2}$ and during electrodepositions at overpotentials of 268 800 and 1,000 mV (Fig. 10d, e). The agglomerates of copper par- 269 ticles remain the main characteristics of the structure of deposits 270 obtained at these overpotentials. The macromorphology of these 271 deposits will be discussed later. $\quad 272$

Anyway, the structure of copper deposits obtained at over- 273 potentials of 800 and $1,000 \mathrm{mV}$ with a quantity of the electricity 274 of $20 \mathrm{~mA} \mathrm{~h} \mathrm{~cm}^{-2}$ was similar to those obtained at lower overpo- 275 tentials before the beginning of dendritic growth. The absence of 276 copper dendrites at overpotentials of 800 and $1,000 \mathrm{mV}$ after the 277 electrodeposition with $20 \mathrm{~mA} \mathrm{~h} \mathrm{~cm}^{-2}$, as well as the similarity of 278 the obtained morphologies of copper deposits with those obtained 279 at lower overpotentials before dendritic growth initiation clearly 280 indicates that there is really lower degree of diffusion control at 281 these overpotentials than at overpotentials of 550 and $700 \mathrm{mV}, 282$ respectively. 283

The concept of "effective overpotential" can be probably ap- 284 plied in other cases where there is a change of hydrodynamic 285 conditions in the near-electrode layer. The change of hydrody- 286 namic conditions, and consequently, of metal morphologies can be 287 caused by stirring of plating solutions in ultrasonic field, ${ }^{33}$ in an 288 imposed magnetic field (magnetohydrodynamic effect - MHD ef- 289 fect), ${ }^{34-39}$ as well as by stirring of solution by RDE (rotating disk 290 electrode). ${ }^{40}$ 


\section{The Concept of "Effective Overpotential" Applied 292 for Metal Electrodeposition Under an Imposed 293 Magnetic Field

Nickel deposits obtained at a cathodic potential of $-1,300 \mathrm{mV} / \mathrm{SCE} 295$ without and with a parallel orientation of magnetic field of 500 Oe, 296 are shown in Fig. 11a, b, respectively. Figure 11a shows that the 297 nickel deposit obtained without an imposed magnetic field consisted 298 of bunch of nickel grains, while it can be seen from Fig. 11b that 299 the nickel deposit obtained under a magnetic field with a parallel 300 orientation to the electrode surface was a porous structure and with- 301 out bunch of nickel grains.

Figure 12 shows copper deposits obtained at a cathodic poten- 303 tial of $-500 \mathrm{mV} / \mathrm{SCE}$ without and with a magnetic field of $500 \mathrm{Oe} 304$ applied to be parallel to the electrode surface. It can be seen from 305
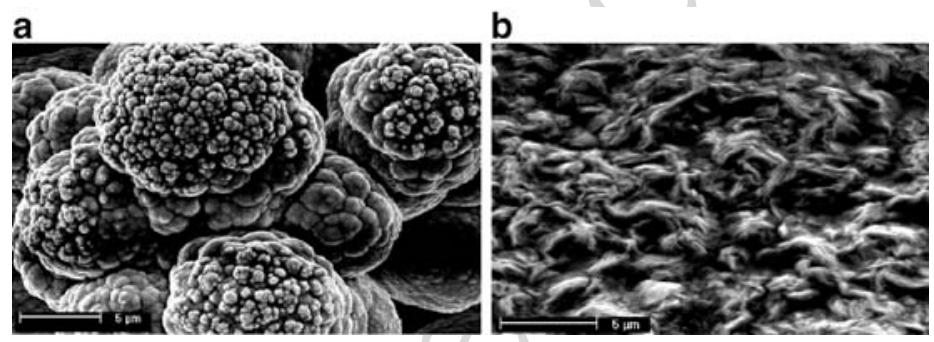

Figure 11. Nickel deposits obtained at a cathodic potential of $-1,300 \mathrm{mV} / \mathrm{SCE}$ : (a) without and (b) with a magnetic field of parallel orientation of $500 \mathrm{Oe}$. (Reprinted from Ref. ${ }^{39}$ with permission from the Serbian Chemical Society).
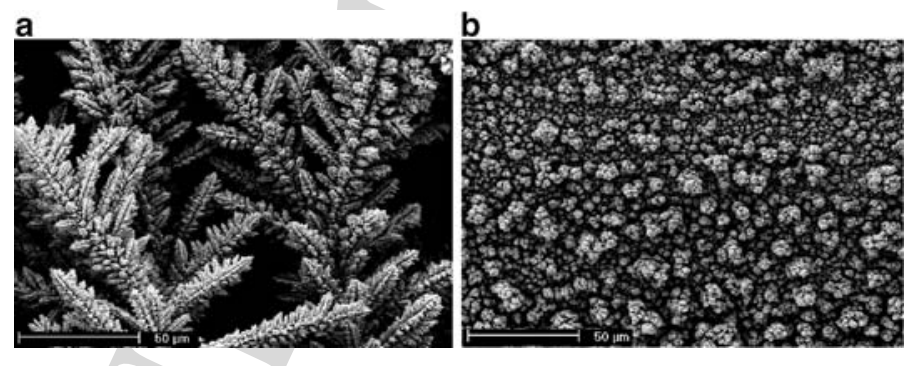

Figure 12. Copper deposits obtained at a cathodic potential of $-500 \mathrm{mV} / \mathrm{SCE}$ : (a) without and (b) with a magnetic field of parallel orientation of 500 Oe. (Reprinted from Ref. ${ }^{39}$ with permission from the Serbian Chemical Society). 


\section{Hydrogen Co-deposition Effects on Copper Electrodeposition}

this figure that the copper deposit obtained without the parallel field 306 (Fig. 12a) had dendritic structure, while the copper deposit obtained 307 with the parallel field (Fig. 12b) had cauliflower-like structure. $\quad 308$

The application of the concept of "effective overpotential" for 309 the case of the change of hydrodynamic conditions caused by mag- 310 netic field effects means that morphologies of nickel and copper 311 deposits obtained under parallel fields (the largest magnetohydro- 312 dynamic (MHD) effect) should be, at macro level, similar to those 313 obtained at some lower overpotentials or potentials without imposed 314 magnetic fields. This assumption can be confirmed by the following 315 consideration:

Figure 13a shows the nickel deposit obtained at a cathodic po- 317 tential of $-1,200 \mathrm{mV} / \mathrm{SCE}$ without an applied magnetic field. It can 318 be noticed that there is similarity at a macro level between the mor- 319 phology of this nickel deposit and the morphology of nickel de- 320 posit obtained at a potential of $-1,300 \mathrm{mV} / \mathrm{SCE}$ under the paral- 321 lel field (Fig. 11b). The both nickel deposits are without dendritic 322
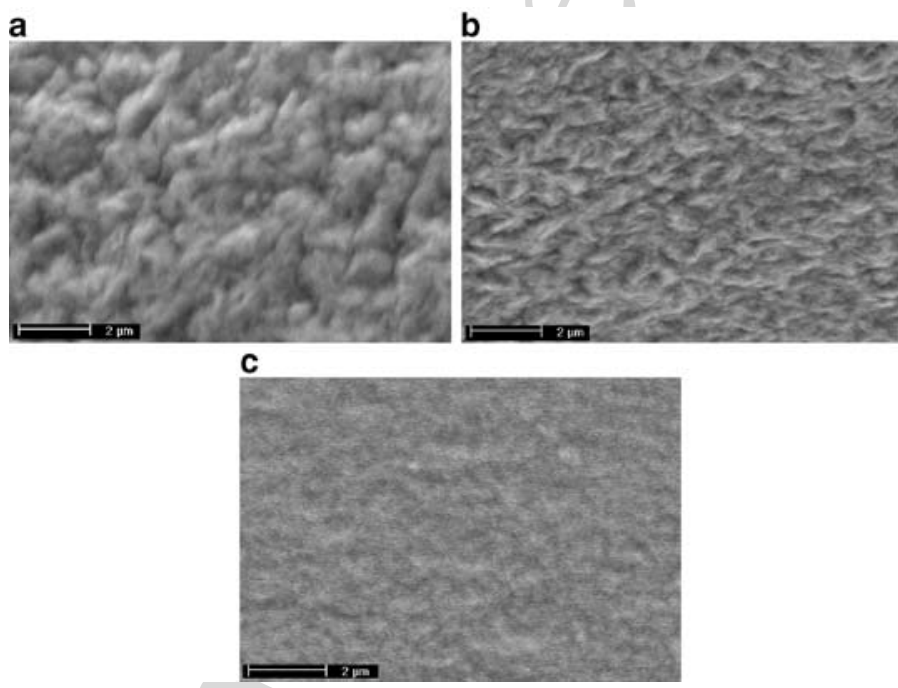

Figure 13. Nickel deposits obtained at a cathodic potential of $-1,200 \mathrm{mV} / \mathrm{SCE}$ : (a) without, (b) with a magnetic field of parallel orientation of $500 \mathrm{Oe}$, and (c) the nickel deposit obtained at a cathodic potential of $-1,000 \mathrm{mV} / \mathrm{SCE}$ without an applied magnetic field. (Reprinted from Ref. ${ }^{39}$ with permission from the Serbian Chemical Society). 
and globular parts and with clearly visible nickel grains. The only 323 difference is in compactness of deposits, which is a consequence of 324 larger nucleation rate and more intensive hydrogen evolution at a po- 325 tential of $-1,300 \mathrm{mV} / \mathrm{SCE}$ than at a potential of $-1,200 \mathrm{mV} / \mathrm{SCE} . \quad 326$

Also, the concept of "effective overpotential" can be illustrated 327 and by the comparison of the nickel deposit obtained at a cathodic 328 potential of $-1,200 \mathrm{mV} / \mathrm{SCE}$ under the parallel field with the nickel 329 deposit obtained at $-1,000 \mathrm{mV} / \mathrm{SCE}$ without an imposed magnetic 330 field. Morphologies of these nickel deposits are shown in Fig. 13b, c. 331 Figure 13b shows the morphology of the nickel deposit obtained at 332 a potential of $-1,200 \mathrm{mV} / \mathrm{SCE}$ under a parallel field of $500 \mathrm{Oe}, 333$ while Fig. 13c shows the morphology of the nickel deposit ob- 334 tained at $-1,000 \mathrm{mV} / \mathrm{SCE}$ without an applied magnetic field. From 335 Fig. 13b, c it can be observed that there is similarity at a macro 336 level between these nickel deposits. The boundaries between adja- 337 cent nickel grains cannot be observed. Anyway, the nickel deposit 338 obtained at $-1,200 \mathrm{mV} / \mathrm{SCE}$ under the parallel field (Fig. 13b) was 339 more similar to that obtained at $-1,000 \mathrm{mV} / \mathrm{SCE}$ without an applied 340 magnetic field than to that obtained at $-1,200 \mathrm{mV} / \mathrm{SCE}$ without an 341 imposed magnetic field (Fig. 13a). 342

This concept can be also applied for the case of the electrodepo- 343 sition of copper. As mentioned earlier, the morphology of the copper 344 deposit obtained at cathodic potential of $-500 \mathrm{mV} / \mathrm{SCE}$ under the 345 parallel field was of cauliflower-like structure (Fig. 12b), while the 346 morphology of the copper deposit obtained without the applied mag- 347 netic field had very dendritic structure (Fig. 12a). It is known that 348 dendritic structures are main characteristic of electrodeposition in 349 conditions of full diffusion control, while cauliflower-like structures 350 are a characteristic of a dominant diffusion in mixed control of elec- 351 trodeposition process. ${ }^{13} \quad 352$

Anyway, it can be seen that the application of a parallel field of 353 500 Oe led to shifting of the formation of characteristic morpholog- 354 ical forms toward lower cathodic potentials for about $100-200 \mathrm{mV}$. 355

Of course, the influence of magnetic field appears to be 356 restricted to the diffusion-limited regions. During electrolysis un- 357 der parallel fields, the Lorentz force induces convective flow of 358 the electrolyte close to electrode surface. A magnetically stimu- 359 lated convection leads to a decrease of the diffusion layer thickness 360 thus increasing the diffusion-limited current density. ${ }^{39}$ As a rule, 361 it was adopted that the limiting diffusion current density depends 362 on magnetic field, as $i_{\mathrm{L}} \infty B^{1 / 3} .{ }^{41}$ Anyway, the increase of the 363 


\section{Hydrogen Co-deposition Effects on Copper Electrodeposition}

limiting current density caused by the effect of applied magnetic 364 fields with a parallel orientation leads to a decrease of the degree of 365 diffusion control of the deposition process, and than, the electrode- 366 position process occurs at some overpotential which is effectively 367 lower. This overpotential at which a metal electrodeposition occurs 368 when the change of hydrodynamic conditions is caused by the ef- 369 fect of imposed magnetic fields (i.e., by the magnetohydrodynamic 370 effect) also represents "effective overpotential" of electrodeposition 371 process. $\quad 372$

Similar effects can be observed during electrodeposition in an 373 ultrasonic field. ${ }^{33}$ Copper deposits obtained in an ultrasonic field 374 were compact and more ordered structure than copper deposits ob- 375 tained without an effect of ultrasonic fields. 376

It is very clear from previous consideration that the proposed 377 concept can be applied and for the case of electrodeposition of 378 nickel. This concept is usable for all cases where there is the change 379 of the hydrodynamic conditions in the near-electrode layer, which 380 can be induced by the agitation of electrolyte by evolving hydrogen, 381 ultrasonic and magnetic fields, or simply by vigorous stirring of an 382 electrolyte.

\section{PHENOMENOLOGY OF A FORMATION OF A 384 HONEYCOMB-LIKE STRUCTURE DURING COPPER 385 ELECTRODEPOSITION 386}

The initial stage of the electrodeposition at an overpotential of 387 $1,000 \mathrm{mV}$ corresponding to the electrodeposition time of $10 \mathrm{~s}$ is 388 given in Fig. 14a-d. These and other experiments whose results are 389 presented in this section (Figs. 14-19) were performed potentiostat- 390 ically from $0.15 \mathrm{M} \mathrm{CuSO}_{4}$ in $0.50 \mathrm{M} \mathrm{H}_{2} \mathrm{SO}_{4}$ at a temperature of 391 $18.0 \pm 1.0^{\circ} \mathrm{C}$, onto vertical stationary copper wire electrodes which 392 were not previously covered by copper thin films. The parallelism 393 between the process of the copper electrodeposition and the hydro- 394 gen evolution can be easily seen in Fig. 14a. From this figure, both 395 the sites of the formation of hydrogen bubbles (i.e., sites at which the 396 hydrogen evolution starts) and the agglomerates of copper grains be- 397 tween them can be noticed.

It can be seen from Fig. 14b that the hydrogen evolution re- 399 action, as well as the copper electrodeposition are initiated at 400 irregularities at an electrode surface. The irregularities at an elec- 401 trode surface represent the most convenient sites (active centres) 402 


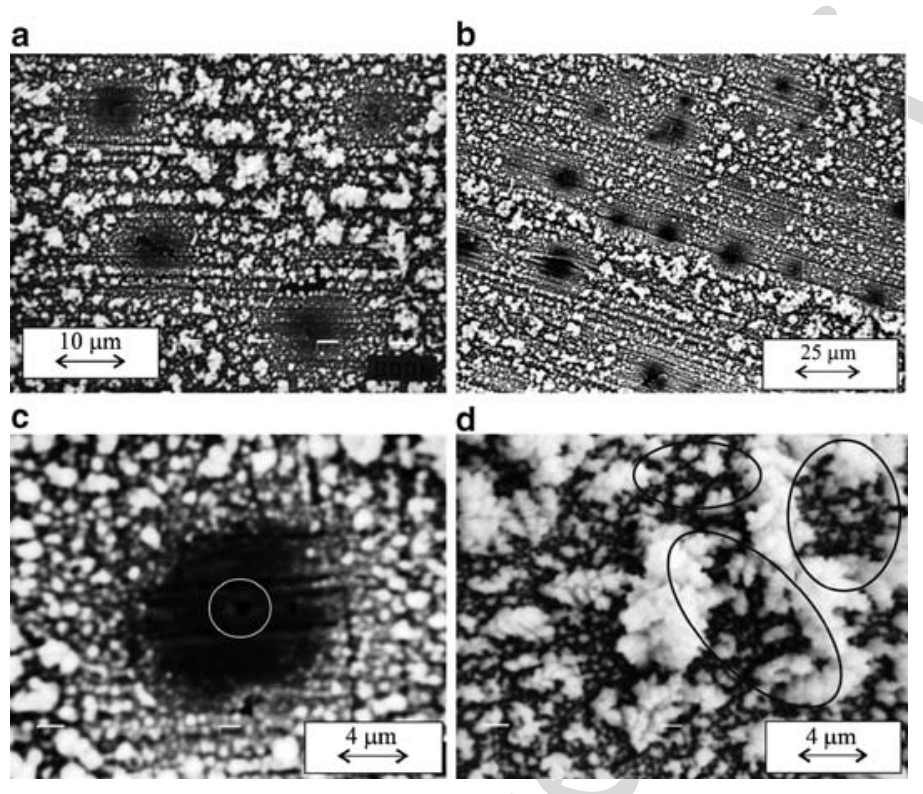

Figure 14. Copper deposit obtained at an overpotential of $1,000 \mathrm{mV}$. Time of electrolysis: $10 \mathrm{~s}$. (Reprinted from Ref. ${ }^{18}$ with permission from Springer).

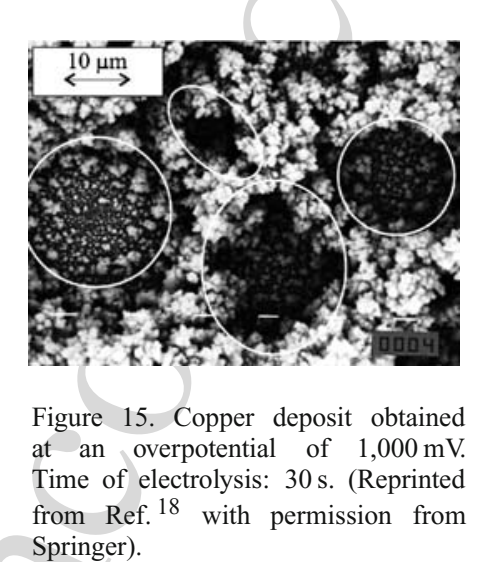

for the beginning of hydrogen evolution, i.e., for the formation of 403 hydrogen bubbles. The true position of the formation of a hydrogen 404 bubble can be seen from Fig. 14c showing a bare part of the copper 405 electrode (part in circle in Fig. 14c). 


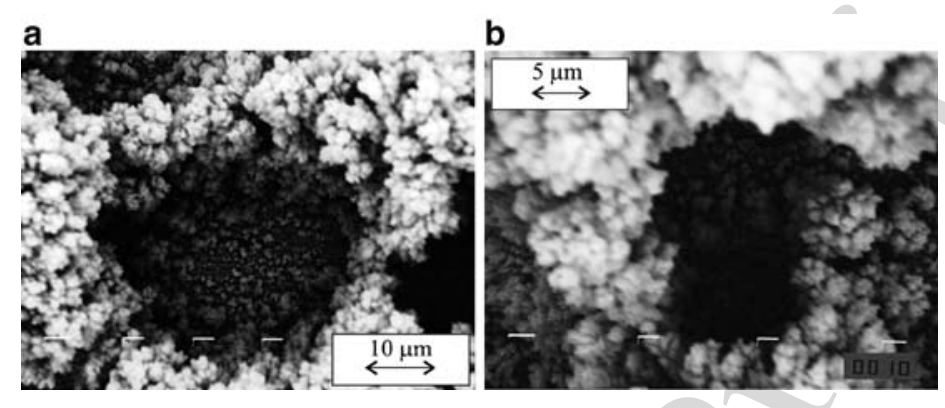

Figure 16. Copper deposit obtained at an overpotential of $1,000 \mathrm{mV}$. Time of electrolysis: $60 \mathrm{~s}$. (Reprinted from Ref. ${ }^{18}$ with permission from Springer).

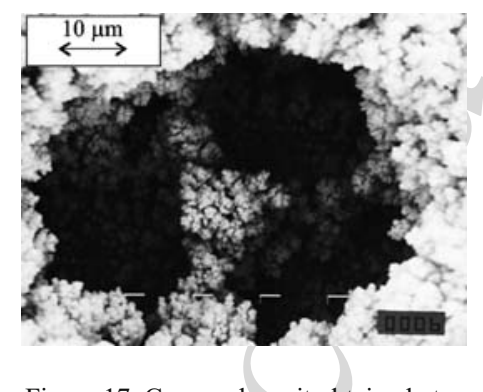

Figure 17. Copper deposit obtained at an overpotential of $1,000 \mathrm{mV}$. Time of electrolysis: $120 \mathrm{~s}$. (Reprinted from Ref. ${ }^{18}$ with permission from Springer).

The mechanism of formation of bubbles at an electrode sur- 407 face has been described for a long time. ${ }^{29-31,42}$ The gas formed at 408 the electrode dissolves in the electrolyte, which becomes supersat- 409 urated. At the nucleation sites on the electrode, small bubbles are 410 formed, grow to a certain size and are then detached. The higher the 411 current density, the more the solution becomes saturated; more and 412 more nucleation sites become active, and also the rate of growth of 413 the bubbles increases. ${ }^{31}$ Jenssen and Hoogland ${ }^{31}$ also pointed out 414 that at lower current densities, only the irregularities at the edges 415 (formed by the cutting of the foil) are active, and the amount of bub- 416 bles formed at the lower edge is sufficient to take up all the hydrogen 417 formed. This is no longer the case at higher current density, and then 418 bubbles are also formed at the less deformed surface. 
a

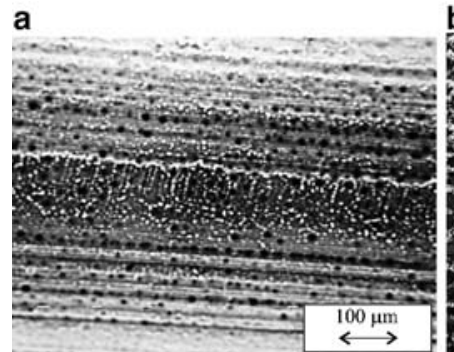

b
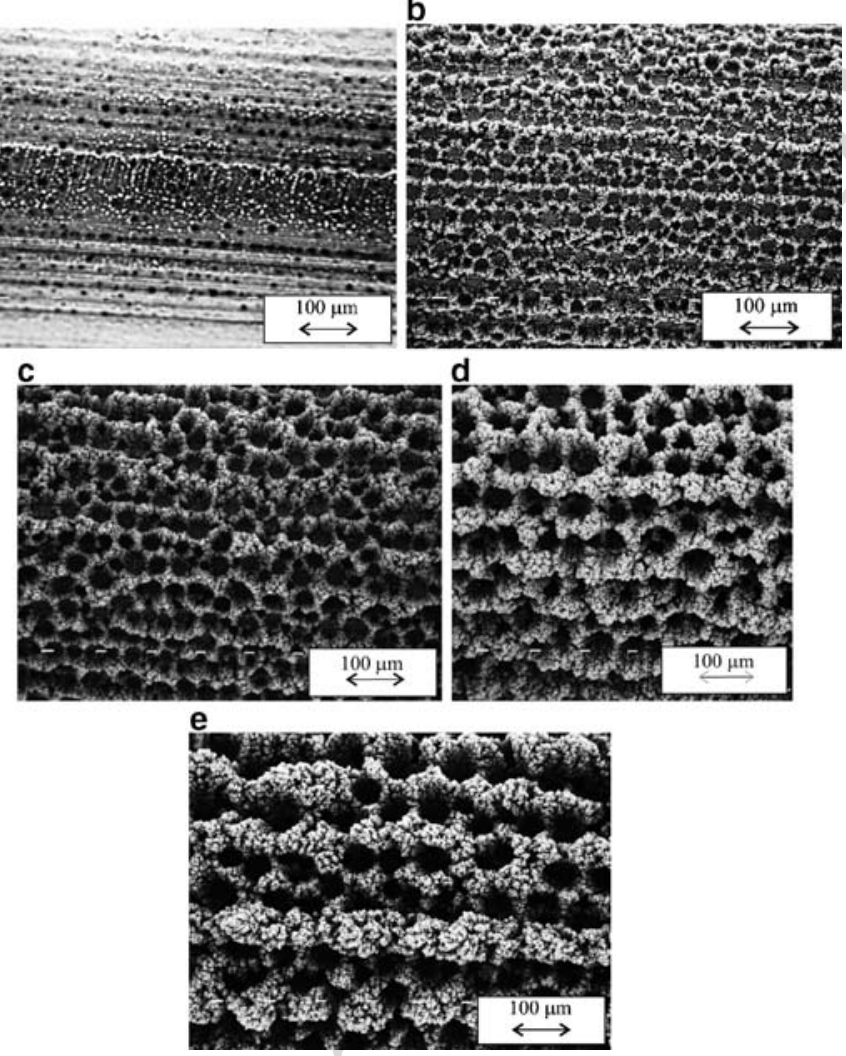

Figure 18. Copper deposits obtained at an overpotential of 1,000 mV. Time of electrolysis: (a) 10, (b) 30, (c) 60, (d) 120, and (e) 150 s. (Reprinted from Ref. ${ }^{18}$ with permission from Springer).

Figure 14d shows typical agglomerates consisted of rela- 420 tively small copper grains and situated between the bubbles (parts 421 in ellipses in this figure). The different size and periodicity of 422 agglomerates of copper grains can be explained as follows: It was 423 assumed $^{43}$ that the active centres have different activity or different 424 critical overpotential with respect to the formation of nuclei. The 425 nuclei can be formed on those centres whose critical overpotential 426 is lower or equal to the overpotential externally applied to the cell. 427 The higher the applied overpotential, the greater the number of 428 


\section{Hydrogen Co-deposition Effects on Copper Electrodeposition}

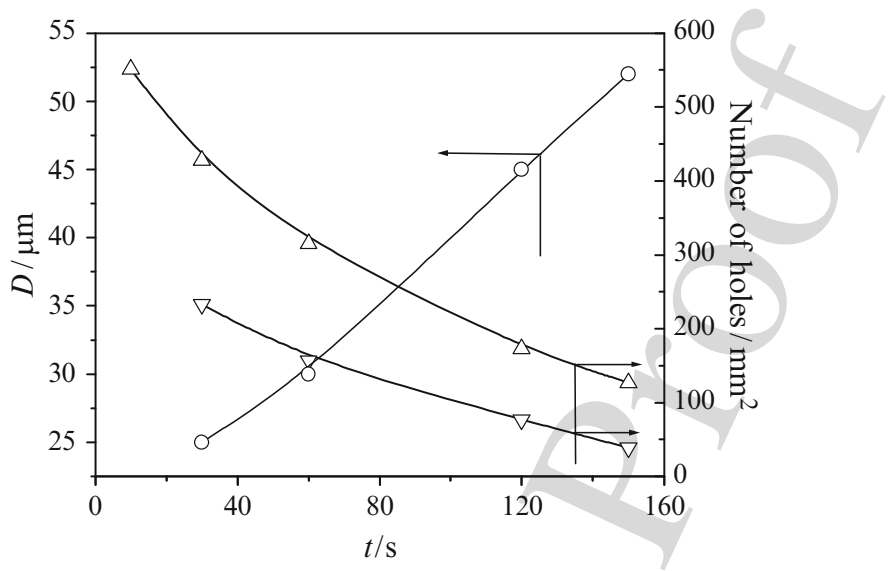

Figure 19. The dependence of average diameters of the surface holes, $D$ (open circles), number of "regular holes" per square millimeter surface area of copper electrodes (open triangles) and number of "irregular holes" per square millimeter surface area of copper electrodes (inverted traingles) on electrolysis times. (Reprinted from Ref. ${ }^{18}$ with permission from Springer).

active sites take part in nucleation process. The active sites are 429 mainly placed on the irregularities at an electrode surface, ${ }^{44}$ as can 430 be seen in Fig. 14b. On the other hand, nucleation does not occur 431 simultaneously over the entire cathode surface, but it is a process 432 extended in time so that crystals generated earlier may be consider- 433 ably larger in size than the ones generated later. Besides, in the case 434 of fast electrodeposition processes, the nucleation exclusion zones 435 around already existing nuclei are formed, ${ }^{45,46}$ and in the case of 436 the slower ones, there is an effect on the nucleation rate distribu- 437 tion around growing grains. ${ }^{47,48}$ This causes the periodicity in the 438 surface structure of polycrystalline electrolytic deposits. ${ }^{49-51} 439$

The copper deposit obtained with the electrodeposition time of 440 $30 \mathrm{~s}$ is given in Fig. 15, from which can be seen two characteristic 441 groups of holes or craters. The origin of one group of holes is due 442 to the attachment of hydrogen bubbles at surface area of an elec- 443 trode. These holes have regular circular shapes and, in Fig. 15 they 444 are given in circles. The second group of holes have irregular shapes, 445 and these holes are given in ellipses in Fig. 15. The formation of 446 
these irregular craters is not associated with the process of hydrogen 447 evolution, and it can be assumed that the origin of these holes is of 448 the agglomerates of relatively small copper grains shown in Fig. 14d. 449

The formation of craters or holes as a consequence of the 450 hydrogen evolution can be explained by the analysis of Figs. 14a, c 451 and 15 in the following way: In the initial stage of the electrodepo- 452 sition, hydrogen bubbles are formed at active sites at an electrode 453 surface (Fig. 14a, b), and copper growth is blocked at these sites. 454 These hydrogen bubbles grow with a time of electrodeposition, and 455 in one moment, they get detached from an electrode surface realiz- 456 ing a fresh electrode surface for a new copper nucleation. This can 457 be seen from Figs. 14c and 15, showing a bare copper electrode at a 458 position where the formation of a hydrogen bubble begins (Fig. 14c) 459 and a position of already formed hole covered with a thin copper film 460 (parts in circles in Fig. 15). Anyway, the processes of the formation 461 of hydrogen bubbles at active sites, their detachment from an elec- 462 trode surface when critical size is reached as well as their repeated 463 formation at growing electrode represent successive steps that led to 464 the formation of this type of holes. The typical crater or hole formed 465 due to the attachment of hydrogen bubbles ("regular hole"), which is 466 obtained with the electrodeposition time of 60 s, is shown in Fig. 16a. 467

The explanation for the formation of the second group of craters 468 can be given as follows: as already pointed out, at an overpotential of 469 $1,000 \mathrm{mV}$, the process of hydrogen evolution is competitive with the 470 process of copper electrodeposition. As a consequence of a parallel 471 evaluation of these processes, both the sites of a formation of hydro- 472 gen bubbles and the agglomerates of copper grains between them 473 were obtained (Fig. 14). The agglomerates of these copper grains 474 exactly represent nucleation centres for the formation of craters or 475 holes belonging to the other group (parts in ellipses in Fig. 14d). The 476 further electrolysis process leads to copper nucleation and growth 477 primarily at these agglomerates owing to the concentration of current 478 lines at them, which will lead to a joining closely formed agglomer- 479 ates and a formation of hole in one moment. This effect of current 480 distribution at growing surface will be enhanced by the additional 481 physical blocking of copper growth by the hydrogen bubbles pre- 482 venting nucleation processes at lateral sides of the agglomerates and 483 enhancing the nucleation processes at the top of the agglomerates. 484 In addition, these agglomerates initiate walls, which will limit the 485 growth of hydrogen bubbles. Hence, as a result of all these parallel 486 


\section{Hydrogen Co-deposition Effects on Copper Electrodeposition}

processes, holes of "irregular" shapes are formed. These holes are 487 situated among those formed due to the attachment of hydrogen 488 bubbles, and these craters are deeper than those obtained due to 489 the attachment of hydrogen bubbles. The typical "irregular hole" is 490 given in Fig. 16b, presenting a hole obtained with the electrodeposi- 491 tion time of $60 \mathrm{~s}$.

Mechanisms describing the formation of holes of this type are 493 based on the amplification of electrode surface coarseness ${ }^{52,53}$ in 494 diffusion-controlled electrodeposition and to the tip ${ }^{54}$ and edge ${ }^{55}$ ef- 495 fects of current density distribution at electrode surface. More about 496 these mechanisms can be found in Ref. ${ }^{13} 497$

With the evaluating electrodeposition process, a coalescence of 498 closely formed hydrogen bubbles was observed. The typical coa- 499 lesced hydrogen bubble obtained at an overpotential of $1,000 \mathrm{mV} 500$ with electrolysis time of $120 \mathrm{~s}$ is shown in Fig. 17. The number of 501 holes formed of coalesced hydrogen bubbles increases with time of 502 electrolysis. In Fig. 17, it can be seen that a structure of hole formed 503 of coalesced hydrogen bubbles consisted of smaller holes which 504 were mutually separated by a "bridge" of copper agglomerates. 505 Agglomerates of copper grains that separate smaller holes inside a 506 large hole are at a lower level than the agglomerates of copper grains 507 around a large hole.

The decrease in a number of formed holes can be easily ob- 509 served in Fig. 18, showing morphologies of copper deposits obtained 510 with times of electrolysis of $10,30,60,120$, and $150 \mathrm{~s}$. This decrease 511 can be primarily ascribed to a coalescence of a closely formed hy- 512 drogen bubbles. On the other hand, the number of craters formed of 513 an initially formed copper agglomerates also decreases with electrol- 514 ysis times, and it can be expected that these craters will completely 515 disappear with a longer time of electrolysis. This is due to the cur- 516 rent distribution at a copper growing surface; that is, the fact that a 517 new copper nucleation and growth primarily takes place at the edges 518 of these holes, which will lead to totally closing and losing of holes 519 from this group with longer electrolysis times. In this way, only the 520 holes formed due to the hydrogen evolution will remain at a surface 521 area of electrode.

Figure 19 shows the dependence of average diameters of craters 523 or holes, $D$, formed due to the attachment of hydrogen bubbles on 524 electrolysis time, from which the increase in average diameters of 525 holes with the electrolysis time can be clearly seen. The dependences 526 of the number of craters or holes formed due to the attachment 527 
of hydrogen bubbles per square millimeter surface area ("regular 528 holes") and those formed due to the effect of current distribution 529 ("irregular holes") on the electrolysis time are also shown in Fig. 19. 530 The decrease in the number of both groups of craters or holes can be 531 observed in this figure.

The logarithm of the number of "regular holes" per square mil- 533 limeter surface area of copper electrode as a function of electroly- 534 sis time gives the straight line, which points out that the decrease 535 in number of holes with electrolysis time follows the first-order re- 536 action low. ${ }^{18}$ This can be very useful in the determination of the 537 mechanism of the formation and growth of holes during metal elec- 538 trodeposition in the presence of hydrogen evolution, as well as in the 539 investigation of the different parameters that affects the honeycomb- 540 like copper structure formation.

\section{THE EFFECT OF DEPOSITION CONDITIONS ON COPPER DEPOSITS MORPHOLOGY}

\section{The Surface Preparation}

The initial stage of electrodeposition of copper from $0.15 \mathrm{M} \mathrm{CuSO}_{4} 545$ in $0.50 \mathrm{M} \mathrm{H}_{2} \mathrm{SO}_{4}$ at an overpotential of $1,000 \mathrm{mV}$, onto stationary 546 vertical copper wire electrodes previously covered by thin copper 547 films is shown in Fig. 20. The detailed description of the formation of 548 this type of cylindrical copper electrodes is described in Refs. ${ }^{56,57} 549$ In this case, for the difference of that observed in Fig. 14b, irregu- 550 larites or active centres at an electrode surface were "killed" by the 551 electrodeposition of uniform thin copper film at an overpotential of 552 $300 \mathrm{mV}$ during 2 min. ${ }^{17}$ Then, a higher energy was needed for the 553 formation of hydrogen bubbles. From Fig. 20, it can be seen that a 554 number of formed bubbles was considerably smaller than number of 555 bubbles formed onto the electrode with active centres (Fig. 14b). Si- 556 multaneously, the diameter of the formed holes was larger, and they 557 were random oriented at electrode surface.

Figure 21 shows copper deposits obtained at an overpotential of 559 $1,000 \mathrm{mV}$ with different quantities of the electricity, onto stationary 560 vertical copper wire electrodes previously covered by thin copper 561 films. The dependences of average diameters of craters or holes, $D 562$ formed due to the attachment of hydrogen bubbles and number of 563 craters or holes formed due to the attachment of hydrogen bubbles 564 
Hydrogen Co-deposition Effects on Copper Electrodeposition

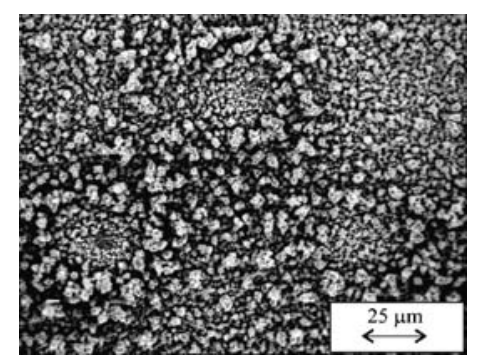

Figure 20. Copper deposit obtained at an overpotential of $1,000 \mathrm{mV}$. Time of electrolysis: $10 \mathrm{~s}$. Solution: $0.15 \mathrm{M}$ $\mathrm{CuSO}_{4}$ in $0.50 \mathrm{M} \mathrm{H}_{2} \mathrm{SO}_{4}$; temperature: $18.0 \pm 1.0^{\circ} \mathrm{C}$; working electrode: copper electrode previously covered by copper thin film. (Reprinted from Ref. ${ }^{18}$ with permission from Springer).

per square millimeter surface area ("regular holes") on electrolysis 565 time, formed on this type of cylindrical copper electrodes is shown 566 in Fig. 22.

Analyzing the data in Figs. 19 and 22, we can notice that av- 568 erage diameters of holes formed at stationary vertical copper wire 569 electrodes which were not previously covered by copper thin films 570 were about two times smaller than those obtained by electrodepo- 571 sition onto copper electrodes previously covered with a thin copper 572 film. On the other hand, the number of the formed holes per square 573 millimeter surface area ("regular holes") was approximately five to 574 ten times larger than the number of holes per square millimeter sur- 575 face area obtained by electrodeposition onto copper electrodes with 576 uniform thin copper films.

The obtained differences clearly point out the significance of 578 preparing a working electrode for electrodeposition processes at 579 high overpotentials, at which there is a parallelism between the pro- 580 cess of the copper electrodeposition and the hydrogen evolution. The 581 observed differences in average diameters of the formed holes or 582 craters as well as in the number of the formed craters or holes can 583 be explained as follows: the surface area of copper electrodes which 584 were not previously covered by copper thin films consisted of a large 585 number of irregularities, which presented active sites (centres), that 586 is, energetic the most convenient sites for the formation of hydrogen 587 

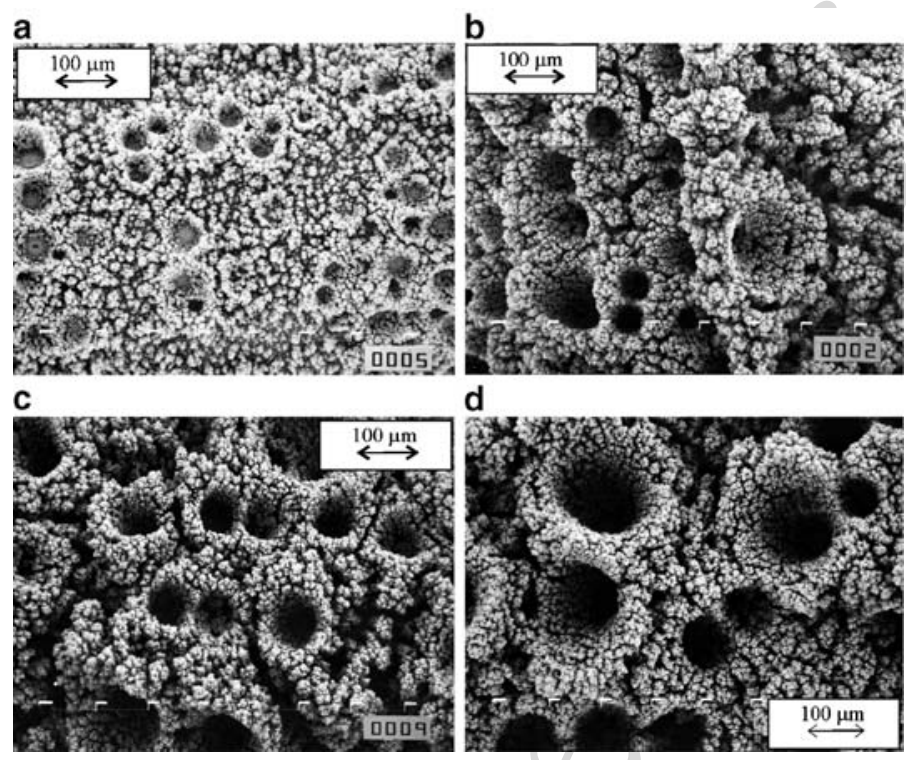

d

Figure 21. Copper deposits obtained potentiostatically at an overpotential of $1,000 \mathrm{mV}$. Quantities of electricity: (a) $2.5 \mathrm{~mA} \mathrm{~h} \mathrm{~cm}^{-2}$, (b) $10 \mathrm{~mA} \mathrm{~h} \mathrm{~cm}^{-2}$, (c) $15 \mathrm{~mA} \mathrm{~h} \mathrm{~cm}{ }^{-2}$, (d) $20 \mathrm{~mA} \mathrm{~h} \mathrm{~cm}{ }^{-2}$. Solution: $0.15 \mathrm{M} \mathrm{CuSO}_{4}$ in $0.50 \mathrm{M}$ $\mathrm{H}_{2} \mathrm{SO}_{4}$; temperature: $18.0 \pm 1.0^{\circ} \mathrm{C}$; working electrode: stationary vertical copper wire electrode previously covered by copper thin film. (Reprinted from Ref. ${ }^{17}$ with permission from Elsevier).

bubbles. In the initial stage of electrodeposition process, the number 588 formed hydrogen bubbles at such electrode was considerably larger 589 than the number of holes formed at the electrode with "killed" active 590 centres. Then, in the growth process, the same quantity of evolved 591 hydrogen is distributed over larger number of hydrogen bubbles, 592 resulting in the formation of honeycomb-like structure with larger 593 number of holes with smaller diameters.

\section{The Effect of Concentration of $\mathrm{Cu}(\mathrm{II})$ Ions}

Figure 23 shows the polarization curves for the copper elec- 596 trodeposition from $0.075 \mathrm{M} \mathrm{CuSO}_{4}$ in $0.50 \mathrm{M} \mathrm{H}_{2} \mathrm{SO}_{4}$ (solution 597 (I)), $0.30 \mathrm{M} \mathrm{CuSO}_{4}$ in $0.50 \mathrm{M} \mathrm{H}_{2} \mathrm{SO}_{4}$ (solution (II)) and $0.60 \mathrm{M} 598$ $\mathrm{CuSO}_{4}$ in $0.50 \mathrm{M} \mathrm{H}_{2} \mathrm{SO}_{4}$ (solution (III)). All experiments whose 599 results are presented in Figs. 23-30 and Table 1 were performed 600 


\section{Author's Proof}

BookID 186658_ChapID 1_Proof\# 1 - 17/02/10

Hydrogen Co-deposition Effects on Copper Electrodeposition

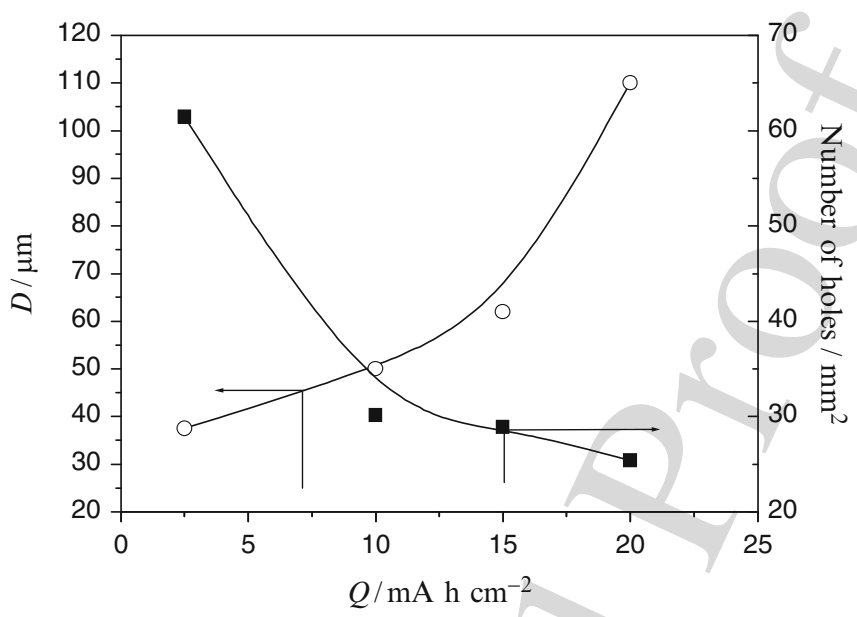

Figure 22. The dependence of average diameters of the surface holes, $D$, (open circles) and number of "regular holes" per square millimeter surface area of copper electrodes (closed squares) on the quantity of the electricity. (Reprinted from Ref. ${ }^{17}$ with permission from Elsevier).

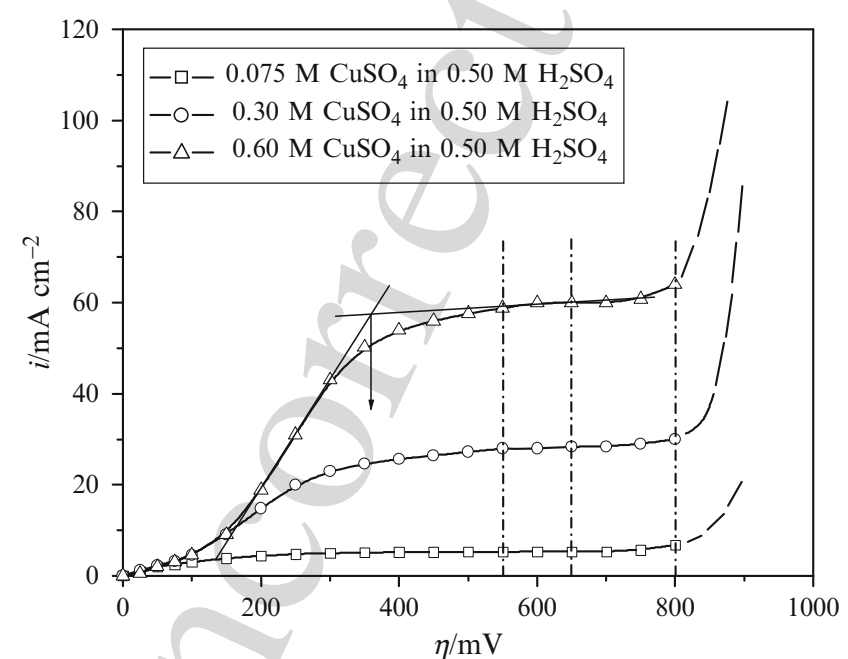

Figure 23. Polarization curves for the cathodic process of copper deposition from: $0.075 \mathrm{M} \mathrm{CuSO}_{4}$ in $0.50 \mathrm{M} \mathrm{H}_{2} \mathrm{SO}_{4}$ (solution (I)), $0.30 \mathrm{M} \mathrm{CuSO}_{4}$ in $0.50 \mathrm{M} \mathrm{H}_{2} \mathrm{SO}_{4}$ (solution (II)), and $0.60 \mathrm{M} \mathrm{CuSO}_{4}$ in $0.50 \mathrm{M} \mathrm{H}_{2} \mathrm{SO}_{4}$ (solution $(I I I))$. (Reprinted from Ref. ${ }^{19}$ with permission from MDPI). 

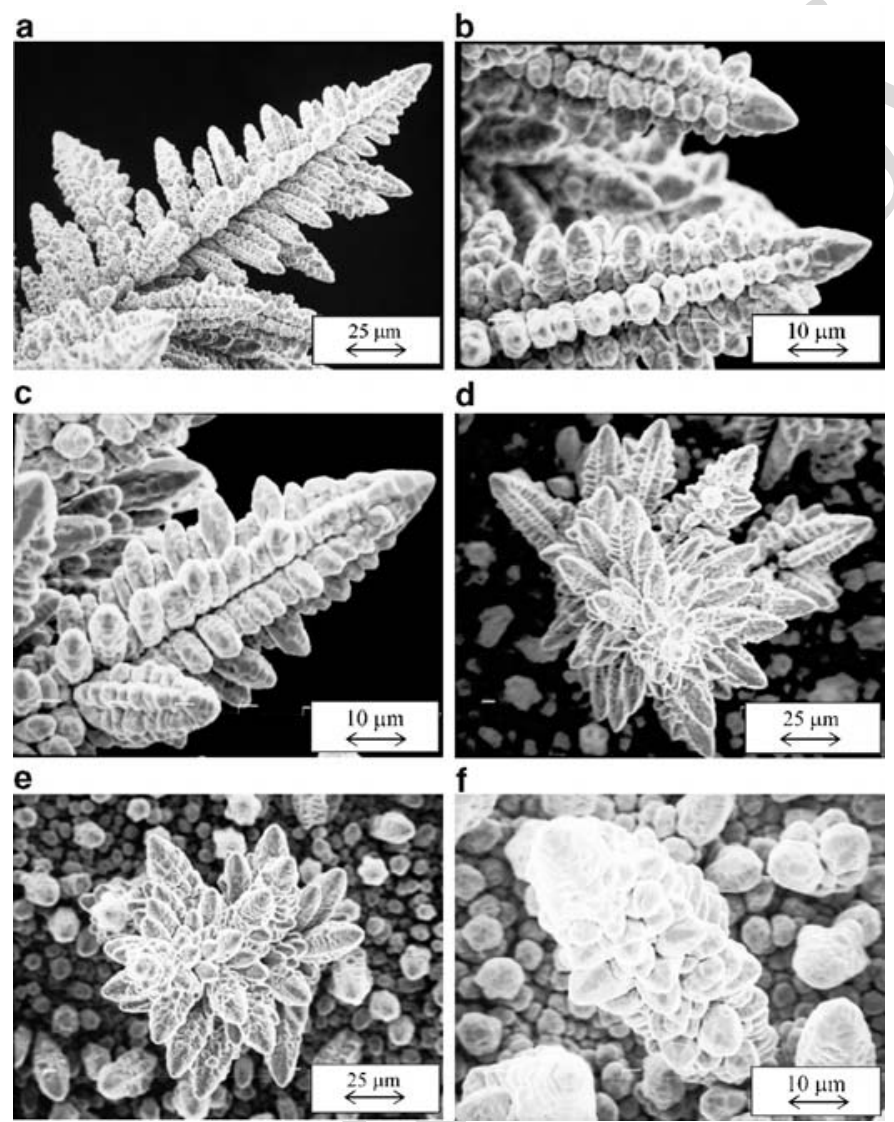

Figure 24. Copper deposits obtained at an overpotential of $650 \mathrm{mV}$. Quantity of electricity: $10 \mathrm{~mA} \mathrm{~h} \mathrm{~cm}{ }^{-2}$. (a, b): solution (I); (c, d): solution (II); (e, f): solution (III). (Reprinted from Ref. ${ }^{19}$ with permission from MDPI).

potentiostatically at a temperature of $18.0 \pm 1.0^{\circ} \mathrm{C}$. The beginning 601 of the plateau of the limiting diffusion current density is deter- 602 mined as the intersect/of straight lines joining currents in mixed 603 activation - diffusion and diffusion control of electrodeposition, as 604 shown in the Fig. 23. The end of this plateau is determined as the 605 overpotential at which current starts to grow with the increasing 606 overpotential. The increase in the concentration of $\mathrm{Cu}$ (II) ions leads 607 


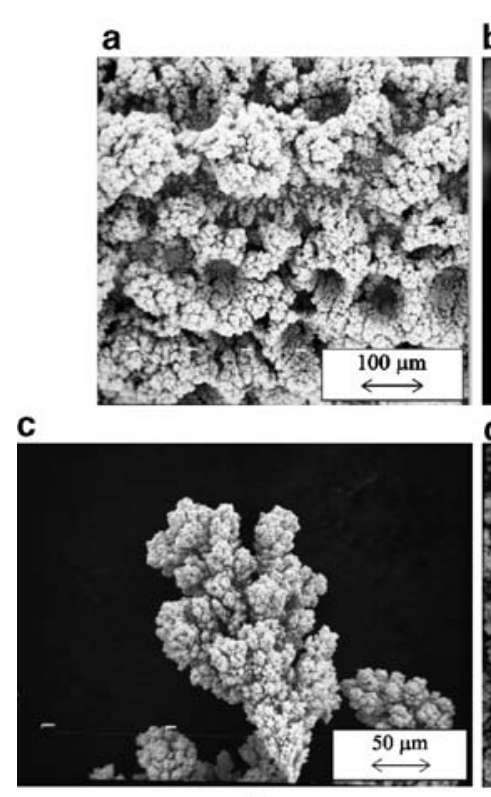

b
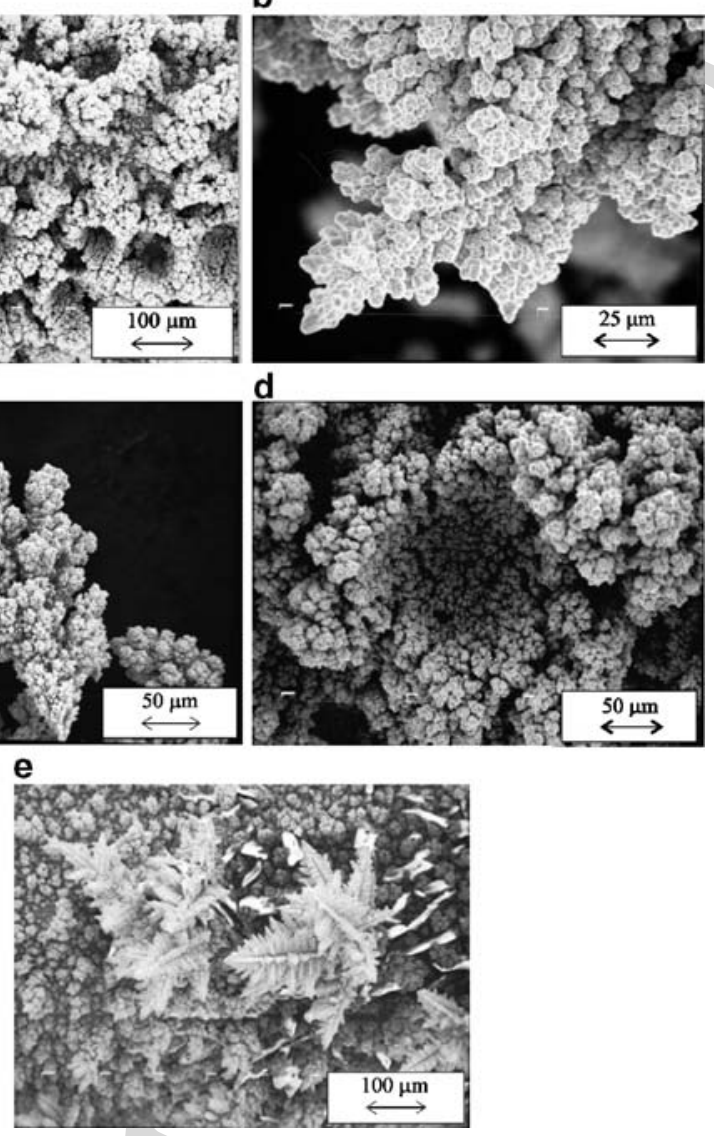

Figure 25. Copper deposits obtained at an overpotential of $800 \mathrm{mV}$. Quantity of electricity: $10 \mathrm{~mA} \mathrm{~h} \mathrm{~cm}^{-2}$. (a) solution (I); (b-d) solution (II); (e) solution (III). (Reprinted from Refs. ${ }^{15,60}$ with permissions from MDPI and Elsevier).

to a shift of overpotentials at which the limiting diffusion current 608 density plateaus initiate toward the larger overpotentials, while the 609 end of these plateaus remains practically constant (Fig. 23). 610

The effect of hydrogen evolution on copper electrodeposition 611 was examined at overpotentials of 550, 650, 800, and $1,000 \mathrm{mV}$. 612 For all examined solutions, overpotentials of 550 and $650 \mathrm{mV} 613$ corresponded to the plateau of the limiting diffusion current density, 614 


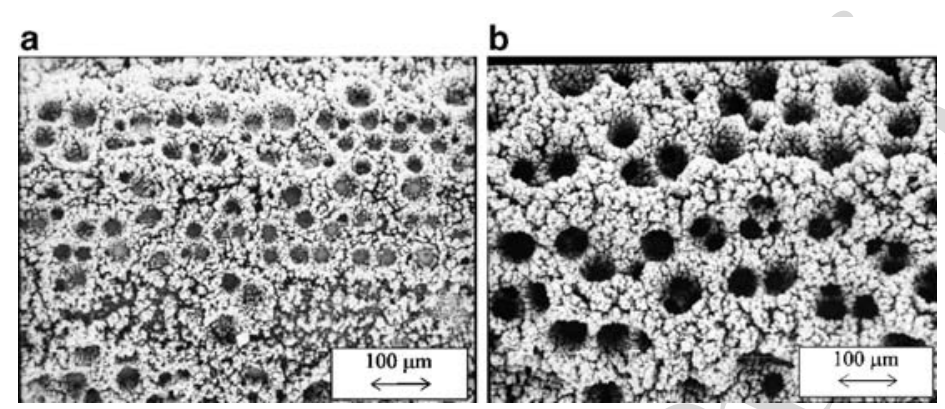

Figure 26. Copper deposits obtained at an overpotential of $1,000 \mathrm{mV}$ from $0.075 \mathrm{M}$ $\mathrm{CuSO}_{4}$ in $0.50 \mathrm{M} \mathrm{H}_{2} \mathrm{SO}_{4}$. Quantity of electricity: (a) $2.5 \mathrm{~mA} \mathrm{~h} \mathrm{~cm}{ }^{-2}$, (b) $20 \mathrm{~mA} \mathrm{~h}$ $\mathrm{cm}^{-2}$. (Reprinted from Ref. ${ }^{58}$ with permission from Elsevier).

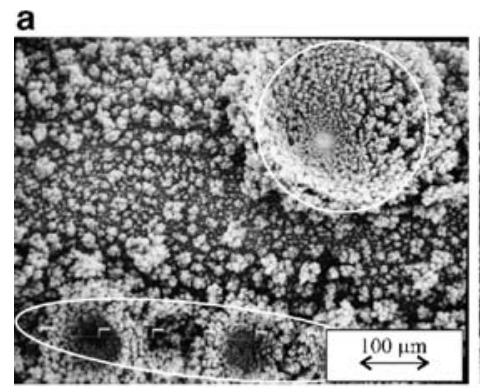

b

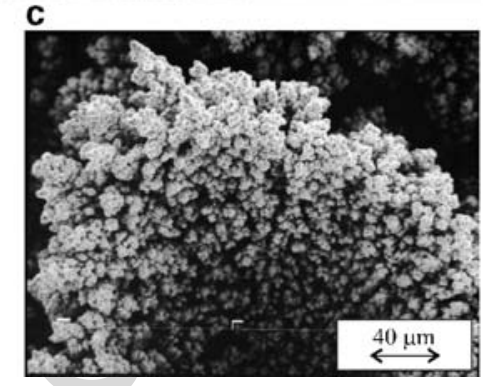

Figure 27. Copper deposits obtained at an overpotential of $1,000 \mathrm{mV}$ from $0.30 \mathrm{M}$ $\mathrm{CuSO}_{4}$ in $0.50 \mathrm{M} \mathrm{H}_{2} \mathrm{SO}_{4}$. (a) Quantity of the electricity: $2.5 \mathrm{~mA} \mathrm{~h} \mathrm{~cm}^{-2},(\mathbf{b}, \mathbf{c})$ quantity of the electricity: $5.0 \mathrm{~mA} \mathrm{~h} \mathrm{~cm}{ }^{-2}$. (Reprinted from Ref. ${ }^{58}$ with permission from Elsevier). 


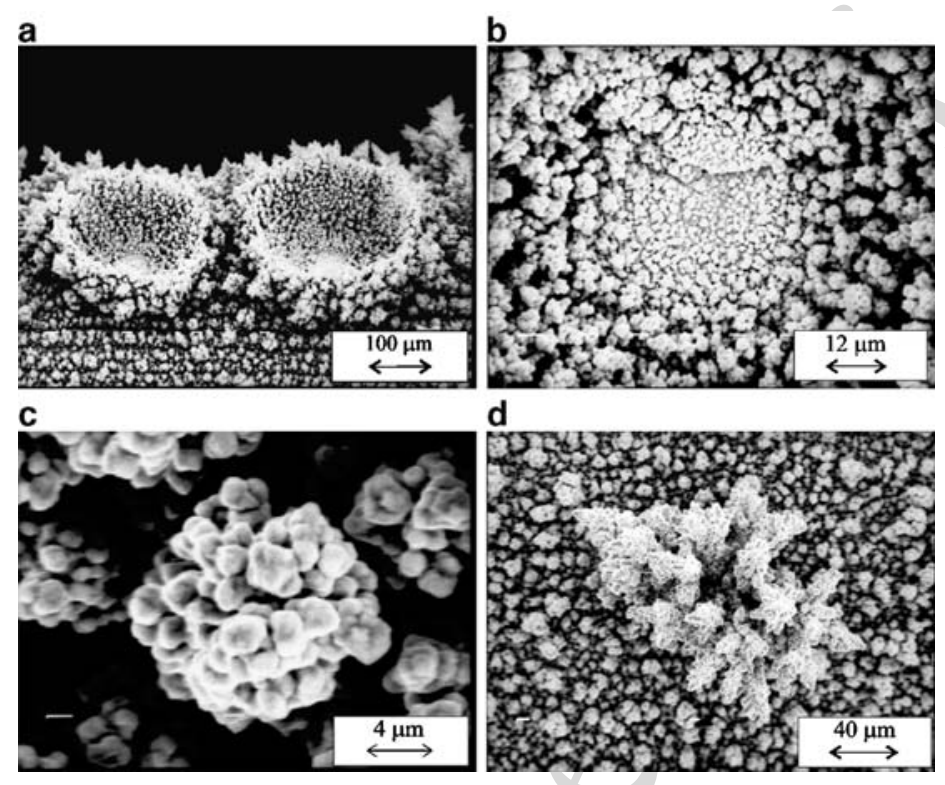

Figure 28. Copper deposits obtained at an overpotential of $1,000 \mathrm{mV}$ from $0.60 \mathrm{M}$ $\mathrm{CuSO}_{4}$ in $0.50 \mathrm{M} \mathrm{H}_{2} \mathrm{SO}_{4}$. Quantity of the electricity: $2.5 \mathrm{~mA} \mathrm{~h} \mathrm{~cm}^{-2}$. (Reprinted from Ref. ${ }^{58}$ with permission from Elsevier).

while overpotentials of 800 and $1,000 \mathrm{mV}$ were about 50 and 615 $250 \mathrm{mV}$ outside the plateau of the limiting diffusion current density, 616 respectively (Fig. 23).

The summary of the obtained values of the average current 618 efficiencies of hydrogen evolution in the dependence of concentra- 619 tion of $\mathrm{Cu}(\mathrm{II})$ ions and overpotential of electrodeposition ${ }^{19,58}$ are 620 given in Table 1.

It can be seen from Table 1 that the average current efficien- 622 cies of hydrogen evolution, $\eta_{\mathrm{av}}\left(\mathrm{H}_{2}\right)$ decreased with the increasing 623 $\mathrm{CuSO}_{4}$ concentration at all overpotentials. At the first sight, this 624 was unexpected because the concentration of $\mathrm{H}_{2} \mathrm{SO}_{4}$ was same for 625 all solutions. The explanation for it can be obtained by the analy- 626 sis of ionic equilibrium of the species in the $\mathrm{CuSO}_{4}-\mathrm{H}_{2} \mathrm{SO}_{4}-\mathrm{H}_{2} \mathrm{O} 627$ system (Fig. 1). According to this equilibrium, it is the result of de- 628 creasing the hydrogen ion concentration with the increasing copper 629 concentration. 59 


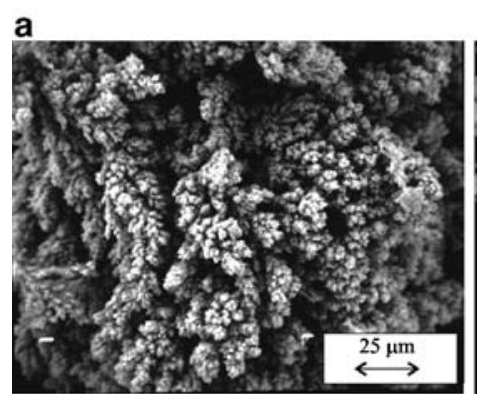

c

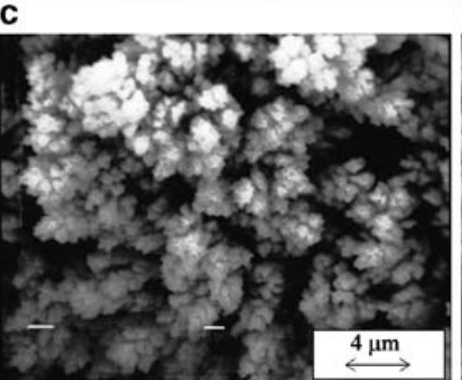

e

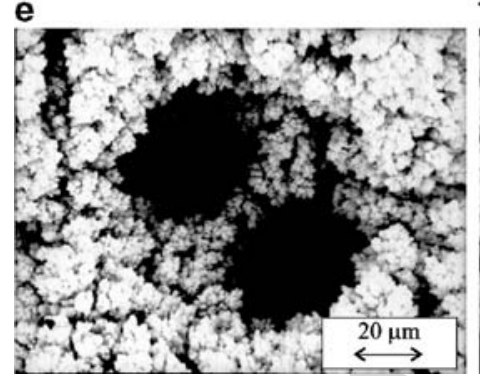

b

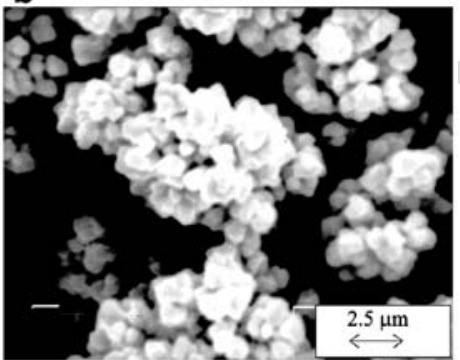

d

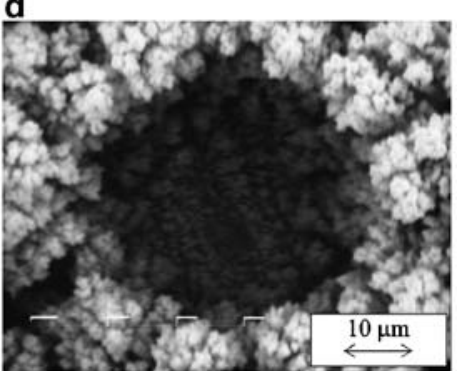

f

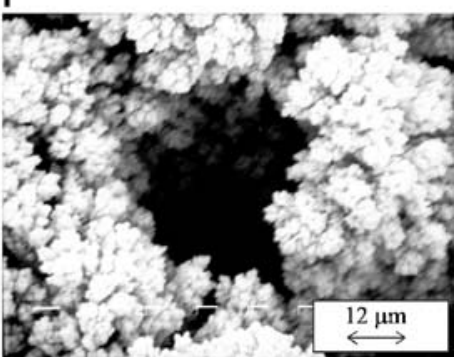

Figure 29. Copper deposits obtained at an overpotential of $1,000 \mathrm{mV}$ from $0.075 \mathrm{M}$ $\mathrm{CuSO}_{4}$ in $0.50 \mathrm{M} \mathrm{H}_{2} \mathrm{SO}_{4}$ : (a, b, e, f) quantity of the electricity: $20 \mathrm{~mA} \mathrm{~h} \mathrm{~cm}{ }^{-2},(\mathbf{c}$, d) quantity of the electricity: $5.0 \mathrm{~mA} \mathrm{~h} \mathrm{~cm}{ }^{-2}$. (Reprinted from Ref. ${ }^{58}$ with permission from Elsevier).

(i) Morphologies of Copper Deposits Obtained at Overpotentials up to $800 \mathrm{mV}$

The copper deposit electrodeposited from $0.075 \mathrm{M} \mathrm{CuSO}_{4}$ in 633 $0.50 \mathrm{M} \mathrm{H}_{2} \mathrm{SO}_{4}$ at an overpotential of $550 \mathrm{mV}$ with a quantity of the 634 electricity of $10 \mathrm{~mA} \mathrm{~h} \mathrm{~cm}^{-2}$ was cauliflower-like structure. Copper 635 

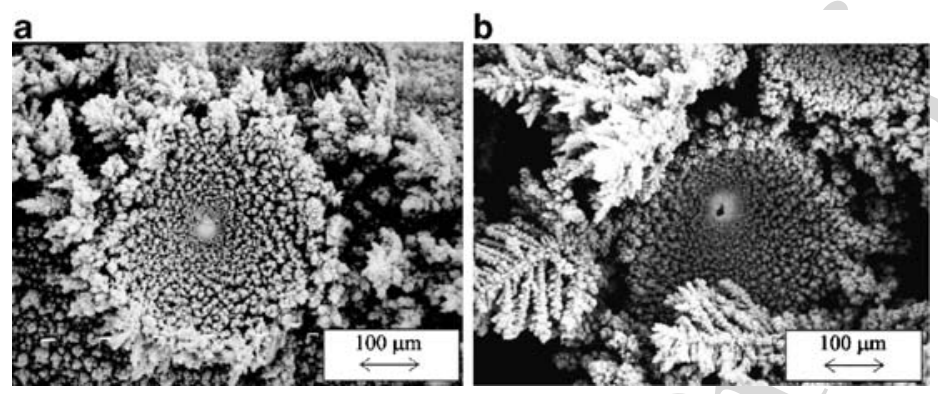

Figure 30. Copper deposits obtained at an overpotential of $1,000 \mathrm{mV}$ from $0.60 \mathrm{M}$ $\mathrm{CuSO}_{4}$ in $0.50 \mathrm{M} \mathrm{H}_{2} \mathrm{SO}_{4}$ : (a) quantity of the electricity: $5.0 \mathrm{~mA} \mathrm{~h} \mathrm{~cm}{ }^{-2}$, (b) quantity of the electricity: $20 \mathrm{~mA} \mathrm{~h} \mathrm{~cm}^{-2}$. (Reprinted from Ref. ${ }^{58}$ with permission from Elsevier).

\section{t1.1 Table 1.}

The average current efficiencies of hydrogen evolution in the function of concentration of $\mathrm{Cu}$ (II) ions. (Reprinted from Refs. ${ }^{19,58}$ with permissions from MDPI and Elsevier).

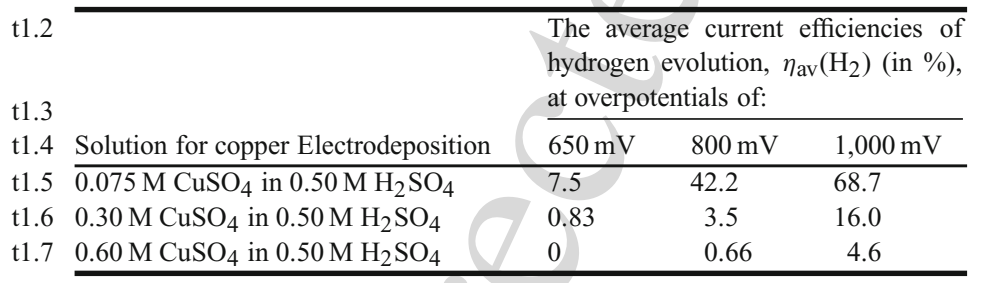

deposits electrodeposited from $0.30 \mathrm{M}$ and $0.60 \mathrm{M} \mathrm{CuSO}_{4}$ in $0.50 \mathrm{M} 636$ $\mathrm{H}_{2} \mathrm{SO}_{4}$ at the same overpotential and with the same quantity of the 637 electricity were globular structures. ${ }^{19}$ Electrodepositions of cop- 638 per with two times larger than the quantity of electricity led to the 639 change of morphology of copper deposits. Copper dendrites were 640 formed during electrodeposition of copper from solution (I), while 641 the mixture of cauliflower-like and globular forms was obtained 642 by electrodeposition from solution (II) and solution (III). At this 643 overpotential, there was hydrogen evolution only from solution (I) 644 (the average current efficiency of hydrogen evolution, $\eta_{\mathrm{av}}\left(\mathrm{H}_{2}\right), 645$ was $1.7 \%) .19$

Morphologies of copper deposits obtained at an overpotential of 647 $650 \mathrm{mV}$ from $0.075 \mathrm{M}, 0.30 \mathrm{M}$, and $0.60 \mathrm{M} \mathrm{CuSO}_{4}$ in $0.50 \mathrm{M} \mathrm{H}_{2} \mathrm{SO}_{4} 648$ 
are shown in Fig. 24. It can be seen from Fig. 24 that copper dendrites 649 were formed during copper electrodeposition from all three solu- 650 tions. Meanwhile, it is very clear from Fig. 24 that the shape of 651 copper dendrites depended strongly on the concentration of $\mathrm{Cu}$ (II) 652 ions. Very branchy copper dendrites consisting of corncob-like ele- 653 ments were formed from solution (I) (Fig. 24a, b). Copper dendrites 654 formed from solution (II) presented a mixture of very branchy 655 dendritic forms (Fig. 24c) and those shaped like flowers (Fig. 24d). 656 Finally, the copper deposits obtained from solution (III) presented a 657 mixture of flower-like (Fig. 24e) and corncob-like forms (Fig. 24f). 658

Figure 25 shows the morphologies of copper deposits obtained 659 at an overpotential of $800 \mathrm{mV}$, from which the strong effect of con- 660 centration of $\mathrm{Cu}$ (II) ions on copper electrodeposition can be seen. 661

The honeycomb-like structure was formed from solution (I) 662 (Fig. 25a).

A mixture of dendritic forms (Fig. 25b), degenerate dendrites, 664 (Fig. 25c) and holes formed due to the attached hydrogen bubbles 665 (Fig. 25d) was obtained by electrodeposition from solution (II). $\quad 666$

Finally, only dendritic copper forms are obtained from solution 667 (III) (Fig. 25e). These dendritic forms were more branchy structures 668 than those formed from the same solution by the electrodeposition 669 at an overpotential of $650 \mathrm{mV}$ and with the same quantity of the 670 electricity (cf. Fig. 24e, f).

The careful analysis of the morphologies of copper deposits 672 shown in Figs. 24 and 25 indicated that an increase in the 673 concentration of $\mathrm{Cu}$ (II) ions led to a shift of the formation of charac- 674 teristic morphological shapes of copper deposits toward higher elec- 675 trodeposition overpotentials by about $100-150 \mathrm{mV}$. This is because 676 of the increase of a critical overpotential of dendritic growth ini- 677 tiation with the increase of concentration of $\mathrm{Cu}(\mathrm{II})$ ions. ${ }^{19}$ For 678 example, copper dendrites formed at $800 \mathrm{mV}$ from solution (III) 679 (Fig. 25e) were very similar to those obtained at $650 \mathrm{mV}$ from $s o-680$ lutions (I) and (II) (Fig. 24a-c). The globular forms obtained from 681 solutions (II) and (III) at an overpotential of $550 \mathrm{mV}$ were very 682 similar to ones obtained from $0.15 \mathrm{M} \mathrm{CuSO}_{4}$ in $0.50 \mathrm{M} \mathrm{H}_{2} \mathrm{SO}_{4}$ at an 683 overpotential of $450 \mathrm{mV} .^{10}$ The different shapes of copper dendrites 684 formed at an overpotential of $650 \mathrm{mV}$ from solutions with different 685 concentrations of $\mathrm{Cu}$ (II) ions (Fig. 24) also pointed out the strong 686 effect of concentration of $\mathrm{Cu}$ (II) ions on electrodeposition of copper 687 at an overpotential of $650 \mathrm{mV}$. 
Hydrogen Co-deposition Effects on Copper Electrodeposition

\section{(ii) Morphologies of Copper Deposits Obtained} at an Overpotential of $1,000 \mathrm{mV}$

The copper deposits obtained from $0.075 \mathrm{MCuSO}_{4}$ in 691 $0.50 \mathrm{M} \mathrm{H}_{2} \mathrm{SO}_{4}$ at an overpotential of $1,000 \mathrm{mV}$ with the quanti- 692 ties of electricity of 2.5 and $20 \mathrm{~mA} \mathrm{~h} \mathrm{~cm}^{-2}$ are shown in Fig. 26, 693 from which it can be seen that honeycomb-like structures were 694 formed by electrodepositions from this solution.

The copper deposits obtained at an overpotential of $1,000 \mathrm{mV} 696$ from $0.30 \mathrm{M} \mathrm{CuSO}_{4}$ in $0.50 \mathrm{M} \mathrm{H}_{2} \mathrm{SO}_{4}$ with quantities of electric- 697 ity of 2.5 and $5.0 \mathrm{~mA} \mathrm{~h} \mathrm{~cm}^{-2}$ are shown in Fig. 27, from which it 698 can be clearly seen that the structures of the deposits obtained from 699 $0.30 \mathrm{M} \mathrm{CuSO}_{4}$ in $0.50 \mathrm{M} \mathrm{H}_{2} \mathrm{SO}_{4}$ were completely different from 700 those obtained from $0.075 \mathrm{M} \mathrm{CuSO}_{4}$ in $0.50 \mathrm{M} \mathrm{H}_{2} \mathrm{SO}_{4}$ (Fig. 26). 701

Two types of craters or holes formed due to the attachment of 702 hydrogen bubbles can be observed by analysis of the copper deposit 703 shown in Fig. 27a. One type of holes is presented in the ellipse in 704 Fig. 27a. These holes are similar to those forming the honeycomb- 705 like structure during copper electrodeposition from $0.075 \mathrm{MCuSO}_{4} 706$ in $0.50 \mathrm{M} \mathrm{H}_{2} \mathrm{SO}_{4}$. These holes are grouped and mutually separated 707 by agglomerates of relatively small copper grains.

The other type of holes is shown in the circle in the same figure. 709 From Fig. 27a, it can be seen that the shape of this hole is dish or 710 shell-like. The diameter of dish-like holes is larger than the diameter 711 of the holes forming the honeycomb-like structure, while their num- 712 ber is smaller than the number of holes forming the honeycomb-like 713 structure. A typical dish-like hole electrodeposited with the quan- 714 tity of the electricity of $5.0 \mathrm{~mA} \mathrm{~h} \mathrm{~cm}^{-2}$ is shown in Fig. $27 \mathrm{~b}$. The 715 bottom of the dish-like hole is covered by almost compact copper 716 deposit (the part in the circle in Fig. 27b), while the wall of this 717 hole consists of small, very disperse agglomerates of copper grains 718 (Fig. 27c). From Fig. 27c, it can also be seen that copper dendrites 719 were formed at the shoulders of the dish-like holes electrodeposited 720 with this quantity of electricity. Also, cauliflower-like forms were 721 formed between the holes or craters belonging to these different 722 types (Fig. 27a).

The electrodeposition processes at an overpotential of $1,000 \mathrm{mV} 724$ from $0.60 \mathrm{M} \mathrm{CuSO}_{4}$ in $0.50 \mathrm{M} \mathrm{H}_{2} \mathrm{SO}_{4}$ led to the formation of dish- 725 like holes only. The typical dish-like holes formed with the quan- 726 tity of the electricity of $2.5 \mathrm{~mA} \mathrm{~h} \mathrm{~cm}^{-2}$ are shown in Fig. 28a, from 727 which it can be seen that copper dendrites were formed at their 728 
shoulders. The bottom of the dish-like holes was almost compact 729 (Fig. 28b), while the interior of the hole was constructed of disperse 730 agglomerates of copper grains (Fig. 28c). Very branched copper den- 731 drites and small cauliflower-like forms were formed among the dish- 732 like holes during the electrodeposition of copper from this solution 733 (Fig. 28d).

On the basis of the presented analysis of the electrodeposition 735 processes at an overpotential of $1,000 \mathrm{mV}$ (Figs. 26-28), it is obvi- 736 ous that increasing the concentration of $\mathrm{Cu}$ (II) ions leads to a change 737 in the shape of the holes from those forming a honeycomb-like struc- 738 $\begin{array}{ll}\text { ture to dish-like holes. } & 739\end{array}$

It should be noted that the honeycomb-like structure was 740 formed from $0.075 \mathrm{M} \mathrm{CuSO}_{4}$ in $0.50 \mathrm{M} \mathrm{H}_{2} \mathrm{SO}_{4}$ at an overpoten- 741 tial of $1,000 \mathrm{mV}$, with a considerably larger quantity of co-deposited 742 hydrogen $\left(\eta_{\mathrm{av}}\left(\mathrm{H}_{2}\right)=68.7 \%\right)$ than that formed by electrodeposition 743 at $800 \mathrm{mV}$ from the same solution $\left.\left(\eta_{\mathrm{av}}\left(\mathrm{H}_{2}\right)=42.2 \%\right),{ }^{19}\right)$ or from 744 $0.15 \mathrm{M} \mathrm{CuSO}_{4}$ in $0.50 \mathrm{M} \mathrm{H}_{2} \mathrm{SO}_{4}$ at $800 \mathrm{mV}\left(\eta_{\mathrm{av}}\left(\mathrm{H}_{2}\right)=10.8 \%\right)$ and 745 $1,000 \mathrm{mV}\left(\eta_{\mathrm{av}}\left(\mathrm{H}_{2}\right)=30.0 \%\right) .{ }^{10}$ It was found ${ }^{19,58}$ that the maxi- 746 mum $\mathrm{CuSO}_{4}$ concentration (in $0.50 \mathrm{M} \mathrm{H}_{2} \mathrm{SO}_{4}$ ) which enabled the 747 formation of the honeycomb-like structure was $0.15 \mathrm{M}$. The critical 748 quantity of evolved hydrogen leading to the change of the hydrody- 749 namic conditions in the near-electrode layer for this solution group 750 was estimated to correspond to $\eta_{\mathrm{av}}\left(\mathrm{H}_{2}\right)$ of $10.0 \%{ }^{19}{ }^{19} 751$

The more vigorous hydrogen evolution at this overpotential 752 from $0.075 \mathrm{M} \mathrm{CuSO}_{4}$ in $0.50 \mathrm{M} \mathrm{H}_{2} \mathrm{SO}_{4}$ makes a more visible chan- 753 nel structure formed through the interior of the deposit. A typical 754 channel structure is shown in Fig. 29a, which was obtained by ma- 755 nipulation of the copper deposit in order that the cross section view 756 could be seen. The top view of a part of the copper deposit shown in 757 Fig. 29a is shown in Fig. 29b, from which it can be seen that irregular 758 channels are distributed over the surface area of the deposit among 759 disperse agglomerates of copper grains. These channels were gen- 760 erated in situ by the simultaneous processes of copper growth and 761 vigorous hydrogen evolution. It is also known ${ }^{61}$ that a channel or 762 a stream copper structure can be formed ex situ by the use of an 763 acoustically excited Ar gas bubble.

Naturally, both the formation holes and channels through the in- 765 terior of the deposit occur simultaneously, and these processes can 766 not be observed separately. As already stated, in the initial stage of 767 the electrodeposition process, both nuclei of copper and "nuclei" 768 
Hydrogen Co-deposition Effects on Copper Electrodeposition

of hydrogen bubbles are formed at the active sites of the electrode 769 surface. ${ }^{18}$ The hydrogen bubbles isolate the substrate and then the 770 current lines are concentrated around these hydrogen bubbles mak- 771 ing rings consisted of agglomerates of copper grains around them. 772 The current lines are also concentrated at the nuclei of copper 773 formed in the initial stage between the hydrogen bubbles. Anyway, 774 the bubbles cause an increase of the local current density around 775 them, resulting in a faster growth of the copper deposit around the 776 growing bubbles, as well as in increasing rate of hydrogen evolution. 777

As a result of the current distribution at the growing copper 778 surface, new copper nucleation and hydrogen evolution will occur 779 primarily at the top of these agglomerates. Some of the new, small, 780 freshly formed hydrogen bubbles which are formed at agglomer- 781 ates around previously formed large hydrogen bubbles will coa- 782 lesce with them, leading to their growth with electrolysis time as 783 already shown. ${ }^{18}$ This is confirmed by the very porous structure of 784 the interior of walls of the holes (Fig. 29c), which consist of dis- 785 perse agglomerates of copper grains among which numerous irregu- 786 lar channels are present. A typical hole formed of growing hydrogen 787 bubbles is shown in Fig. 29d. In the growth process, the coales- 788 cence of closely formed large hydrogen bubbles can also be observed 789 (Fig. 29e).

Meanwhile, some of the freshly formed hydrogen bubbles will 791 not find a way to coalesce with the large hydrogen bubbles be- 792 cause they are situated among copper nuclei which initiate a bar- 793 rier for their development into large hydrogen bubbles. This effect, 794 with already discussed current density distribution will lead to the 795 formation of a porous channel structure through the interior of the 796 copper deposit (Fig. 29a).

Simultaneously, holes of irregular shapes (Fig. 29f) were 798 formed from nuclei of copper formed in the initial stage of the 799 electrodeposition between the hydrogen bubbles. ${ }^{18}$ The current dis- 800 tribution at the growing copper surface was responsible for the 801 formation of this type of hole.

Anyway, there are two effects of hydrogen evolution on copper 803 electrodeposition leading to the formation of the honeycomb-like 804 structures. The first effect is a stirring of the solution in the near- 805 electrode layer caused by a vigorous hydrogen evolution leading 806 to the decrease of the diffusion layer thickness and the increase of 807 the limiting diffusion current density. ${ }^{10}$ The second effect concerns 808 
the morphology of the copper deposits due to the effect of hydro- 809 gen bubbles on the current density distribution on the growing elec- 810 trode surface. The uniform distribution of morphological forms on 811 the electrode surface means the same hydrodynamic conditions exist 812 over the whole electrode surface and the honeycomb-like structure 813 indicates to the local effect of hydrogen bubbles.

Dish-like holes were formed from the more concentrated 815 solution $\left(0.60 \mathrm{M} \mathrm{CuSO}_{4}\right.$ in $\left.0.50 \mathrm{M} \mathrm{H}_{2} \mathrm{SO}_{4}\right)$, accompanied by a con- 816 siderably lower quantity of evolved hydrogen $\left(\eta_{\mathrm{av}}\left(\mathrm{H}_{2}\right)=4.6 \%\right)$ than 817 was the case with the holes forming a honeycomb-like structure 818 $\left(0.075 \mathrm{M}\right.$ and $0.15 \mathrm{M} \mathrm{CuSO}_{4}$ in $\left.0.50 \mathrm{M} \mathrm{H}_{2} \mathrm{SO}_{4}\right)$. $\quad 819$

On the basis of the obtained value of the average current effi- 820 ciency of hydrogen evolution of $4.6 \%$ and morphologies of copper 821 deposits shown in Fig. 28 (very branchy copper dendrites developed 822 between dish-like craters or holes), it is clear that the hydrogen evo- 823 lution was insufficient to produce effective stirring of the solution 824 in the near-electrode layer, which would lead to a decrease of the 825 diffusion layer thickness, and consequently, no change in the hy- 826 drodynamic conditions and no inhibition of dendritic growth. The 827 electrodeposition process was primarily controlled by the diffusion 828 of ions to the electrode surface, rather than the kinetics of the elec- 829 trodeposition. $^{13,23}$

The initial stage of the formation of dish-like holes was the same 831 as the initial stage of the formation of the honeycomb-like structure. 832 The nuclei of copper and the "nuclei" of hydrogen bubbles were 833 formed at active sites on the electrode surface and the formed hy- 834 drogen bubbles isolate the substrate causing a concentration of the 835 current lines about them. Meanwhile, because of the low hydrogen 836 co-deposition current density, the number of the formed "nuclei" 837 of hydrogen bubbles was smaller than the number which led to the 838 formation of the honeycomb-like structure. In the growth process, 839 they have enough space to develop into large bubbles, making holes 840 with a dish-like shape at the surface area of electrode. Dendrites 841 formed at their shoulders (Fig. 28a) as well as very developed den- 842 drites between them (Fig. 28d) clearly indicate the insufficiency of 843 the evolved hydrogen to disturb the diffusion layer of the macroelec- 844 trode. Further copper nucleation and hydrogen evolution primarily 845 occur at the shoulders of the growing holes and the copper den- 846 drites between them. Most of the freshly formed hydrogen bub- 847 bles at the shoulder of the dish-like holes coalesce with previously 848 


\section{Hydrogen Co-deposition Effects on Copper Electrodeposition}

formed large hydrogen bubbles, leading to their growth with the 849 electrolysis time (Fig. 30a) and making the interior of holes very 850 porous and constructed of cauliflower- or raspberry-like forms. At 851 the same time, the almost compact deposit at the bottom of the dish- 852 like holes represents the position of the formation of the initial bub- 853 ble (Fig. 28b), and it can be supposed that its origin is the thin copper 854 film previously electrodeposited at $400 \mathrm{mV}$. It is of interest to note 855 that regardless of the quantity of electricity passed, or the deposi- 856 tion time, the dendrites grew only at the edges of the dish-like holes. 857 This is due to the fact that the electrodeposition of copper occurs 858 on the dendrite branches in the same way as on any other part of 859 the electrode surface, except on the tip of the dendrite protrusions 860 themselves, where the process is under activation control, resulting 861 in regular dendritic forms (Fig. 30b). ${ }^{62-64}$ At larger deposition times, 862 the growth of dendrites become dominant and the dish-like protru- 863 sion cease to grow. Also, it can be seen from Figs. 28a and 30a that 864 in the "shadow" of the dish-like holes there is a lower density of 865 grains on the initial substrate relative to the overshadowed parts of 866 electrode, which is the consequence of the concentration of current 867 lines at them.

In dependence on the quantity of electricity, the average diam- 869 eter of the dish-like holes was in the range of $200-360 \mu \mathrm{m}$. The 870 number of dish-like holes was estimated to be 2.5 holes $/ \mathrm{mm}^{2}$ sur- 871 face area of the copper electrode, and it did not change with the 872 quantity of the electricity, which can be explained by the absence 873 of coalescence of the formed hydrogen bubbles. The comparative 874 dependences of the average diameters, $D$, and the number of holes 875 per square millimeter surface area of copper electrodes on the quan- 876 tity of the electricity for both, dish-like holes and holes making the 877 honeycomb-like structure during the electrodeposition at $1,000 \mathrm{mV} 878$ from $0.075 \mathrm{M} \mathrm{CuSO}_{4}$ in $0.50 \mathrm{M} \mathrm{H}_{2} \mathrm{SO}_{4}$ are shown in Fig. 31, from 879 which it can be seen that the number of formed dish-like holes per 880 square millimeter surface area of the copper electrode was consider- 881 ably smaller than the number of holes forming the honeycomb-like 882 structure and that the average diameter of the dish-like holes was 883 about five times larger than the average diameter of the holes form- 884 ing the honeycomb-like structure. This illustrates successfully the 885 fact that a smaller number of "nuclei" of hydrogen bubbles is formed 886 in the initial stage of electrodeposition of dish-like holes in relation 887 to the number of formed "nuclei" of hydrogen bubbles leading to the 888 formation of the honeycomb-like structure. 


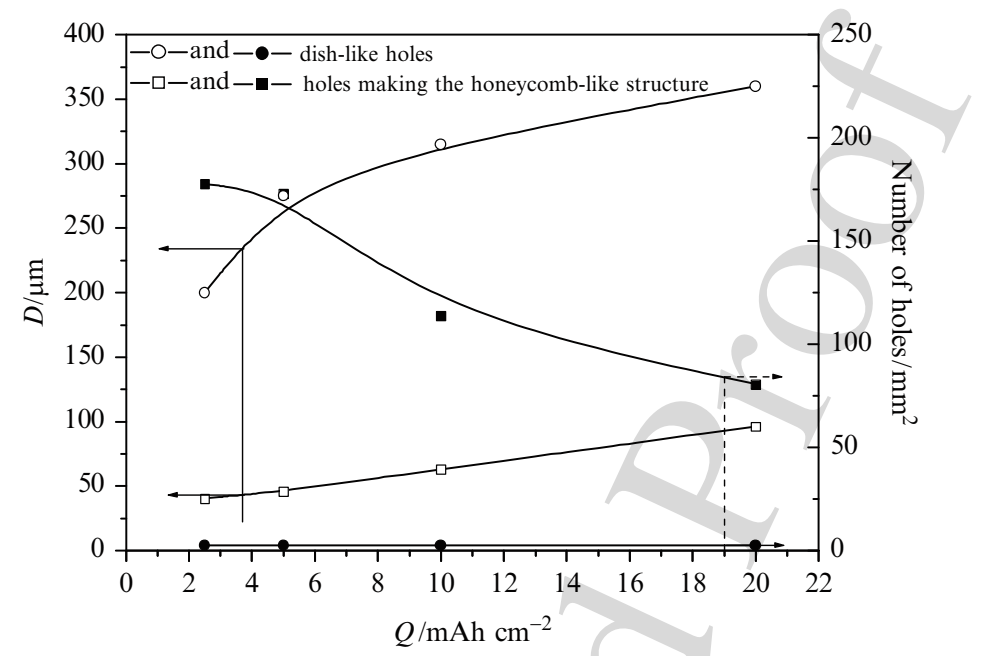

Figure 31. The dependence of average diameters of the surface holes, D, (open style) and number of holes per square millimeter surface area of copper electrodes (solid style) on quantities of electricity, for electrodepositions of copper from $0.075 \mathrm{M} \mathrm{CuSO}_{4}$ in $0.50 \mathrm{M} \mathrm{H}_{2} \mathrm{SO}_{4}$ and $0.60 \mathrm{M} \mathrm{CuSO}_{4}$ in $0.50 \mathrm{M} \mathrm{H}_{2} \mathrm{SO}_{4}$. (Reprinted from Ref. ${ }^{58}$ with permission from Elsevier).

Furthermore, the morphology of the copper deposit obtained 890 from $0.60 \mathrm{MCuSO}_{4}$ in $0.50 \mathrm{M} \mathrm{H}_{2} \mathrm{SO}_{4}$ at an overpotential of 891 $1,000 \mathrm{mV}$ consisted of all the morphological forms characteristic for 892 copper electrodeposition at high overpotentials: holes formed due to 893 hydrogen evolution (Fig. 28a), dendritic forms (Fig. 28d), and small 894 cauliflower-like forms (Fig. 28d). The formation of these different 895 morphological forms which leads to nonuniformity of the elec- 896 trode surface can be explained by different local electrodeposition 897 conditions inside the diffusion layer of the macroelectrode. It is 898 known $^{65}$ that electrochemical processes on microelectrodes in bulk 899 solution can be under activation control at overpotentials which 900 correspond to the plateau of the limiting diffusion current density 901 of the macroelectrode. Bockris et al. ${ }^{63,64}$ and Popov et al. ${ }^{62}$ showed 902 that electrodeposition to the tip of a dendrite, consequently to a 903 microelectrode, inside the diffusion layer of the macroelectrode is 904 under activation control, while the same process is simultaneously 905 under full diffusion control on the macroelectrode. In the absence 906 of dendrite precursors, some cauliflower-like forms can be formed 907 


\section{Hydrogen Co-deposition Effects on Copper Electrodeposition}

on the surface of the macroelectrode when the electrodeposition 908 process is under full linear diffusion control. Then, local spherical 909 diffusion layers inside the diffusion layer of the macroelectrode are 910 formed around them. ${ }^{10}$ Hence, for defined electrodeposition con- 911 ditions, control of the electrodeposition process at some specified 912 points of the macroelectrode can be different from the process con- 913 trol at the macroelectrode in general. This explains and the nonuni- 914 formity of the electrode surface obtained from $0.60 \mathrm{M} \mathrm{CuSO}_{4}$ in 915 $0.50 \mathrm{M} \mathrm{H}_{2} \mathrm{SO}_{4}$.

The polarization characteristic of a macroelectrode is easy to de- 917 termine, as well as the kind of mass transfer control on it. It is very 918 difficult, or even impossible, to do the same for some specified points 919 on it. On the other hand, ${ }^{13,66}$ the morphology of metal deposits in- 920 dicates the conditions under which they were formed. Hence, from 921 the local morphology of a deposit, the type of process control on 922 selected points of the macroelectrode can be derived. 923

The morphology of the copper deposit obtained at an over- 924 potential of $1,000 \mathrm{mV}$ from $0.30 \mathrm{M} \mathrm{CuSO}_{4}$ in $0.50 \mathrm{M} \mathrm{H}_{2} \mathrm{SO}_{4}$ pre- 925 sented a mixture of morphological forms characteristic for copper 926 deposits obtained from solutions with lower $(0.075 \mathrm{M})$ and higher 927 $(0.60 \mathrm{M})$ concentrations of $\mathrm{Cu}$ (II) ions. Thus, a mixture of both types 928 of holes was obtained by the electrodeposition at this overpotential 929 from $0.30 \mathrm{M} \mathrm{CuSO}_{4}$ in $0.50 \mathrm{M} \mathrm{H}_{2} \mathrm{SO}_{4}$. It was estimated that the per- 930 cent of holes forming the honeycomb-like structure was about $80 \% 931$ of the total number of formed holes. On the basis of this fact, it 932 can be concluded that for a concentration of supporting electrolyte 933 of $0.50 \mathrm{M} \mathrm{H}_{2} \mathrm{SO}_{4}$, the concentration of $0.30 \mathrm{M} \mathrm{CuSO}_{4}$ presents the 934 transitional concentration between lower and higher concentrations 935 of $\mathrm{Cu}$ (II) ions. This could be explained by different hydrodynamic 936 conditions at different points of the electrode surface.

\section{The Effect of Concentration of $\mathrm{H}_{2} \mathrm{SO}_{4}$}

The polarization curves for the electrodeposition of copper from 939 $0.15 \mathrm{M} \mathrm{CuSO}_{4}$ with the addition of $0.125,0.25$, and $1.0 \mathrm{M} \mathrm{H}_{2} \mathrm{SO}_{4} 940$ are shown in Fig. 32. All experiments whose results are presented 941 in Figs. 32-37 and Table 2 were performed potentiostatically at a 942 temperature of $18.0 \pm 1.0^{\circ} \mathrm{C}$. It can be seen from Fig. 32 that the 943 beginning of the plateau of the limiting diffusion current density 944 was slightly shifted to higher electrodeposition overpotentials with 945 the decreasing concentration of $\mathrm{H}_{2} \mathrm{SO}_{4}$. The ends of the plateau of 946 


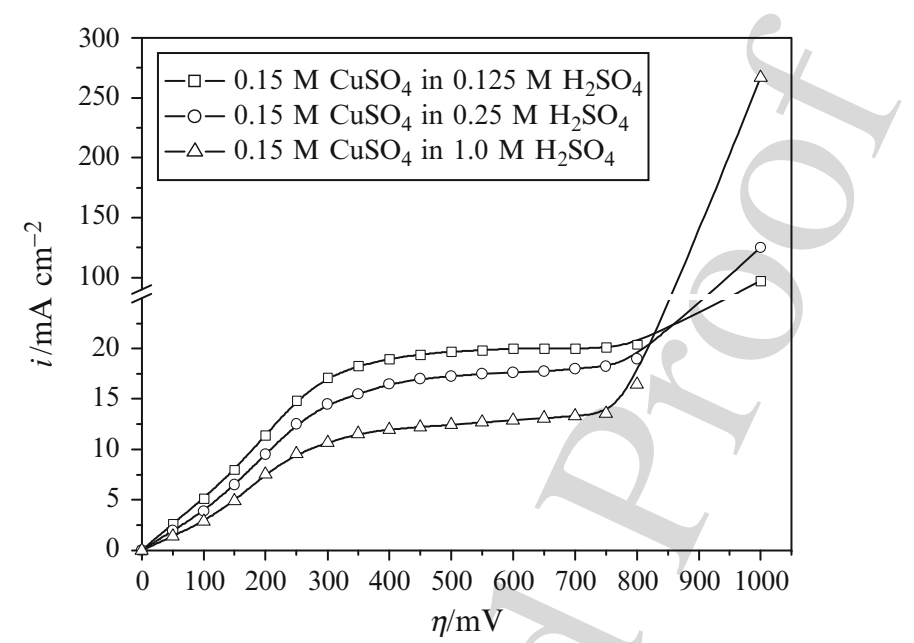

Figure 32. Polarization curves for the cathodic process of copper deposition from: $0.15 \mathrm{M} \mathrm{CuSO}_{4}$ in $0.125 \mathrm{M} \mathrm{H}_{2} \mathrm{SO}_{4}, 0.15 \mathrm{M} \mathrm{CuSO}_{4}$ in $0.25 \mathrm{M} \mathrm{H}_{2} \mathrm{SO}_{4}$, and $0.15 \mathrm{M} \mathrm{CuSO}_{4}$ in $1.0 \mathrm{M} \mathrm{H}_{2} \mathrm{SO}_{4}$. (Reprinted from Ref. ${ }^{67}$ with permission from Elsevier).

the limiting diffusion current density practically do not depend on 947 the concentration of $\mathrm{H}_{2} \mathrm{SO}_{4}$ and they correspond to an overpotential 948 of about $750 \mathrm{mV}$. The negligible shifting of the end of the plateau 949 of the limiting diffusion current density to lower electrodeposition 950 overpotentials can be only observed at a polarization curve obtained 951 from $0.15 \mathrm{M} \mathrm{CuSO}_{4}$ in $1.0 \mathrm{M} \mathrm{H}_{2} \mathrm{SO}_{4}$. At overpotentials higher than 952 $750 \mathrm{mV}$, the fastest growth of current with increasing overpotential 953 is obtained from $0.15 \mathrm{MCuSO}_{4}$ in $1.0 \mathrm{M} \mathrm{H}_{2} \mathrm{SO}_{4}$ and it decreases 954 with the decrease of the $\mathrm{H}_{2} \mathrm{SO}_{4}$ concentration. The limiting diffusion 955 current density value decreased with the increasing concentration of 956 $\mathrm{H}_{2} \mathrm{SO}_{4}$. The decrease in the values of the limiting diffusion current 957 density with increasing $\mathrm{H}_{2} \mathrm{SO}_{4}$ concentration is a consequence of 958 the decrease of the $\mathrm{Cu}$ (II) ion activity with increasing acidity of the 959 solution.

The effect of hydrogen evolution on copper electrodeposition 961 was examined at overpotentials of 550,650,800, and $1,000 \mathrm{mV} .962$ At an oyerpotential of $550 \mathrm{mV}$, there was hydrogen evolution only 963 from $0.15 \mathrm{M} \mathrm{CuSO}_{4}$ in $1.0 \mathrm{M} \mathrm{H}_{2} \mathrm{SO}_{4}$ (the average current efficiency 964 of hydrogen evolution, $\eta_{\mathrm{av}}\left(\mathrm{H}_{2}\right)$, was $\left.0.75 \%\right) .{ }^{67}$ The summary of 965 

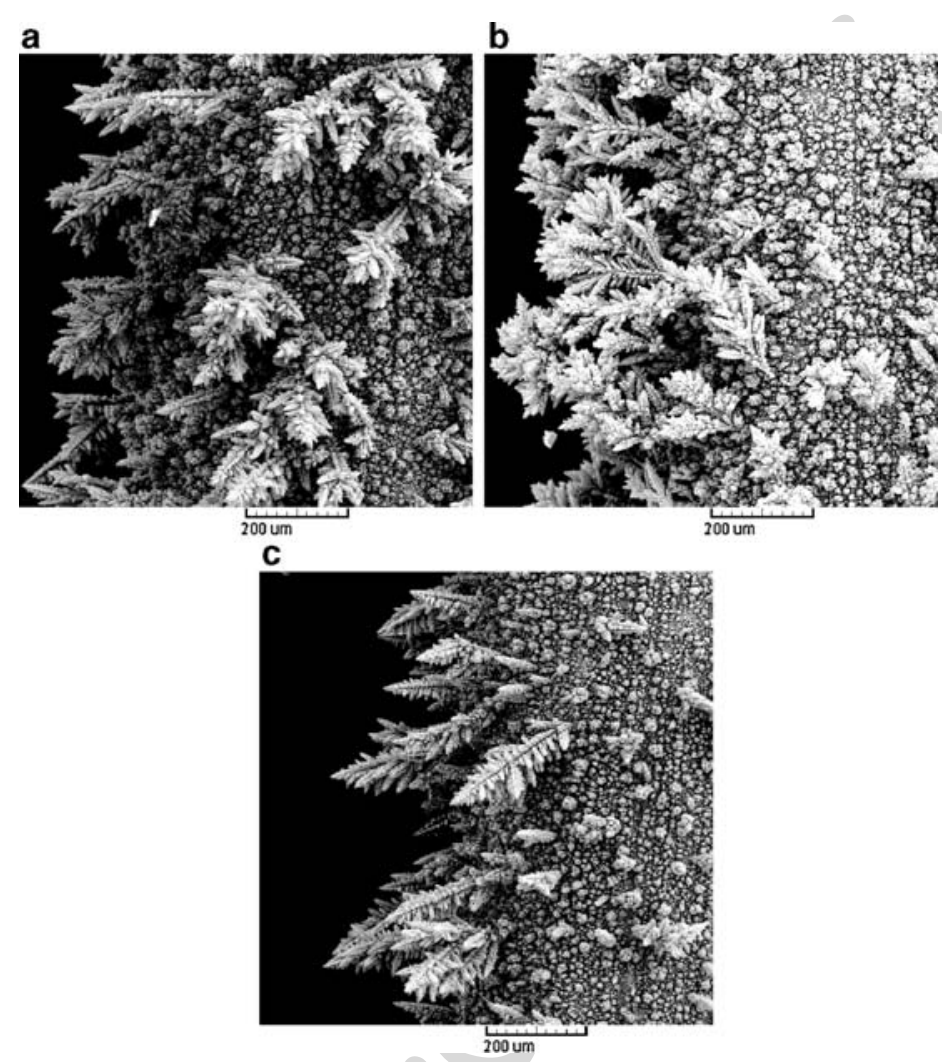

Figure 33. Copper deposits obtained at an overpotential of $650 \mathrm{mV}$ from: (a) $0.15 \mathrm{M}$ $\mathrm{CuSO}_{4}$ in $0.125 \mathrm{M} \mathrm{H}_{2} \mathrm{SO}_{4}$, (b) $0.15 \mathrm{M} \mathrm{CuSO}_{4}$ in $0.25 \mathrm{M} \mathrm{H}_{2} \mathrm{SO}_{4}$, and (c) $0.15 \mathrm{M}$ $\mathrm{CuSO}_{4}$ in $1.0 \mathrm{M} \mathrm{H}_{2} \mathrm{SO}_{4}$. Quantity of electricity: $10 \mathrm{~mA} \mathrm{~h} \mathrm{~cm}^{-2}$. (Reprinted from Ref. ${ }^{67}$ with permission from Elsevier).

the obtained values of the average current efficiencies of hydrogen 966 evolution in the dependence of concentration of $\mathrm{H}_{2} \mathrm{SO}_{4}$ at overpo- 967 tentials of 650,800 , and $1,000 \mathrm{mV}^{60,67}$ are given in Table 2. For 968 all examined solutions, overpotentials of 550 and $650 \mathrm{mV}$ corre- 969 sponded to the plateau of the limiting diffusion current density, while 970 overpotentials of 800 and $1,000 \mathrm{mV}$ were about 50 and $250 \mathrm{mV} 971$ outside the plateau of the limiting diffusion current density, respec- 972 tively (Fig. 32). 

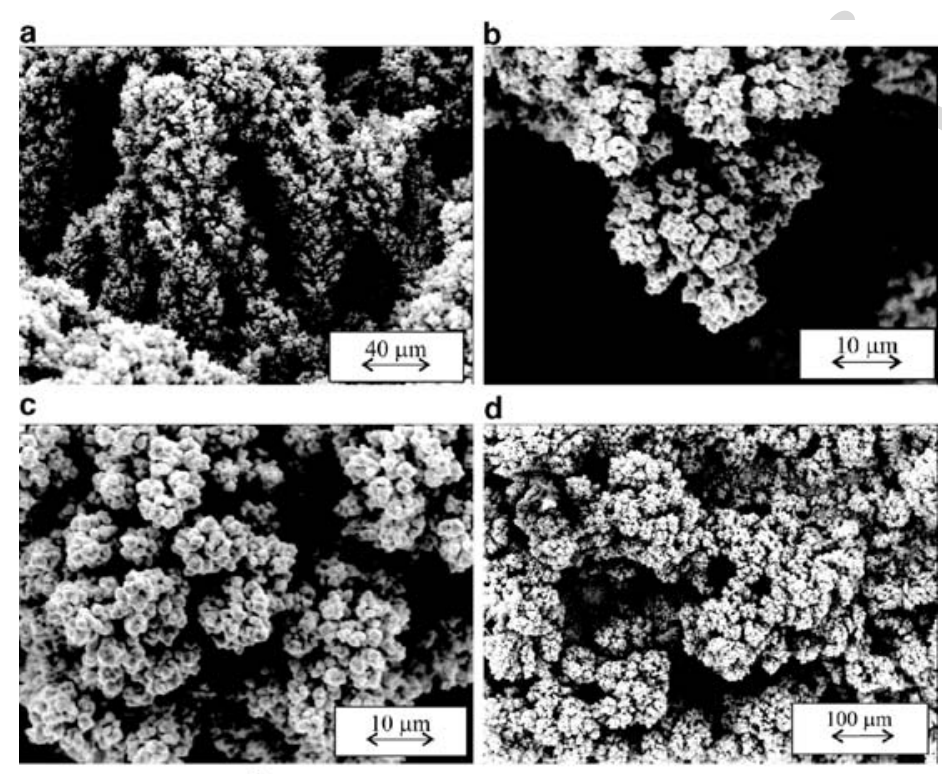

d

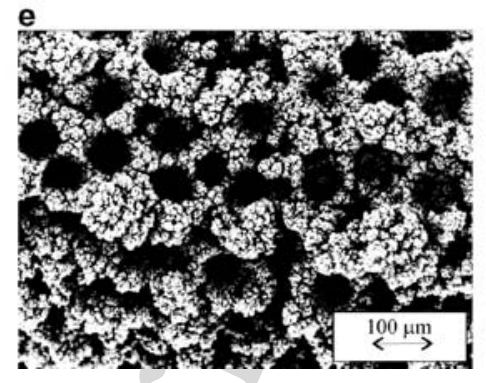

Figure 34. Copper deposits obtained at an overpotential of $800 \mathrm{mV}$ from: (a-c) $0.15 \mathrm{M} \mathrm{CuSO}_{4}$ in $0.125 \mathrm{M} \mathrm{H}_{2} \mathrm{SO}_{4}$; (d) $0.15 \mathrm{M} \mathrm{CuSO}_{4}$ in $0.25 \mathrm{M} \mathrm{H}_{2} \mathrm{SO}_{4}$, and (e) $0.15 \mathrm{M} \mathrm{CuSO}_{4}$ in $1.0 \mathrm{M} \mathrm{H}_{2} \mathrm{SO}_{4}$. Quantity of electricity: $10 \mathrm{~mA} \mathrm{~h} \mathrm{~cm}{ }^{-2}$. (Reprinted from Ref. ${ }^{60}$ with permission from Elsevier).

(i) Morphologies of Copper Deposits Obtained at Overpotentials 974 up to $800 \mathrm{mV}$

Electrodeposition of copper at an overpotential of $550 \mathrm{mV}$ from 976 $0.15 \mathrm{M} \mathrm{CuSO}_{4}$ in $0.125 \mathrm{M} \mathrm{H}_{2} \mathrm{SO}_{4}$, as well as from $0.15 \mathrm{M} \mathrm{CuSO}_{4} 977$ in $0.25 \mathrm{M} \mathrm{H}_{2} \mathrm{SO}_{4}$ led to the formation of dendritic forms with the 978 quantity of the electricity of $10 \mathrm{~mA} \mathrm{~h} \mathrm{~cm}^{-2} \cdot{ }^{67}$ The number of copper 979 
Hydrogen Co-deposition Effects on Copper Electrodeposition

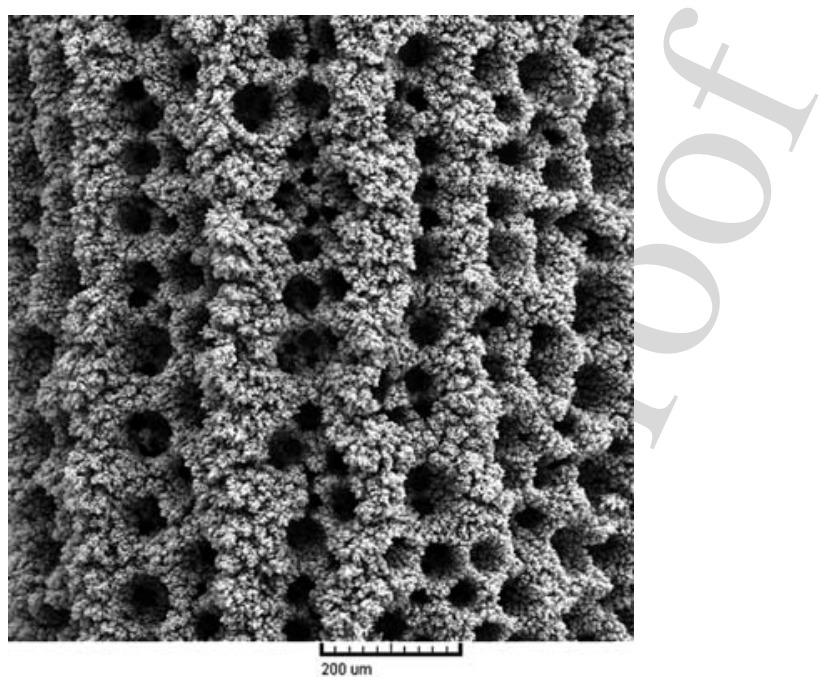

Figure 35. The copper deposit obtained at an overpotential of $1,000 \mathrm{mV}$ from $0.15 \mathrm{M} \mathrm{CuSO}_{4}$ in $1.0 \mathrm{M} \mathrm{H}_{2} \mathrm{SO}_{4}$.

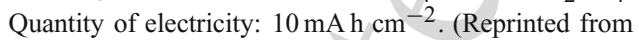
Ref. ${ }^{67}$ with permission from Elsevier).

dendrites formed at a surface area of copper electrodes increased 980 with the decrease of the $\mathrm{H}_{2} \mathrm{SO}_{4}$ concentration. Cauliflower-like 981 forms were obtained by electrodeposition at the same overpoten- 982 tial from $0.15 \mathrm{M} \mathrm{CuSO}_{4}$ in $1.0 \mathrm{M} \mathrm{H}_{2} \mathrm{SO}_{4}$ with the quantity of the 983 electricity of $10 \mathrm{~mA} \mathrm{~h} \mathrm{~cm}^{-2}$. Some of them were developed in den- 984 dritic forms by the electrodeposition with the double quantity of 985 electricity.

986

Copper dendrites were formed by electrodeposition processes at 987 an overpotential of $650 \mathrm{mV}$ from all three solutions (Fig. 33). It can 988 be seen from Fig. 33 that the number of formed dendritic forms in- 989 creased with the decrease of $\mathrm{H}_{2} \mathrm{SO}_{4}$ concentration. Also, the branch- 990 ing of these forms increased with the decrease of the concentration 991 of $\mathrm{H}_{2} \mathrm{SO}_{4}$. The corncob-like forms were grouped in flower-like or 992 tree-like forms, or even formed individually at an electrode surface 993 (Fig. 33).

The analysis of copper electrodeposition processes at overpo- 995 tentials of 550 and $650 \mathrm{mV}$ has shown that the decrease of $\mathrm{H}_{2} \mathrm{SO}_{4} 996$ concentration led to the shift of the formation of dendritic forms 997 


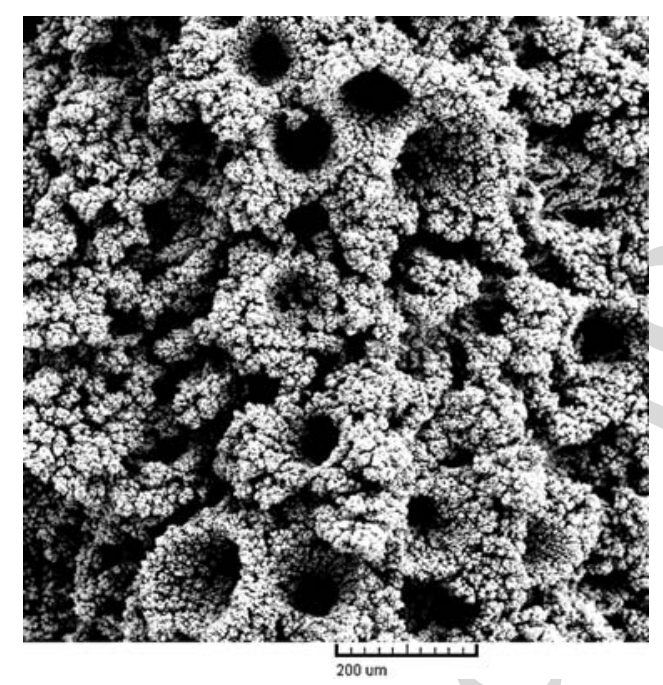

Figure 36. The copper deposit obtained at an overpotential of $1,000 \mathrm{mV}$ from $0.15 \mathrm{M} \mathrm{CuSO}_{4}$ in $0.25 \mathrm{M} \mathrm{H}_{2} \mathrm{SO}_{4}$.

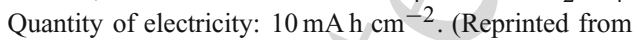
Ref. ${ }^{67}$ with permission from Elsevier).

toward higher overpotentials of electrodeposition. This effect was 998 the same as the one which had been noticed in case of the increas- 999 ing concentration of $\mathrm{Cu}(\mathrm{II})$ ions, ${ }^{19}$ as it was discussed considering 1000 minimum overpotential for dendritic growth initiation.

1001

The morphologies of the copper deposits obtained at an 1002 overpotential of $800 \mathrm{mV}$ are presented in Fig. 34. A channel struc- 1003 ture (Fig. 34a), degenerated dendrites (Fig. 34b), and cauliflower-like 1004 forms (Fig. 34c) were formed by copper electrodeposition from 1005 $0.15 \mathrm{M} \mathrm{CuSO}_{4}$ in $0.125 \mathrm{M} \mathrm{H}_{2} \mathrm{SO}_{4}$. Holes originating from attached 1006 hydrogen bubbles were formed by electrodeposition from $0.15 \mathrm{M} 1007$ $\mathrm{CuSO}_{4}$ in $0.25 \mathrm{MH}_{2} \mathrm{SO}_{4}$ (Fig. 34d). Degenerate dendrites and 1008 cauliflower-like forms, similar to those shown in Fig. 34b, c, were 1009 also formed by electrodeposition from this solution. Finally, the 1010 honeycomb-like structure, constructed from holes formed due to 1011 attached hydrogen bubbles and cauliflower-like agglomerates of 1012 copper grains between them, was formed by the electrodeposition 1013 from $0.15 \mathrm{M} \mathrm{CuSO}_{4}$ in $1.0 \mathrm{M} \mathrm{H}_{2} \mathrm{SO}_{4}$ (Fig. 34e). 
Hydrogen Co-deposition Effects on Copper Electrodeposition
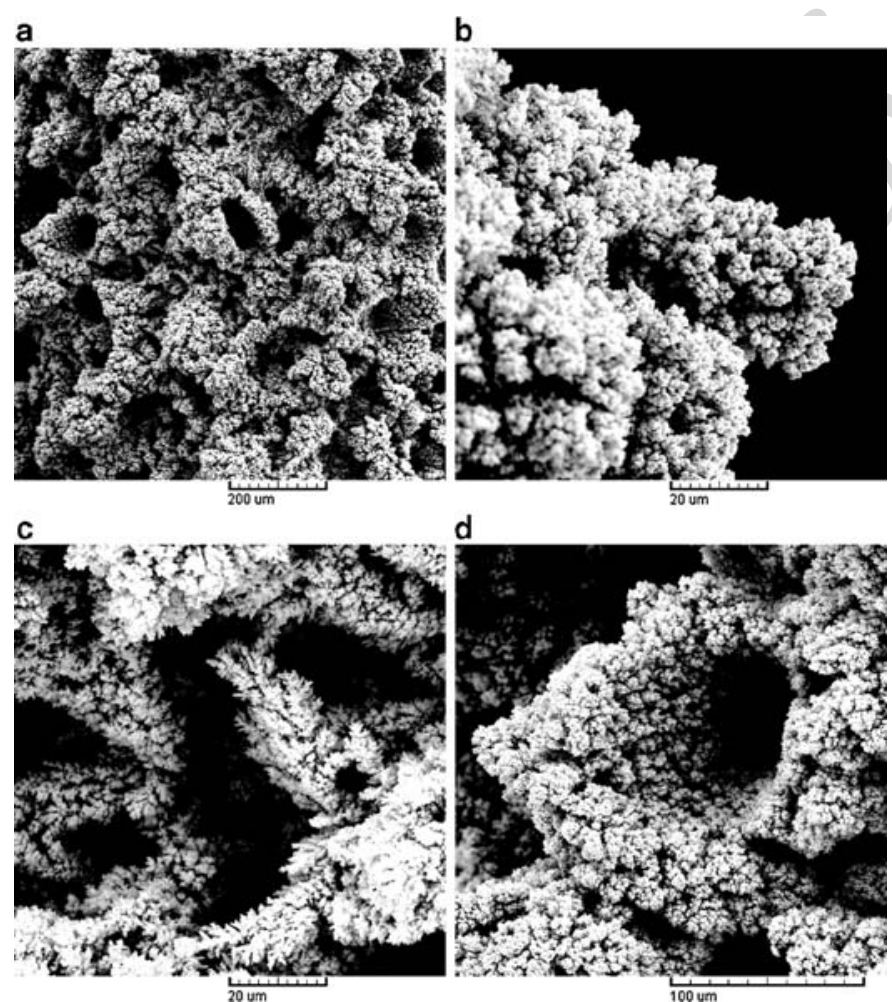

Figure 37. The copper deposit obtained at an overpotential of $1,000 \mathrm{mV}$ from $0.15 \mathrm{M} \mathrm{CuSO}_{4}$ in $0.125 \mathrm{M} \mathrm{H}_{2} \mathrm{SO}_{4}$. Quantity of electricity: $10 \mathrm{mAh} \mathrm{cm}{ }^{-2}$. (Reprinted from Ref. ${ }^{67}$ with permission from Elsevier).

$$
\text { t2.1 Table } 2 \text {. }
$$

The average current efficiencies of hydrogen evolution in the function of $\mathrm{H}_{2} \mathrm{SO}_{4}$ concentration. (Reprinted from Refs. ${ }^{60,67}$ with permissions from Elsevier).

\begin{tabular}{lllcl}
\cline { 3 - 5 } t2.2 & & \multicolumn{2}{c}{$\begin{array}{l}\text { The average current efficiencies of } \\
\text { hydrogen evolution, } \eta_{\text {av }}\left(\mathrm{H}_{2}\right) \text { (in \%), } \\
\text { t2.3 overpotentials of: }\end{array}$} \\
\cline { 3 - 5 } t2.4 & Solution for copper Electrodeposition & $650 \mathrm{mV}$ & $800 \mathrm{mV}$ & $1,000 \mathrm{mV}$ \\
t2.5 & $0.15 \mathrm{M} \mathrm{CuSO}_{4}$ in $0.125 \mathrm{M} \mathrm{H}_{2} \mathrm{SO}_{4}$ & 0 & 4.83 & 20.3 \\
t2.6 & $0.15 \mathrm{M} \mathrm{CuSO}_{4}$ in $0.25 \mathrm{M} \mathrm{H}_{2} \mathrm{SO}_{4}$ & 0.32 & 9.05 & 26.4 \\
t2.7 & $0.15 \mathrm{M} \mathrm{CuSO}_{4}$ in $1.0 \mathrm{M} \mathrm{H}_{2} \mathrm{SO}_{4}$ & 3.3 & 23.3 & 45.7 \\
\cline { 2 - 5 }
\end{tabular}


Morphologies of copper deposits obtained at an overpotential 1017 of 1,000 mV from these copper solutions are shown in Figs. 35-37. 1018 The honeycomb-like structure was formed by the electrodeposition 1019 from $0.15 \mathrm{M} \mathrm{CuSO}_{4}$ in $1.0 \mathrm{M} \mathrm{H}_{2} \mathrm{SO}_{4}$ (Fig. 35). From Fig. 35 it can be 1020 seen that holes were lined up in parallel rows. The average diameter 1021 of formed holes was $50 \mu \mathrm{m}$, while the number of formed holes was 1022 $71 / \mathrm{mm}^{2}$ surface area of the copper electrode. 1023

The honeycomb-like structure was also formed by electrodepo- 1024 sition at $1,000 \mathrm{mV}$ from $0.15 \mathrm{M} \mathrm{CuSO}_{4}$ in $0.25 \mathrm{M} \mathrm{H}_{2} \mathrm{SO}_{4}$ (Fig. 36). 1025 However, in contrast to parallely lined up holes formed from $0.15 \mathrm{M} 1026$ $\mathrm{CuSO}_{4}$ in $1.0 \mathrm{M} \mathrm{H}_{2} \mathrm{SO}_{4}$, holes which made this honeycomb-like 1027 structure were random oriented at the electrode surface. The number 1028 of the formed holes was $14 / \mathrm{mm}^{2}$ surface area of the copper electrode 1029 and it was about five times smaller than the number of holes formed 1030 from $0.15 \mathrm{M} \mathrm{CuSO}_{4}$ in $1.0 \mathrm{M} \mathrm{H}_{2} \mathrm{SO}_{4}$. The decrease of concentration 1031 of $\mathrm{H}_{2} \mathrm{SO}_{4}$ led to the increase of the diameter of holes, and the aver- 1032 age diameter of holes formed from this solution was estimated to be 1033 about $110 \mu \mathrm{m}$.

1034

The random-oriented holes were also formed during copper ele- 1035 ctrodeposition at $1,000 \mathrm{mV}$ from $0.15 \mathrm{M} \mathrm{CuSO}_{4}$ in $0.125 \mathrm{M} \mathrm{H}_{2} \mathrm{SO}_{4} 1036$ (Fig. 37a). However, the detailed analysis of the copper deposit 1037 shown in Fig. 37a revealed the presence of morphological forms 1038 which were not obtained by electrodeposition processes from $0.15 \mathrm{M} 1039$ $\mathrm{CuSO}_{4}$ in both $0.25 \mathrm{M}$ and $1.0 \mathrm{M} \mathrm{H}_{2} \mathrm{SO}_{4}$. Aside from holes and 1040 cauliflower-like agglomerates of copper grains between them, the 1041 presence of degenerate dendrites (Fig. 37b) and irregular channels 1042 formed by evolved hydrogen around dendritic and cauliflower-like 1043 particles (Fig. 37c) were also noticed by the analysis of the copper 1044 deposit electrodeposited from $0.15 \mathrm{M} \mathrm{CuSO}_{4}$ in $0.125 \mathrm{M} \mathrm{H}_{2} \mathrm{SO}_{4} .1045$ Additionally, degenerate dendrites were formed at the shoulders of 1046 some of holes (Fig. 37d). The average diameter of the formed holes 1047 was $120 \mu \mathrm{m}$, while their number was estimated to be $7 / \mathrm{mm}^{2}$ surface 1048 area of the copper electrode.

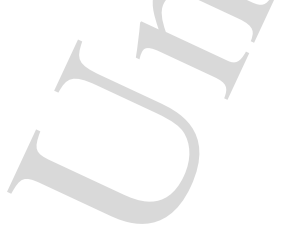


Hydrogen Co-deposition Effects on Copper Electrodeposition

\section{The Effect of Temperature on Electrodeposition} of Disperse Copper Deposits

The polarization curves for the electrodeposition of copper from 1052 $0.15 \mathrm{M} \mathrm{CuSO}_{4}$ in $0.50 \mathrm{M} \mathrm{H}_{2} \mathrm{SO}_{4}$ at temperatures of $14.0 \pm 0.5,1053$ $35.0 \pm 0.5$ and $50.0 \pm 0.5^{\circ} \mathrm{C}$ are given in Fig. 38. It can be seen 1054 from Fig. 38 that increasing the temperature leads to an increase of 1055 the limiting diffusion current density, as well as to a shift of both the 1056 beginning and the end of the plateau of the limiting diffusion current 1057 density toward lower electrodeposition overpotentials.

It is clear from Fig. 38 that an overpotential of $550 \mathrm{mV}$ belongs 1059 to the plateau of the limiting diffusion current density at all analyzed 1060 temperatures. An overpotential of $650 \mathrm{mV}$ belongs to the plateau 1061 of the limiting diffusion current density only at a temperature of 1062 $14.0 \pm 0.5^{\circ} \mathrm{C}$. This overpotential is about $50 \mathrm{mV}$ outside the plateau 1063 at a temperature of $35.0 \pm 0.5^{\circ} \mathrm{C}$ and about $100 \mathrm{mV}$ outside at a 1064

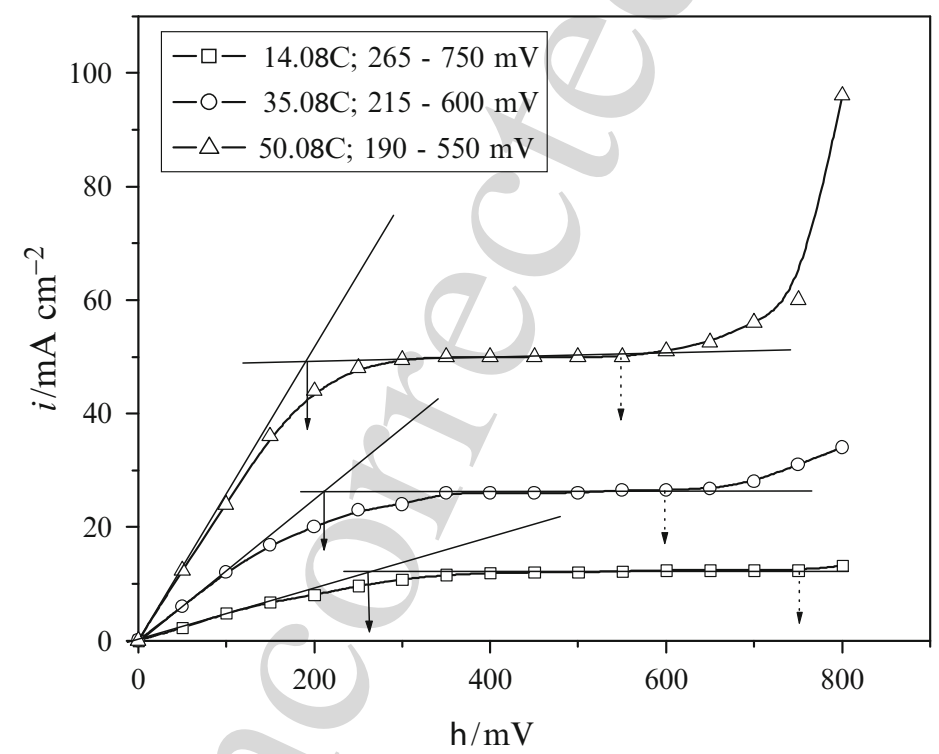

Figure 38. Polarization curves for curves for electrodeposition of copper from $0.15 \mathrm{M} \mathrm{CuSO}_{4}$ in $0.50 \mathrm{M} \mathrm{H}_{2} \mathrm{SO}_{4}$ at temperatures of $14.0 \pm 0.5^{\circ} \mathrm{C}, 35.0 \pm 0.5^{\circ} \mathrm{C}$, and $50.0 \pm 0.5^{\circ} \mathrm{C}$. (Reprinted from Ref. ${ }^{68}$ with permission from the Serbian Chemical Society). 
t3.1 Table 3 .

The values of the average current efficiencies of hydrogen evolution, $\eta_{\mathrm{av}}\left(\mathrm{H}_{2}\right)$ (in \%) in the dependence on temperature of electrodeposition.

(Reprinted from Ref. ${ }^{68}$ with permission from the Serbian Chemical Society).

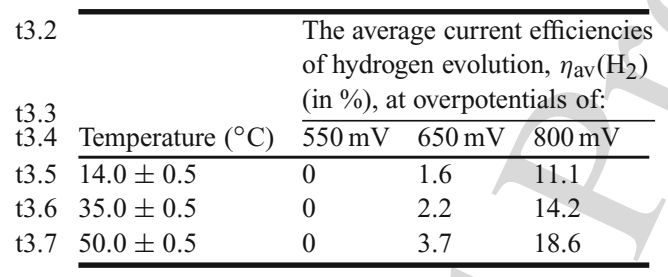

temperature of $50.0 \pm 0.5^{\circ} \mathrm{C}$. Finally, an overpotential of $800 \mathrm{mV} 1065$ is outside the plateau of the limiting diffusion current density at all 1066 temperatures.

The average current efficiences for hydrogen evolution reaction, 1068 $\eta_{\mathrm{av}}\left(\mathrm{H}_{2}\right)$, at overpotentials of 650 and $800 \mathrm{mV}$ are summarized in 1069 Table $3,{ }^{68}$ which also includes the values of the average current effi- 1070 ciences of hydrogen evolution of $0.0 \%$ obtained at an overpotential 1071 of $550 \mathrm{mV}$. It can be clearly seen from Table 3 that the electrodeposi- 1072 tion processes at overpotentials of 650 and $800 \mathrm{mV}$ are accompanied 1073 by the increase of the average current efficiencies of hydrogen evo- 1074 lution with increasing temperature, causing a shift of the end of the 1075 limiting diffusion current density plateau toward lower values of the 1076 overpotential. This is due to the increased rate of hydrogen evolution 1077 with increasing temperature. In totality, the three groups of the aver- 1078 age current efficiences of hydrogen evolution are of significance in 1079 the investigation of the effect of temperture on the electrodeposition 1080 of copper at high overpotentials.

The first group is characterized by electrodeposition of copper 1082 at an overpotential of $550 \mathrm{mV}$, (potential at which there is no hydro- 1083 gen evolution or hydrogen evolution was below the sensitivity of the 1084 measurement technique).

The second group is characterized by processes of electrodepo- 1086 sition at an overpotential of $650 \mathrm{mV}$ (potential at which the average 1087 


\section{Hydrogen Co-deposition Effects on Copper Electrodeposition}

current efficiencies of hydrogen evolution were below the critical 1088 value of the average current efficiency of hydrogen evolution of 1089 $10.0 \%$, leading to a change of the hydrodynamic conditions in the 1090 near-electrode layer in this solution).

Finally, the third group includes electrodeposition processes at 1092 $800 \mathrm{mV}$, which are accompanied by an average current efficiency of 1093 hydrogen evolution above the critical value of $10.0 \%$. 1094

The morphologies of the copper deposits electrodeposited at an 1095 overpotential of $550 \mathrm{mV}$ are cauliflower-like and dendritic ones. ${ }^{68} 1096$ The size of the cauliflower-like particles did not change with in- 1097 creasing temperature, but the size of sub-particles constituting the 1098 cauliflower-like forms which decreased with increasing temperature 1099 of electrodeposition. The decrease of the size of sub-particles with 1100 increasing temperature can be explained by the well-known depen- 1101 dence of the nucleation rate on temperature, ${ }^{69}$ which was derived by 1102 Volmer and Weber. ${ }^{70}$

The morphologies of the copper deposits obtained at an over- 1104 potential of $650 \mathrm{mV}$ are shown in Fig. 39, from which the strong 1105 effect of temperature on the electrodeposition of copper at an over- 1106 potential of $650 \mathrm{mV}$ can immediately be clearly seen. Very branched 1107 copper dendrites were formed during electrodeposition at a temper- 1108 ature of $14.0^{\circ} \mathrm{C}$ (Fig. 39a). They were constructed of corncob-like 1109 elements (Fig. 39b). This is in accordance with the position of an 1110 overpotential of $650 \mathrm{mV}$ in the limiting diffusion current density 1111 plateau. Dendritic forms were obtained during electrodeposition at 1112 a temperature of $35.0^{\circ} \mathrm{C}$ (Fig. 39c) but holes, the origin of which 1113 was attached hydrogen bubbles, were also formed (the part in the 1114 circle in Fig. 39d). The increased hydrogen evolution at a tempera- 1115 ture of $50.0^{\circ} \mathrm{C}$ compared to that at $35.0^{\circ} \mathrm{C}$ led to a change of the 1116 shape of the copper dendrites, which become similar to cauliflower- 1117 like forms (Fig. 39e) or, probably, degenerate dendrites were formed. 1118 Also, the holes formed due to the attachment of hydrogen bubbles 1119 can be observed in this copper deposit (Fig. 39f). These facts were 1120 unexpected because the current efficiency of the hydrogen evolution 1121 reaction was lower than $10.0 \%$, but it can be explained by the find- 1122 ings of Vogt and Balzer. ${ }^{71}$ They showed that the bubble coverage of 1123 an electrode surface increased with temperature more than linearly. 1124 Besides, Krenz ${ }^{72}$ observed an increase in bubble coverage of about 1125 $50 \%$ as the temperature was raised from 25 to $50^{\circ} \mathrm{C}$. 

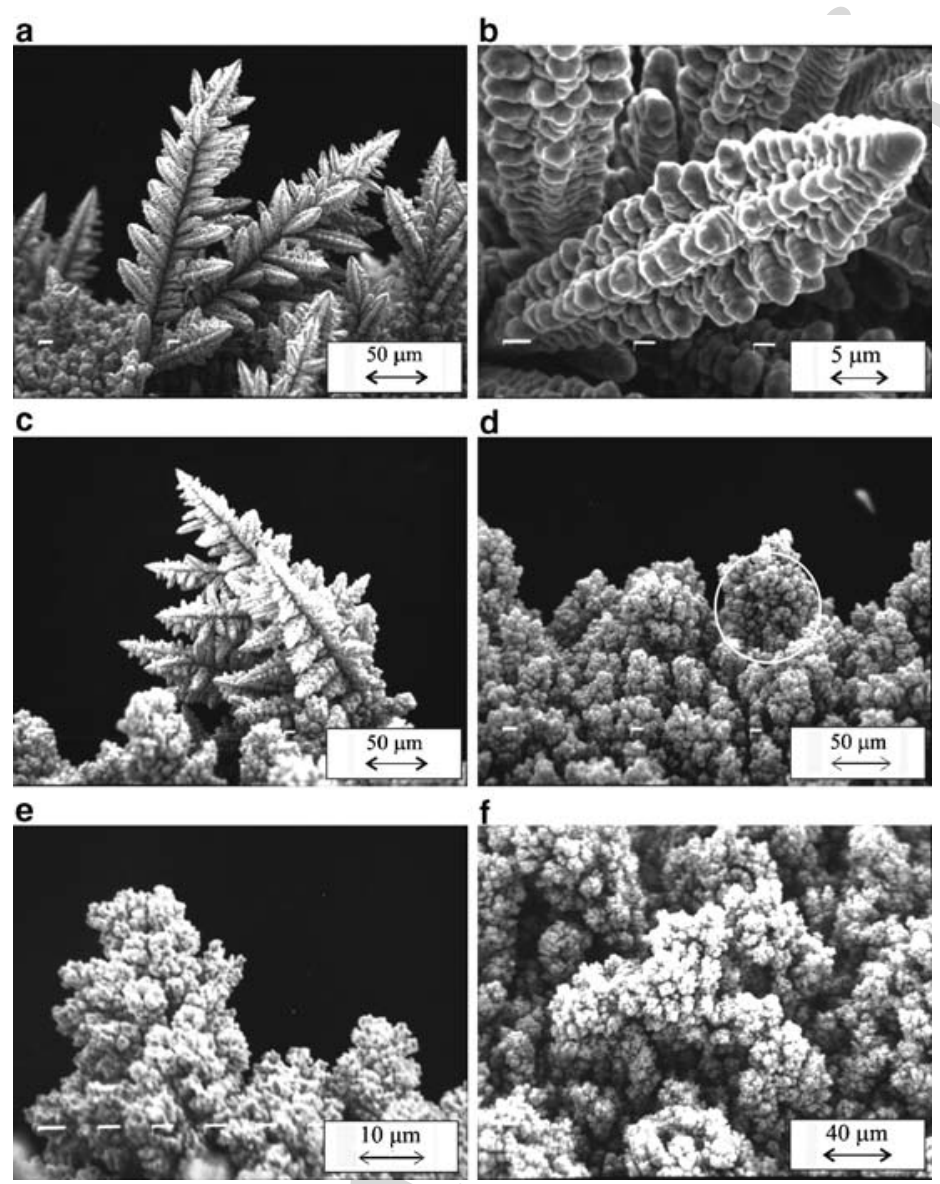

Figure 39. Morphologies of copper deposits electrodeposited at an overpotential of $650 \mathrm{mV}$ at temperatures of: $(\mathbf{a}, \mathbf{b}) 14.0 \pm 0.5^{\circ} \mathrm{C},(\mathbf{c}, \mathbf{d}) 35.0 \pm 0.5^{\circ} \mathrm{C}$, and $(\mathbf{e}, \mathbf{f})$ $50.0 \pm 0.5^{\circ}$ C. (Reprinted from Ref. ${ }^{68}$ with permission from the Serbian Chemical Society).

The morphologies of the copper deposits electrodeposited at an 1127 overpotential of $800 \mathrm{mV}$ are shown in Fig. 40, from which the strong 1128 effect of evolved hydrogen on the morphologies of copper deposits 1129 is visible. Very porous structures, holes formed due to the attach- 1130 ment of hydrogen bubbles, cauliflower-like forms, and the absence 1131 


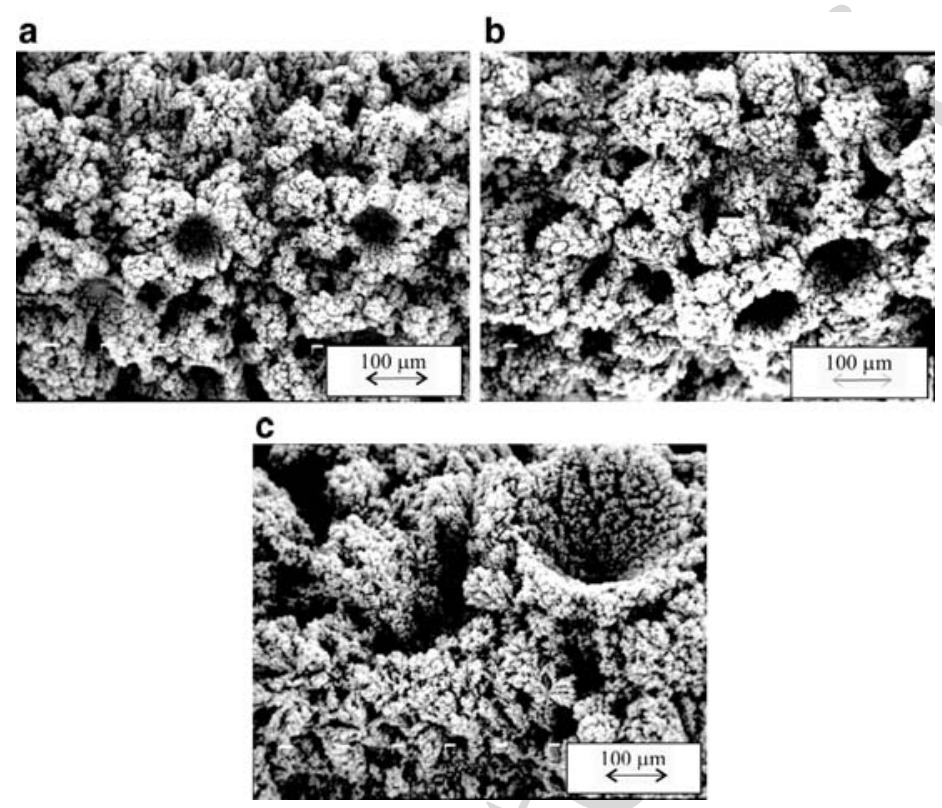

Figure 40. Morphologies of copper deposits electrodeposited at an overpotential of $800 \mathrm{mV}$ at temperatures of: (a) $14.0 \pm 0.5^{\circ} \mathrm{C}$, (b) $35.0 \pm 0.5^{\circ} \mathrm{C}$, and (c) $50.0 \pm 0.5^{\circ} \mathrm{C}$. (Reprinted from Ref. ${ }^{68}$ with permission from the Serbian Chemical Society).

of dendritic forms were the main characteristics of copper deposits 1132 obtained at this overpotential. A decreased number of holes per 1133 square millimeter surface area of copper electrodes and the increased 1134 diameter of the holes with increasing temperature can be observed 1135 from Fig. 40. Also, the portions of the copper structure consisting 1136 of disperse agglomerates of copper grains, among which irregular 1137 channels were formed, increased with increasing temperature of the 1138 solution.

First, it is necessary to note that the decrease of the number 1140 of holes per square millimeter surface area of the copper electrode 1141 with intensification of hydrogen evolution was very surprising. It 1142 is opposed to the already observed phenomena ${ }^{10,17,18}$ when it was 1143 shown that intensification of hydrogen evolution reaction leads to 1144 an increase of the number of holes. Thus, the unexpected develop- 1145 ment of the copper structures with intensification of the hydrogen 1146 
evolution reaction clearly highlights the necessity to take into con- 1147 sideration the effect of temperature on some properties of electro- 1148 plating solution, as well as the already mentioned increased bubble 1149 coverage with the increasing temperature. The properties of an elec- 1150 trolyte of importance in metal electrodeposition processes which are 1151 affected by a change of temperature are the viscosity ${ }^{73}$ and surface 1152 tension of the electrolyte. ${ }^{71}$

In Ref. ${ }^{68}$ are given the values of the viscosity and surface 1154 tension of a copper solution containing $0.15 \mathrm{M} \mathrm{CuSO}_{4}$ in $0.50 \mathrm{M} 1155$ $\mathrm{H}_{2} \mathrm{SO}_{4}$ at the examined temperatures. As expected, both the viscos- 1156 ity and the surface tension of this solution decrease with increas- 1157 ing temperature. The decrease of the surface tension of the solution 1158 lowers the break-off diameter of hydrogen bubble from the electrode 1159 surface, ${ }^{71}$ while the decreased viscosity of the solution probably fa- 1160 cilitates the transport of the detached hydrogen bubbles through the 1161 interior of the deposit, thus forming a channel structure through it. 1162 A typical channel structure formed at an overpotential of $800 \mathrm{mV}$ at 1163 a temperature of $50.0^{\circ} \mathrm{C}$ is shown in Fig. $41 \mathrm{a}$, while the top view of 1164 this deposit shows that very disperse cauliflower-like agglomerates 1165 of copper grains were surrounded by irregular channels (Fig. 41b). 1166

Hence, increase the temperature led to a redistribution of 1167 evolved hydrogen from those creating a honeycomb-like struc- 1168 ture (holes formed due to the attachment of hydrogen bubbles 1169 with cauliflower-like agglomerates of copper grains between them) 1170 to those making a copper structure with the dominant presence 1171 of cauliflower-like forms and irregular channels between them. 1172

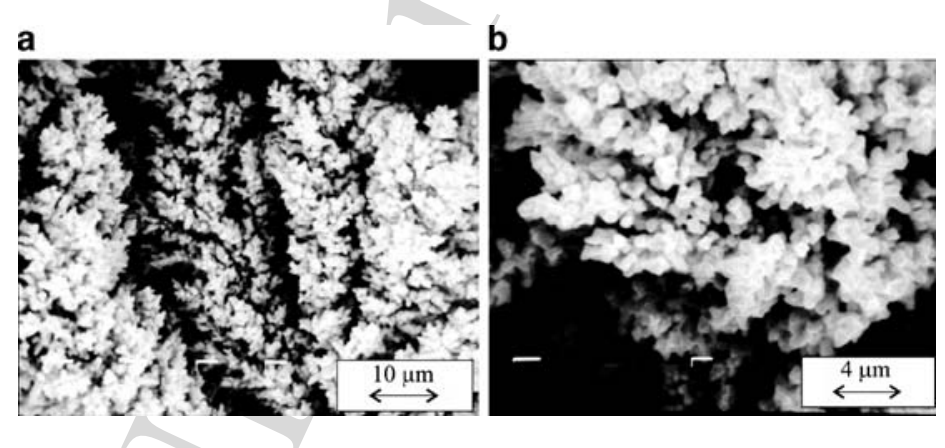

Figure 41. Morphologies of copper deposits electrodeposited at an overpotential of $800 \mathrm{mV}$ at a temperature of $50.0 \pm 0.5^{\circ} \mathrm{C}$. (Reprinted from Ref. ${ }^{68}$ with permission from the Serbian Chemical Society). 
Hydrogen Co-deposition Effects on Copper Electrodeposition

This increase of the portion of channel structure to the overall 1173 structure of the deposit in relation to the portion of holes to the 1174 overall structure is probably due to changes of the properties of the 1175 electroplating solution, caused by the dependences of the viscosity 1176 and surface tension of solution on temperature. As a result of this, 1177 the formation of holes becomes less possible and hence large holes 1178 appear only due to the edge effect, as can be clearly seen from 1179 Fig. 40c. It is obvious that the probability of the formation of the 1180 nucleus of such a structure decreases with lowering of the break-off 1181 diameter of the bubbles.

Also, it is necessary to note that increasing the temperature led 1183 to the formation of morphological forms of copper deposits char- 1184 acteristic for electrodeposition at higher overpotentials, probably 1185 because of the increase of bubble coverage with increasing tempera- 1186 ture. The effect of temperature was opposite to those observed with 1187 increasing the concentration of $\mathrm{Cu}(\mathrm{II})$ ions, ${ }^{19}$ when increasing con- 1188 centration of $\mathrm{Cu}$ (II) ions led to a the formation of morphological 1189 forms of copper deposits characteristic for electrodeposition at lower 1190 overpotentials. $^{19}$

5. Analysis of Deposition Conditions with the Aspect 1192 of the Honeycomb-like Structure Formation 1193

It is obvious that the honeycomb-like structures can be considered 1194 as possible electrodes in electrochemical devices such as fuel cells 1195 and sensors due to their very open and porous structure. Analysis of 1196 the effect of different parameters of electrolysis given in this section 1197 enables to be systematized electrodeposition conditions leading to 1198 the formation of this structure type.

The acceleration of electrochemical processes through the 1200 increase of concentration of $\mathrm{Cu}$ (II) ions above $0.15 \mathrm{M} \mathrm{CuSO}_{4} 1201$ (in $0.50 \mathrm{M} \mathrm{H}_{2} \mathrm{SO}_{4}$ ) showed an unfavorable effect to the formation of 1202 the honeycomb-like structure due to the formation of dish-like holes 1203 with the higher concentrations of $\mathrm{Cu}$ (II) ions. ${ }^{58} 1204$

The formation of degenerate dendrites (Fig. 37b), a channel 1205 structure around dendritic and cauliflower-like particles (Fig. 37c) 1206 and holes with the shoulders of degenerated dendrites (Fig. 37d) 1207 clearly points out that hydrodynamic conditions in the near-electrode 1208 layer were not changed by electrodeposition of copper from $0.15 \mathrm{M} 1209$ $\mathrm{CuSO}_{4}$ in $0.125 \mathrm{M} \mathrm{H}_{2} \mathrm{SO}_{4}$. This was very surprising having in mind 1210 a relatively high average current efficiency of hydrogen evolution 1211 
of $20.3 \%$ by which this deposit was formed. Anyway, it is very 1212 clear that the quantity of evolved hydrogen is not the only parameter 1213 responsible for the formation of the honeycomb-like structures, and 1214 therefore, the analysis of the composition of electrodeposition solu- 1215 tions and electrodeposition conditions is very important. In order to 1216 explain different morphological forms obtained under hydrogen co- 1217 deposition, Fritz equation, ${ }^{74}$ modified by Stephan, ${ }^{75}$ for the bubble 1218 break-off diameter at zero current, $d_{0}$ will be used.

This bubble break-off diameter, $d_{0}$, can be presented by (13):

$$
d_{0}=1.20 \vartheta \sqrt{\frac{\gamma}{\mathrm{g}\left(\rho_{\mathrm{L}}-\rho_{\mathrm{G}}\right)}} * \mathrm{~g}
$$

where $\vartheta$ is contact angle, $\gamma$ is surface tension, $\rho_{\mathrm{L}}$ is a density of 1221 liquid phase, and $\rho_{\mathrm{G}}$ is a density of gaseous phase.

The bubble break-off diameter depends on a current density 1223 and as it was shown by numerous experiments, ${ }^{71,76,77}$ it decreases 1224 with increasing current density. The fact that break-off diameter de- 1225 creases with increasing current density is the result of varying elec- 1226 trode potential which affect the wettability and, hence, the contact 1227 angle supports the conclusion that (13) is a basic relationship to ex- 1228 plain the dependence of the break-off diameter on the current den- 1229 sity. Then, the bubble break-off diameter, $d$ can be presented by 1230 (14): $:^{71}$

$$
\frac{d}{d_{0}}=\left(1+0.2 \frac{I / S}{\mathrm{Am}^{-2}}\right)^{-0.45}
$$

where $I / S$ is the superficial current density.

Using (13) and (14) as well as the fact that a contact angle de- 1233 creases with lowering surface tension, ${ }^{78}$ the formation of morpholo- 1234 gies of copper deposits shown in Figs. 35-37 can be considered as 1235 follows. In Table 4 are given the values for a density and a surface 1236 tension of the examined solutions. As expected, ${ }^{79}$ the density of cop- 1237 per solutions increased with the increase of concentration of $\mathrm{H}_{2} \mathrm{SO}_{4}, 1238$ while the increasing concentration of $\mathrm{H}_{2} \mathrm{SO}_{4}$ lowered the surface 1239 tension values of the examined solutions. The use of electroplating 1240 solution with lower surface tension generates more hydrogen bub- 1241 bles during copper electrodeposition, ${ }^{78}$ which is definitely confirmed 1242 in this investigation. It can be seen from Table 4 that the change of 1243 the density and the surface tension with increasing $\mathrm{H}_{2} \mathrm{SO}_{4}$ concen- 1244 tration was less than $5 \%$. 
Hydrogen Co-deposition Effects on Copper Electrodeposition

t4.1 Table 4.

The values of the density, $\rho$, and the surface tension, $\gamma$, of copper solutions containing $0.15 \mathrm{M} \mathrm{CuSO}_{4}$ in $0.125,0.25$ and $1.0 \mathrm{M}$

$\mathrm{H}_{2} \mathrm{SO}_{4}$. (Reprinted from Ref. ${ }^{67}$ with permission from Elsevier).

\begin{tabular}{llll} 
t0.2 & Solution for copper electrodeposition & $\rho\left(\mathrm{kg} \mathrm{dm}^{-3}\right)$ & $\gamma \times 10^{3}\left(\mathrm{~J} \mathrm{~m}^{-2}\right)$ \\
\cline { 2 - 4 } t0.3 & $0.15 \mathrm{M} \mathrm{CuSO}_{4}$ in $0.125 \mathrm{M} \mathrm{H}_{2} \mathrm{SO}_{4}$ & 1.033 & 100.2 \\
t0.4 & $0.15 \mathrm{M} \mathrm{CuSO}_{4}$ in $0.25 \mathrm{M} \mathrm{H}_{2} \mathrm{SO}_{4}$ & 1.038 & 98.7 \\
t0.5 & $0.15 \mathrm{M} \mathrm{CuSO}_{4}$ in $1.0 \mathrm{M} \mathrm{H}_{2} \mathrm{SO}_{4}$ & 1.081 & 97.6
\end{tabular}

In order to apply (14) to potentiostatic conditions of electrode- 1246 position, an average current density, $I_{\mathrm{av}} / \mathrm{S}$ should be taken into con- 1247 sideration. An average current density, $I_{\mathrm{av}} / \mathrm{S}$ can be presented by 1248 (15), and it was shown that the average current density increased 1249 with the increasing concentration of $\mathrm{H}_{2} \mathrm{SO}_{4}{ }^{67}$

$$
I_{\mathrm{av}} / S=\int_{0}^{t} i \mathrm{~d} t / t
$$

Hence, according to (13), the increase of a density and the 1251 decrease of a surface tension of solution lead to a decrease of the 1252 bubble break-off diameter. According to (14) and (15), at the same 1253 deposition overpotential, copper electrodeposition by the higher av- 1254 erage current density in addition decreases the break-off diameter 1255 of hydrogen bubbles. It is very clear from the above consideration 1256 that the contribiution of the average current density to the decrease 1257 of the break-off diameter is larger than the contribution of the den- 1258 sity and the surface tension of the solutions. It can be concluded 1259 that the change of the break-off diameter of hydrogen bubbles with 1260 the change of $\mathrm{H}_{2} \mathrm{SO}_{4}$ concentration is consequence of synergetic 1261 effect of electroplating solutions properties and electrodeposition 1262 conditions. Anyway, the analysis of densities and surface tensions 1263 of the examined solutions, as well as the average current densities 1264 of electrodeposition successfully explains the change of the size of 1265 holes formed under the described hydrogen co-deposition conditions 1266 (Figs. 35-37).

Finally, the analysis of the break-off diameter (or the diame- 1268 ter of the detached hydrogen bubble) can give an explanation why 1269 the change of hydrodynamic conditions in the near-electrode layer is 1270 achieved from the copper solution with the lower quantity of evolved 1271 hydrogen (i.e. from $0.15 \mathrm{M} \mathrm{CuSO}_{4}$ in $0.50 \mathrm{M} \mathrm{H}_{2} \mathrm{SO}_{4}$ at $800 \mathrm{mV} 1272$ 
with the quantity of evolved hydrogen corresponding to $\eta_{\mathrm{av}}\left(\mathrm{H}_{2}\right)$ of 1273 $10.8 \%$, but not from $0.15 \mathrm{M} \mathrm{CuSO}_{4}$ in $0.125 \mathrm{M} \mathrm{H}_{2} \mathrm{SO}_{4}$ where the 1274 quantity of evolved hydrogen corresponded to $\eta_{\mathrm{av}}\left(\mathrm{H}_{2}\right)$ of $\left.20.3 \%\right) . \quad 1275$

An increase of the density and the lowering of surface tension 1276 of the solution decreases the break-off diameter of bubble ((13) and 1277 (14)), and consequently, reduce the time needed for its detachment 1278 from an electrode surface. After the detachment of hydrogen bubble, 1279 the further electrodeposition process occurs by the formation of new 1280 hydrogen bubbles at an energetically active sites of electrode surface. 1281 A successive processes of the formation of hydrogen bubbles at an 1282 energetically active sites of electrode surface and their ability to rela- 1283 tively fast achieve the critical size for the detachment from electrode 1284 surface, produces an sufficient amount of hydrogen bubbles which 1285 can cause an effective stirring of solution in the near-electrode layer. 1286 This will lead to the decrease of the cathode diffusion layer thick- 1287 ness and the increase of the limiting diffusion current density, and as 1288 a result of this, the change of hydrodynamic conditions in the near- 1289 electrode layer is achieved. In this way, copper structures constructed 1290 of holes and agglomerates of copper grains between them, as well as 1291 without dendritic forms (denoted as the honeycomb-like structure) 1292 are formed.

On the other hand, the use of an electroplating solution of lower 1294 density and higher surface tension increases the break-off diam- 1295 eter of hydrogen bubbles. It means that during electrodeposition 1296 process from such a solution, newly formed hydrogen bubbles co- 1297 alesce primarily with hydrogen bubbles formed in the initial stage of 1298 electrodeposition, increasing their diameter and prolonging a time 1299 needed for their detachment from electrode surface. In this way, the 1300 number of formed hydrogen bubbles will not be sufficient to cause 1301 an effective stirring of solution in the near-electrode layer. As a re- 1302 sult of insufficient change of hydrodynamic conditions in the near- 1303 electrode layer, dendritic growth is not inhibited completely and 1304 degenerate dendrites as well as dendritic particles inside channels 1305 formed of evolved hydrogen were obtained.

The analysis of a number of holes formed per square millime- 1307 ter surface area of copper electrodes and the average diameter of 1308 holes obtained from $0.15 \mathrm{M} \mathrm{CuSO}_{4}$ in $0.50 \mathrm{M} \mathrm{H}_{2} \mathrm{SO}_{4}$ at $800 \mathrm{mV} 1309$ and from $0.15 \mathrm{M} \mathrm{CuSO}_{4}$ in $0.125 \mathrm{M} \mathrm{H}_{2} \mathrm{SO}_{4}$ at $1,000 \mathrm{mV}$ confirms 1310 above consideration. The number of holes formed due to the attached 1311 hydrogen bubbles from $0.15 \mathrm{M} \mathrm{CuSO}_{4}$ in $0.50 \mathrm{M} \mathrm{H}_{2} \mathrm{SO}_{4}$ at $800 \mathrm{mV} 1312$ was $10 / \mathrm{mm}^{2}$ surface area of copper electrode, ${ }^{17}$ while their average 1313 
Hydrogen Co-deposition Effects on Copper Electrodeposition

diameter was approximately $98.7 \mu \mathrm{m}$. This number was for about 1314 $40 \%$ larger than the number of holes formed from $0.15 \mathrm{M} \mathrm{CuSO}_{4}$ in 1315 $0.125 \mathrm{M} \mathrm{H}_{2} \mathrm{SO}_{4}$ at $1,000 \mathrm{mV}$. The average diameter of holes formed 1316 from $0.15 \mathrm{M} \mathrm{CuSO}_{4}$ in $0.125 \mathrm{M} \mathrm{H}_{2} \mathrm{SO}_{4}$ at $1,000 \mathrm{mV}$ was for about 1317 $20 \%$ larger than the average diameter of those formed from $0.15 \mathrm{M} 1318$ $\mathrm{CuSO}_{4}$ in $0.50 \mathrm{M} \mathrm{H}_{2} \mathrm{SO}_{4}$ at $800 \mathrm{mV}$.

Anyway, the results of the performed qualitative consideration 1320 clearly indicate that Fritz equation ${ }^{74}$ modified by Stephan ${ }^{75}$ can be 1321 applied for the examination of copper electrodeposition processes 1322 under hydrogen co-deposition in potentiostatic conditions. 1323

The acceleration of electrochemical processes through the in- 1324 crease of a temperature of electrolysis showed an unfavorable effect 1325 to the formation of the honeycomb-like structures. ${ }^{68}$ The increase of 1326 a temperature leads to the decrease of number of holes because of 1327 the effect of a temperature on some properties of solutions such as a 1328 viscosity and a surface tension. ${ }^{68,71-73} 1329$

Hence, the conditions which must be fulfilled in order to get the 1330 honeycomb-like structure are: electrodeposition from the solutions 1331 with lower concentrations of $\mathrm{Cu}$ (II) ions $\left(0.15 \mathrm{M} \mathrm{CuSO}_{4}\right.$ and less) in 1332 a concentration range from $0.25 \mathrm{M}$ to $1.0 \mathrm{M} \mathrm{H}_{2} \mathrm{SO}_{4}$, at a temperature 1333 of $18.0 \pm 1.0^{\circ} \mathrm{C}$ and at overpotentials outside the plateau of the lim- 1334 iting diffusion current density at which hydrogen evolution is vigor- 1335 ous enough to change hydrodynamic conditions in the near-electrode 1336 layer. The critical quantity of evolved hydrogen enabling the for- 1337 mation of the honeycomb-like structures under the given electrode- 1338 position conditions corresponds to the average current efficiency of 1339 hydrogen evolution, $\eta_{\mathrm{av}}\left(\mathrm{H}_{2}\right)$ of $10.0 \%{ }^{19} 1340$

The number of craters or holes forming the honeycomb-like 1341 structure increased rapidly with the quantity of evolved hydrogen, as 1342 can be seen from Fig. 42 which shows the dependence of the number 1343 of holes or craters formed due to the attachment of hydrogen bubbles 1344 on the average current efficiency of hydrogen evolution.

\section{INFLUENCE OF IONIC EQUILIBRIUM IN THE 1346 $\mathrm{CUSO}_{4}-\mathrm{H}_{2} \mathrm{SO}_{4}-\mathrm{H}_{2} \mathrm{O}$ SYSTEM ON THE FORMATION 1347 OF IRREGULAR ELECTRODEPOSITS OF COPPER 1348}

The most suitable way to analyze the ionic equilibrium in the 1349 $\mathrm{CuSO}_{4}-\mathrm{H}_{2} \mathrm{SO}_{4}-\mathrm{H}_{2} \mathrm{O}$ system was the examination of electrode- 1350 position processes at overpotentials outside the plateau of the 1351 


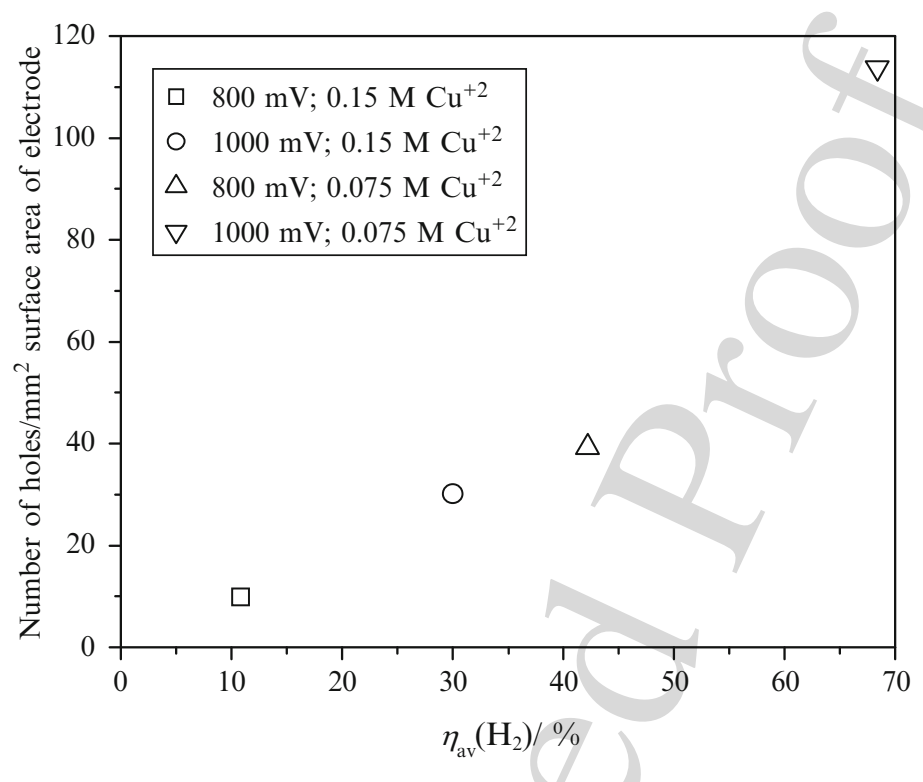

Figure 42. The dependence of the number of holes formed due to the attachment of hydrogen bubbles per square millimeter surface area of copper electrode on the average current efficiency of hydrogen evolution. (Reprinted from Ref. ${ }^{19}$ with permission from MDPI).

limiting diffusion current density, due to the hydrogen evolution 1352 reaction which occurs parallel to the copper electrodeposition. In 1353 order to do it, two sets of acid sulfate solutions were analyzed. In 1354 one set of experiments, the concentration of $\mathrm{CuSO}_{4}$ was the same 1355 $\left(0.15 \mathrm{M} \mathrm{CuSO}_{4}\right)$, while the concentration of $\mathrm{H}_{2} \mathrm{SO}_{4}$ was different 1356 $\left(0.125,0.25\right.$, and $\left.1.0 \mathrm{M} \mathrm{H}_{2} \mathrm{SO}_{4}\right)$. The other set of experiments was 1357 performed with a constant concentration of $\mathrm{H}_{2} \mathrm{SO}_{4}$ and different 1358 concentrations of $\mathrm{CuSO}_{4}\left(0.075,0.30\right.$, and $0.60 \mathrm{M} \mathrm{CuSO}_{4}$ in $0.50 \mathrm{M} 1359$ $\mathrm{H}_{2} \mathrm{SO}_{4}$ ). Then, the volumes of the evolved hydrogen (calculated as 1360 the average current efficiencies of hydrogen evolution) and the mor- 1361 phologies of copper deposits obtained at an overpotential of $800 \mathrm{mV} 1362$ for the same ratio of $\mathrm{CuSO}_{4} / \mathrm{H}_{2} \mathrm{SO}_{4}$ were mutually compared and 1363 discussed in terms of the relative concentrations of hydrogen ions 1364 $\left(\mathrm{H}^{+}\right)$as a function of the $\mathrm{H}_{2} \mathrm{SO}_{4}$ concentration. ${ }^{60} 1365$

The ratios $\mathrm{CuSO}_{4} / \mathrm{H}_{2} \mathrm{SO}_{4}$ were: 1.2 (for the copper solutions 1366 containing $0.15 \mathrm{M} \mathrm{CuSO}_{4}$ in $0.125 \mathrm{M} \mathrm{H}_{2} \mathrm{SO}_{4}$ and $0.60 \mathrm{M} \mathrm{CuSO}_{4} 1367$ 
Hydrogen Co-deposition Effects on Copper Electrodeposition

in $0.50 \mathrm{M} \mathrm{H}_{2} \mathrm{SO}_{4}$ ), 0.60 (for the copper solutions containing $0.15 \mathrm{M} 1368$ $\mathrm{CuSO}_{4}$ in $0.25 \mathrm{M} \mathrm{H}_{2} \mathrm{SO}_{4}$ and $0.30 \mathrm{M} \mathrm{CuSO}_{4}$ in $0.50 \mathrm{M} \mathrm{H}_{2} \mathrm{SO}_{4}$ ), and 1369 0.15 (for the copper solutions containing $0.15 \mathrm{M} \mathrm{CuSO}_{4}$ in $1.0 \mathrm{M} / 1370$ $\mathrm{H}_{2} \mathrm{SO}_{4}$ and $0.075 \mathrm{M} \mathrm{CuSO}_{4}$ in $\left.0.50 \mathrm{M} \mathrm{H}_{2} \mathrm{SO}_{4}\right) .{ }^{60} 1371$

Analyzing the $\mathrm{CuSO}_{4} / \mathrm{H}_{2} \mathrm{SO}_{4}$ ratio of 1.2 by insight into the 1372 ionic equilibrium of the species in the $\mathrm{CuSO}_{4}-\mathrm{H}_{2} \mathrm{SO}_{4}-\mathrm{H}_{2} \mathrm{O}$ system 1373 (Fig. 1), where the position of the $\mathrm{Cu}$ concentration of $0.15 \mathrm{M}$ can 1374 easily be calculated, it can be noticed that the relative concentration 1375 of $\mathrm{H}^{+}$ions is larger for the copper solution containing $0.15 \mathrm{M} 1376$ $\mathrm{CuSO}_{4}$ in $0.125 \mathrm{M} \mathrm{H}_{2} \mathrm{SO}_{4}$ than it is for the one containing $0.60 \mathrm{M} 1377$ $\mathrm{CuSO}_{4}$ in $0.50 \mathrm{M} \mathrm{H}_{2} \mathrm{SO}_{4}$. This is confirmed by the larger aver- 1378 age current efficiency of hydrogen evolution from $0.15 \mathrm{M} \mathrm{CuSO}_{4} 1379$ in $0.125 \mathrm{M} \mathrm{H}_{2} \mathrm{SO}_{4}(4.83 \%)$ than from $0.60 \mathrm{M} \mathrm{CuSO}_{4}$ in $0.50 \mathrm{M} 1380$ $\mathrm{H}_{2} \mathrm{SO}_{4}(0.66 \%)$. The obtained morphologies of the copper de- 1381 posits (Figs. 34a-c and 25e) also were in a good agreement with the 1382 determined average current efficiency of hydrogen evolution and 1383 this ionic equilibrium. The formation of degenerate dendrites from 1384 $0.15 \mathrm{M} \mathrm{CuSO}_{4}$ in $0.125 \mathrm{M} \mathrm{H}_{2} \mathrm{SO}_{4}$ is the consequence of the larger 1385 quantity of evolved hydrogen from this solution than from $0.60 \mathrm{M} 1386$ $\mathrm{CuSO}_{4}$ in $0.50 \mathrm{M} \mathrm{H}_{2} \mathrm{SO}_{4}$ when copper dendrites only were formed. 1387

A similar consideration can also be applied to the $\mathrm{CuSO}_{4} / 1388$ $\mathrm{H}_{2} \mathrm{SO}_{4}$ ratio of 0.60 . According to the ionic equilibrium in 1389 $\mathrm{CuSO}_{4}-\mathrm{H}_{2} \mathrm{SO}_{4}-\mathrm{H}_{2} \mathrm{O}$ system, the relative concentration of $\mathrm{H}^{+}$ions 1390 is larger for a copper solution containing $0.15 \mathrm{M} \mathrm{CuSO}_{4}$ in $0.25 \mathrm{M} 1391$ $\mathrm{H}_{2} \mathrm{SO}_{4}$ than for one containing $0.30 \mathrm{M} \mathrm{CuSO}_{4}$ in $0.50 \mathrm{M} \mathrm{H}_{2} \mathrm{SO}_{4} .1392$ The experimentally determined average current efficiency of hydro- 1393 gen evolution and the observed morphologies of the copper deposits 1394 (Figs. 34d and 25b, d) were also in good agreement with the cal- 1395 culation of this ionic equilibrium. The presence of dendritic forms 1396 during electrodeposition from $0.30 \mathrm{M} \mathrm{CuSO}_{4}$ in $0.50 \mathrm{M} \mathrm{H}_{2} \mathrm{SO}_{4}$ at 1397 $800 \mathrm{mV}$ (Fig. 25b) clearly indicates that copper electrodeposition 1398 was accompanied by a smaller quantity of evolved hydrogen from 1399 this solution than from $0.15 \mathrm{M} \mathrm{CuSO}_{4}$ in $0.25 \mathrm{M} \mathrm{H}_{2} \mathrm{SO}_{4}$. 1400

Finally, the honeycomb-like copper structures were obtained 1401 with a $\mathrm{CuSO}_{4} / \mathrm{H}_{2} \mathrm{SO}_{4}$ ratio of 0.15 . The honeycomb-like copper 1402 structure was formed from $0.075 \mathrm{M} \mathrm{CuSO}_{4}$ in $0.50 \mathrm{M} \mathrm{H}_{2} \mathrm{SO}_{4}$ un- 1403 der more vigorous hydrogen evolution than that formed from $0.15 \mathrm{M} 1404$ $\mathrm{CuSO}_{4}$ in $1.0 \mathrm{M} \mathrm{H}_{2} \mathrm{SO}_{4}$, which is also in agreement with the calcu- 1405 lation of the ionic equilibrium in the $\mathrm{CuSO}_{4}-\mathrm{H}_{2} \mathrm{SO}_{4}-\mathrm{H}_{2} \mathrm{O}$ system. 1406 


\section{THE SHAPE OF ELECTROCHEMICALLY FORMED 1407 COPPER POWDER PARTICLES AND THEIR 1408 DEPENDENCE ON THE QUANTITY OF EVOLVED / 1409 HYDROGEN

In spite of detailed investigations of the formation and properties of 1411 metal powders obtained by electrolysis, ${ }^{13,22-25}$ the first report which 1412 considered the effect of hydrogen evolution on the shape of powder 1413 particles was given recently. ${ }^{80}$

It was found ${ }^{80}$ that two types of powder copper particles are 1415 formed, depending on the quantity of evolved hydrogen. The first 1416 type is formed with a quantity of evolved hydrogen which is insuf- 1417 ficient to change the hydrodynamic conditions in the near-electrode 1418 layer $\left(\eta_{\mathrm{av}}\left(\mathrm{H}_{2}\right)<10.0 \%\right)$, whereas the second type is formed when 1419 the quantity of evolved hydrogen is sufficient to change the hydro- 1420 dynamic conditions in the near-electrode layer $\left(\eta_{\mathrm{av}}\left(\mathrm{H}_{2}\right)>10.0 \%\right) . \quad 1421$

The first type of copper powder particles is shown in Fig. 43a. 1422 These particles were obtained by tapping the copper deposit obtained 1423 by electrodeposition from $0.15 \mathrm{M} \mathrm{CuSO}_{4}$ in $0.50 \mathrm{M} \mathrm{H}_{2} \mathrm{SO}_{4}$ at an 1424 overpotential of $700 \mathrm{mV}$ which was accompanied by $\eta_{\mathrm{av}}\left(\mathrm{H}_{2}\right)$ of 1425 $1.97 \% .{ }^{10}$ It can be seen from Fig. 43a that the copper particles were 1426 highly branched dendrites. The typical branchy from which these 1427 powder particles are constructed is presented in Fig. 43b.

The basic element from which this type of powder particles 1429 is constructed was obtained by a treatment of the copper powder 1430
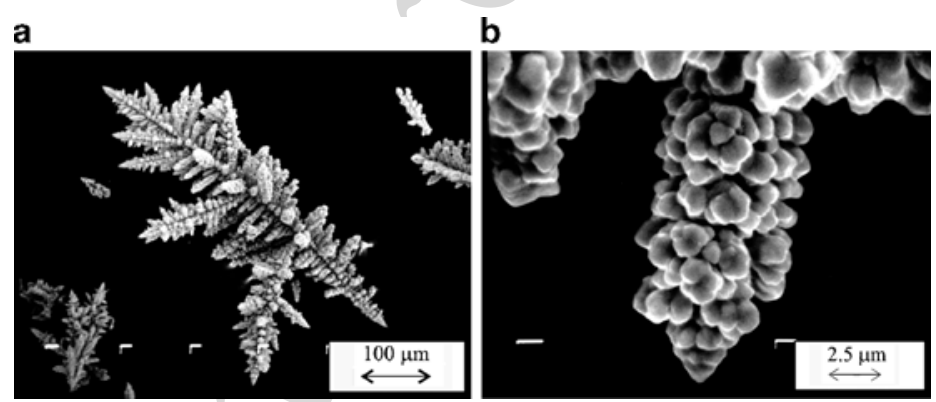

Figure 43. SEM photomicrographs of copper powder particles obtained by electrodeposition from $0.15 \mathrm{M} \mathrm{CuSO}_{4}$ in $0.50 \mathrm{M} \mathrm{H}_{2} \mathrm{SO}_{4}$, at an overpotential of $700 \mathrm{mV}$. (Reprinted from Ref. ${ }^{80}$ with permission from Elsevier). 

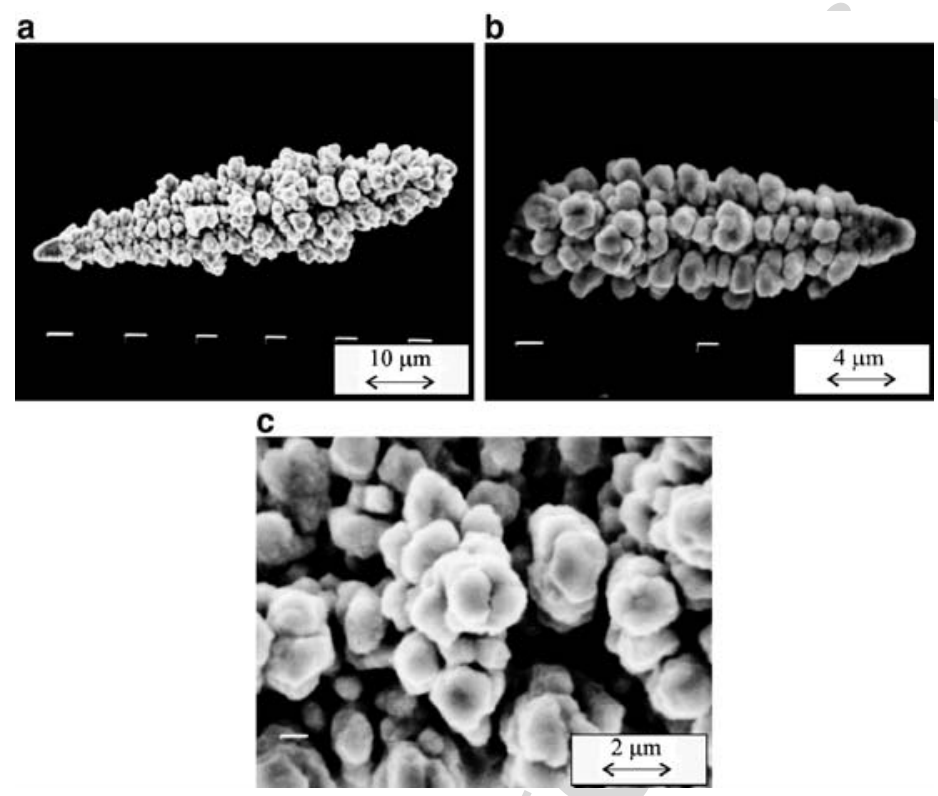

Figure 44. SEM photomicrographs of copper powder particles shown in Fig. 43 after treatment in an ultrasonic field. (Reprinted from Ref. ${ }^{80}$ with permission from Elsevier).

particles shown in Fig. 43 in an ultrasonic field. The resulting 1431 particles are shown in Fig. 44. From Fig. 44a, b, it can be seen that 1432 the particles obtained had a corncob-like structure. They all took 1433 the form of branches of dendrites but, although they had the same 1434 surface structure, a difference in their size was noticeable. Analy- 1435 sis of these branches at the micro level revealed that the branches 1436 consisted of agglomerates of copper grains (Figs. 43b and 44c). 1437

According to Wranglen, ${ }^{81}$ a dendrite consists of a stalk and 1438 branches (primary, secondary, etc.). It is obvious from Figs. 431439 and 44 that the corncob-like elements forming the branches consti- 1440 tute the dendritic character of these particles. These corncob-like 1441 elements can be grouped in different forms of dendritic particles 1442 or alternatively can be formed individually at the electrode surface. 1443 This can easily be seen from Fig. 45, which shows disperse deposits 1444 immediately before they were tapped from the electrode surface. 1445 They were all obtained by electrodeposition processes when the 1446 

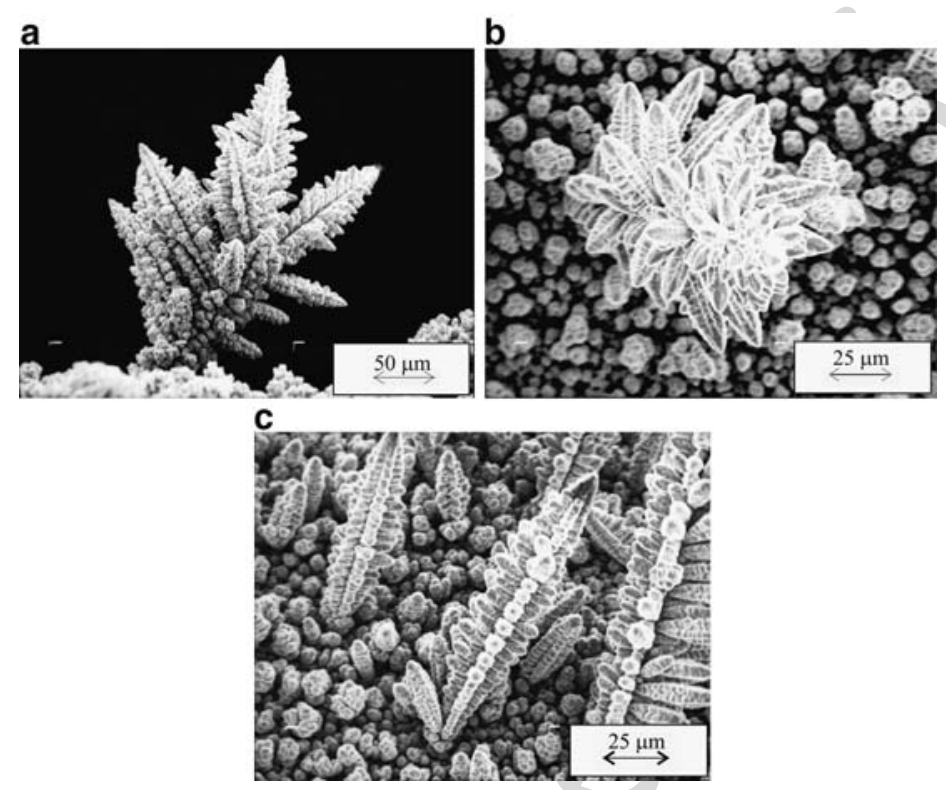

Figure 45. SEM photomicrographs of the copper powder deposits obtained by electrodeposition at an overpotential of $650 \mathrm{mV}$ from: (a) $0.075 \mathrm{M} \mathrm{CuSO}_{4}$ in $0.50 \mathrm{M}$ $\mathrm{H}_{2} \mathrm{SO}_{4}$; (b, c) $0.30 \mathrm{M} \mathrm{CuSO}_{4}$ in $0.50 \mathrm{M} \mathrm{H}_{2} \mathrm{SO}_{4}$. (Reprinted from Ref. ${ }^{80}$ with permission from Elsevier).

quantities of evolved hydrogen were below the critical value for a 1447 change in the hydrodynamic conditions in the near-electrode layer. 1448 Figure 45 a shows the powder deposit electrodeposited at an overpo- 1449 tential of $650 \mathrm{mV}$ from $0.075 \mathrm{M} \mathrm{CuSO}_{4}$ in $0.50 \mathrm{M} \mathrm{H}_{2} \mathrm{SO}_{4}\left(\eta_{\mathrm{av}}\left(\mathrm{H}_{2}\right) \quad 1450\right.$ was $7.5 \%),{ }^{19}$ whereas Fig. $45 \mathrm{~b}$, c shows the powder deposits elec- 1451 trodeposited at the same overpotential but from $0.30 \mathrm{M} \mathrm{CuSO}_{4}$ in 1452 $0.50 \mathrm{M} \mathrm{H}_{2} \mathrm{SO}_{4}\left(\eta_{\mathrm{av}}\left(\mathrm{H}_{2}\right)\right.$ was $\left.0.83 \%\right) .{ }^{19}$ The electrodeposition pro- 1453 cess which led to the formation of the highly branched dendritic 1454 particles was controlled by the diffusion of ions to the electrode 1455 surface, rather than electron transfer control. ${ }^{13}$

The powder particles belonging to the second type are shown 1457 in Fig. 46a. They are obtained by tapping the copper deposit elec- 1458 trodeposited from $0.15 \mathrm{M} \mathrm{CuSO}_{4}$ in $0.50 \mathrm{M} \mathrm{H}_{2} \mathrm{SO}_{4}$ at an overpo- 1459 tential of $1,000 \mathrm{mV}$ at which the electrodeposition of copper was 1460 accompanied by vigorous hydrogen evolution, corresponding to 1461 

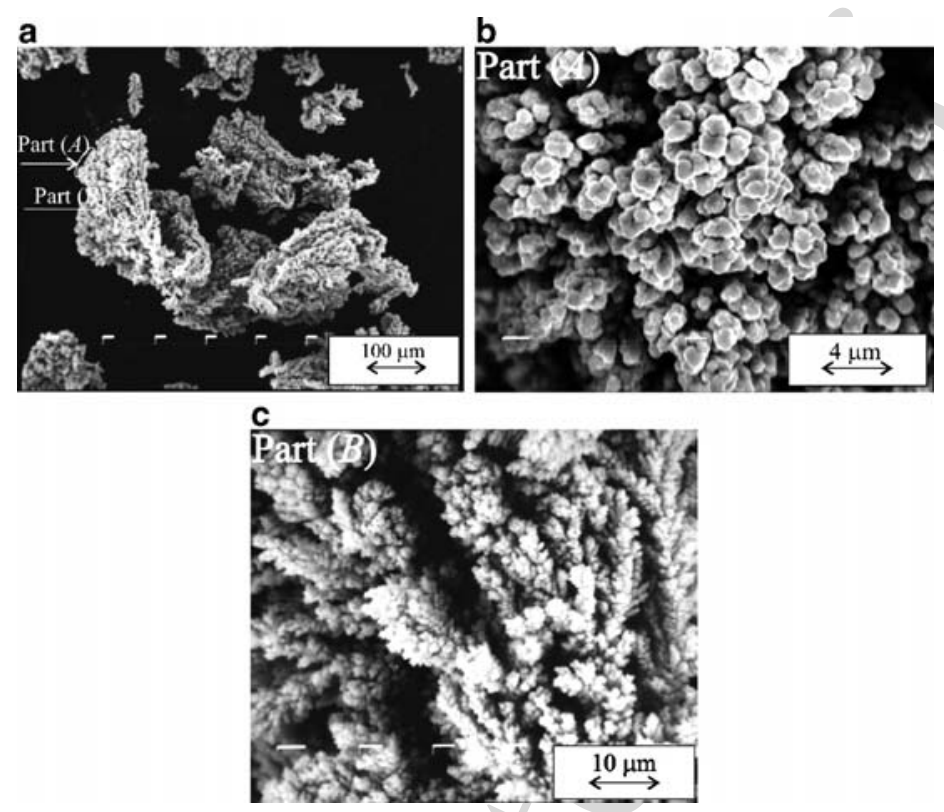

Figure 46. SEM photomicrographs of copper powder particles obtained by electrodeposition from $0.15 \mathrm{M} \mathrm{CuSO}_{4}$ in $0.50 \mathrm{M} \mathrm{H}_{2} \mathrm{SO}_{4}$, at an overpotential of $1,000 \mathrm{mV}$. (Reprinted from Ref. ${ }^{80}$ with permission from Elsevier).

$\eta_{\mathrm{av}}\left(\mathrm{H}_{2}\right)$ of $30.0 \%{ }^{10}$ These powder particles were sponge-like and 1462 the difference between them and those formed when the quantity of 1463 evolved hydrogen was below the critical value for a change in the 1464 hydrodynamic conditions (Figs. 43-45) is clear. For this reason, fur- 1465 ther analysis of these particles is necessary. The parts of the powder 1466 particle denoted with Part $(A)$ and Part $(B)$ in Fig. 46a are shown 1467 at higher magnifications in Fig. 46b, c, respectively. It can be seen 1468 from Fig. 46b that these particles actually have a cauliflower-like 1469 structure. In Fig. 46c, a porous, channel structure through the in- 1470 terior of the powder particle can be seen. These channels were 1471 generated in situ by the simultaneous processes of the formation of 1472 copper particles and vigorous hydrogen evolution. 1473

The basic element from which this type of powder particles 1474 is constructed was obtained by treatment of the particles shown in 1475 Fig. 46a in an ultrasonic field. Figure 47 shows the particles obtained 1476 

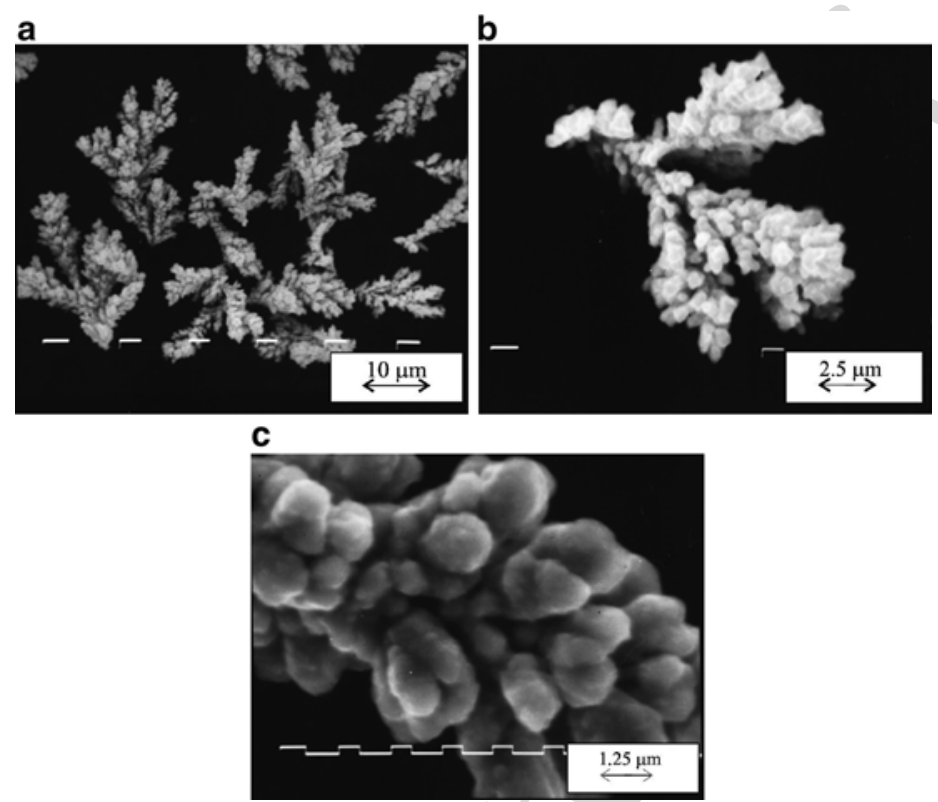

Figure 47. SEM photomicrographs of copper powder particles shown in Fig. 46 after treatment in an ultrasonic field. (Reprinted from Ref. ${ }^{80}$ with permission from Elsevier).

after treatment in an ultrasonic field. It can be seen that the structure 1477 of the basic element of which these powder particles are com- 1478 posed was completely different to that obtained when the amount 1479 of evolved hydrogen was below the critical value for a change in the 1480 hydrodynamic conditions in the near-electrode layer. In this case, 1481 corncob-like structures were not formed. The particles obtained had 1482 irregular shapes and had the appearance of degenerate dendrites. 1483 This shape is obviously caused by the vigorous hydrogen evolu- 1484 tion, or hydrogen stream, which prevents the growth of the copper 1485 deposit in one direction, resulting in particles with a curvilinear 1486 form. Agglomerates of copper grains can also clearly be seen in 1487 these powder particles (Fig. 47b, c).

Although the powder particles obtained with evolved hydrogen 1489 below and above the critical value for a change in the hydrodynamic 1490 conditions were very different at the macro level, their similarity at 1491 the micro level is very clear. Both types of powder particles consisted 1492 


\section{Hydrogen Co-deposition Effects on Copper Electrodeposition}

of agglomerates of copper grains. The only difference lay in the size 1493 of the individual copper grains of which these agglomerates were 1494 constituted - that is, the individual copper grains obtained at an over- 1495 potential of $1,000 \mathrm{mV}$ were considerably smaller. This difference 1496 can be explained by the higher nucleation rate at an overpotential 1497 of $1,000 \mathrm{mV}$ than at an overpotential of $700 \mathrm{mV}$. 1498

The mechanism of electrodeposition of copper under intensive 1499 hydrogen evolution is completely different from that which led to the 1500 formation of dendritic particles. The quantity of evolved hydrogen 1501 corresponding to an average current efficiency of hydrogen evolution 1502 of $30.0 \%$ was sufficient to cause mixing of the solution in the near- 1503 electrode layer, decreasing the cathode diffusion layer thickness and 1504 increasing the limiting diffusion current density. The formation of 1505 this type of powder particle can be successfully explained by the 1506 concept of "effective overpotential.""10 1507

\section{ACKNOWLEDGMENT}

The work was supported by the Ministry of Science and Tech- 1509 nological Development of the Republic of Serbia under the 1510 research project: "Deposition of ultrafine powders of metals and 1511 alloys and nanostructured surfaces by electrochemical techniques" 1512 (No. 142032G).

\section{REFERENCES}

${ }^{1}$ H.-C. Shin, J. Dong, and M. Liu, Adv. Mater. 15 (2003) 1610.

$\begin{array}{ll}{ }^{2} \text { D. R. Gabe, J. Appl. Electrochem. } 27 \text { (1997) 908. } & 1516 \\ { }^{3} \text { J. K. Dennis and T. E. Such, Nickel and Chromium Plating, Newnes-Butterworths, } & 1517\end{array}$

London (1972). 1518

${ }^{4}$ R. Weiner and A. Walmsley, Chromium Plating, Finishing Publications Ltd., Ted- 1519 dington, Middlesex, England (1980). 1520

${ }^{5}$ F. A. Lowenheim, Electroplating, McGraw-Hill Book Company, New York; 1521

St. Louis (1978). $\quad 1522$

${ }^{6}$ T. J. Wolery, EQ3NR - A Computer Program for Geochemical Aqueous Speciation- 1523 Solubility Calculations: Theoretical Manual and User'guide, Version 7.0. Lawrence 1524 Livermore National Laboratory, Livermore, CA (1992). 1525

${ }^{7}$ A. Roine, HSC Chemistry: Chemical Reaction and Equilibrium Software with 1526 Extensive Thermochemical Database. 4.0. Outokumpu Research Oy, Finland 1527 (1999).

${ }^{8}$ J. M. Casas, F. Alvarez, and L. Cifuentes, Chem. Eng. Sci. 55 (2000) 6223. 
N.D. Nikolić and K.I. Popov

${ }^{9}$ K. S. Pitzer, Activity Coefficients in Electrolyte Solutions, 2nd edition, CRC, Boca 1530 Raton, FL (1991). 1531

${ }^{10}$ N. D. Nikolić, K. I. Popov, Lj. J. Pavlović, and M. G. Pavlović, J. Electroanal. Chem. 1532 588 (2006) 88.

${ }^{11}$ V. D. Jović, B. M. Jović, and M. G. Pavlović, Electrochim. Acta 51 (2006) 5468.1534

${ }^{12}$ V. D. Jović, B. M. Jović, V. Maksimović, and M. G. Pavlović, Electrochim. Acta 521535

(2007) 4254. 1536

${ }^{13}$ K. I. Popov, S. S. Djokić, and B. N. Grgur, Fundamental Aspects of Electromet- 1537

allurgy, Kluwer Academic/Plenum Publishers, New York (2002), and references 1538

$\begin{array}{ll}\text { therein. } & 1539 \\ & \end{array}$

${ }^{14}$ H. Vogt, J. Appl. Electrochem. 25 (1995) 764.

${ }^{15}$ J. Eigeldinger, and H. Vogt, Electrochim. Acta 45 (2000) 4449.

${ }^{16}$ H. Vogt, Electrochim. Acta 50 (2005) 2073.

${ }^{17}$ N. D. Nikolić, K. I. Popov, Lj. J. Pavlović, and M. G. Pavlović, Surf. Coat. Technol. 1543

201 (2006) 560. 1544

${ }^{18}$ N. D. Nikolić, K. I. Popov, Lj. J. Pavlović, and M. G. Pavlović, J. Solid State Elec- 1545

trochem. 11 (2007) 667. 1546

${ }^{19}$ N. D. Nikolić, K. I. Popov, Lj. J. Pavlović, and M. G. Pavlović, Sensors 7 (2007) 1. 1547

${ }^{20}$ G. E. Dima, A. C. A. de Vooys, and M. T. M. Koper, J. Electroanal. Chem. 554-555 1548

(2003) $15 . \quad 1549$

${ }^{21}$ D. Pletcher and Z. Poorbedi, Electrochim. Acta 24 (1979) 1253.

${ }^{22}$ A. Calusaru, Electrodeposition of Metal Powders, Elsevier Scientific Publishing 1551

Company, Amsterdam; Oxford; New York (1979) 296.

${ }^{23}$ K. I. Popov and M. G. Pavlović, in Modern Aspects of Electrochemistry, Vol. 24, 1553

Ed. by R. W. White, J. O'M. Bockris, and B. E. Conway, Plenum Press, New York 1554

(1993) 299-391. 1555

${ }^{24}$ N. D. Nikolić, S. B. Krstić, Lj. J. Pavlović, M. G. Pavlović, and K. I. Popov, "The 1556

Mutual Relation of Decisive Characteristics of Electrolytic Copper Powder and 1557

Effect of Deposition Conditions On Them", in Electroanalytical Chemistry Re- 1558

search Trends, Ed. by K. Hayashi, NOVA Publishers (2009) Chap. 8, 185-209. 1559

${ }^{25}$ M. G. Pavlović and K. I. Popov (2005). Metal Powder Production by Electrol- 1560 ysis, Electrochemistry Encyclopedia, http://electrochem.cwru.edu/ed/encycl/art- 1561

p04-metalpowder.htm. 1562

${ }^{26}$ M. G. Pavlović, N. D. Nikolić, and K. I. Popov, J. Serb. Chem. Soc. 68 (2003) 649. 1563

${ }^{27}$ J. O’M. Bockris, Z. Nagy, and D. Dražić, J. Electrochem. Soc. 120 (1973) 30. 1564

${ }^{28}$ K. I. Popov, M. D. Maksimović, J. D. Trnjančev, and M. G. Pavlović, J. Appl. Elec- 1565

trochem. 11 (1981) $239 . \quad 1566$

${ }^{29}$ N. Ibl, Chemie Ing. Techn. 33 (1961) 69.

${ }^{30}$ N. Ibl, Chemie Ing. Techn. 35 (1963) 353. 1568

${ }^{31}$ L. J. Jenssen and J. G. Hoogland, Electrochim. Acta 15 (1970) 1013.

${ }^{32}$ J. O'M. Bockris, A. K. N. Reddy, and M. Gamboa-Aldeco, Modern Electro- 1570

chemistry 2A, Fundamentals of Electrodics, Kluwer Academic/Plenum Publishers, 1571

New York, 2nd edition (2000). $\quad 1572$

${ }^{33}$ L. Martins, J. I. Martins, A. S. Romeira, M. E. Costa, J. Costa, and M. Bazzaoui, 1573

Mater. Sci. Forum 455-456 (2004) 844.

${ }^{34}$ N. D. Nikolić, H. Wang, H. Cheng, C. Guerrero, E. V. Ponizovskaya, G. Pan, and 1575

N. Garcia, J. Electrochem. Soc. 151 (2004) C577. 1576

${ }^{35}$ N. D. Nikolic, H. Wang, H. Cheng, C. A. Guerrero, and N. Garcia, J. Magn. Magn. 1577

Mater. 272-276 (2004) 2436.

${ }^{36}$ N. D. Nikolić, J. Serb. Chem. Soc. 70 (2005) 1213.

${ }^{37}$ N. D. Nikolić, J. Serb. Chem. Soc. 70 (2005) 785. 1580

${ }^{38}$ N. D. Nikolić, J. Serb. Chem. Soc. 71 (2006) 1083. 


\section{Hydrogen Co-deposition Effects on Copper Electrodeposition}

${ }^{39}$ N. D. Nikolić, J. Serb. Chem. Soc. 72 (2007) 787.

${ }^{40}$ M. G. Pavlović, Š. Kindlova, and I. Roušar, Electrochim. Acta 37 (1992) 23.

${ }^{41}$ R. Aogaki, K. Fueki, and T. Mukaibo, Denki Kagaku 43 (1975) 509.

${ }^{42}$ J. P. Glas and J. W. Westwater, Int. J. Heat Mass Transf. 7 (1964) 1427.

${ }^{43}$ R. Kaishew and B. Mutafctschiew, Electrochim. Acta 10 (1965) 643.

${ }^{44}$ S. Štrbac, Z. Rakočević, K. I. Popov, M. G. Pavlović, and R. Petrović, J. Serb. Chem. 1587

Soc. 64 (1999) 483.

${ }^{45}$ I. Markov, A. Boynov, and S. Toshev, Electrochim. Acta 18 (1973) 377.

${ }^{46}$ K. I. Popov, B. N. Grgur, E. R. Stojilković, M. G. Pavlović, and N. D. Nikolić, J. Serb. 1590

Chem. Soc. 62 (1997) 433. 1591

${ }^{47}$ A. Milchev, W. S. Kruijt, M. Sluyters-Rehbach, and J. H. Sluyters, J. Electroanal. 1592

Chem. 362 (1993) $21 . \quad 1593$

${ }^{48}$ W. S. Kruijt, M. Sluyters-Rehbach, J. H. Sluyters, and A. Milchev, J. Electroanal. 1594

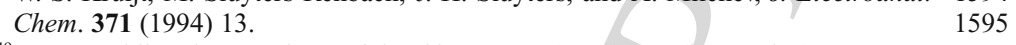

${ }^{49}$ N. Kovarskii and A. V. Lisov, Elektrokhimiya 20 (1984) 221 (in Russian). 1596

${ }^{50}$ N. Kovarskii and A. V. Lisov, Elektrokhimiya 20 (1984) 833 (in Russian). 1597

${ }^{51}$ N. Kovarskii and T. A. Arzhanova, Elektrokhimiya 20 (1984) 452 (in Russian). 1598

${ }^{52}$ K. I. Popov, Lj. J. Pavlović, M. G. Pavlović, and M. I. Čekerevac, Surf. Coat. Technol. 1599

35 (1988) 39. 1600

${ }^{53}$ K. I. Popov, M. G. Pavlović, Lj. J. Pavlović, M. I. Čekerevac, and G. Ž. Remović, 1601

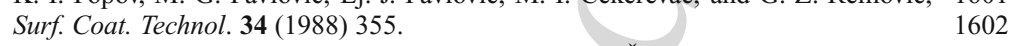

${ }^{54}$ K. I. Popov, M. G. Pavlović, E. R. Stojilković, and Z. Ž. Stevanović, Hydrometal- 1603 lurgy 46 (1997) 321. 1604

${ }^{55}$ K. I. Popov, S. K. Zečević, and S. M. Pešić, J. Serb. Chem. Soc. 61 (1996) 583. 1605

${ }^{56}$ K. I. Popov, N. D. Nikolić, and Z. Rakočević, J. Serb. Chem. Soc. 67 (2002) 635. 1606

${ }^{57}$ K. I. Popov, N. D. Nikolić, and Z. Rakočević, J. Serb. Chem. Soc. 67 (2002) 769. 1607

${ }^{58}$ N. D. Nikolić, Lj. J. Pavlović, M. G. Pavlović, and K. I. Popov, Electrochim. Acta 521608

$\begin{array}{ll}\text { (2007) 8096. } & 1609\end{array}$

${ }^{59}$ N. D. Nikolić, Lj. J. Pavlović, G. Branković, M. G. Pavlović, and K. I. Popov, J. Serb. 1610

Chem. Soc. 73 (2008) 753.

${ }^{60}$ N. D. Nikolić, Lj. J. Pavlović, S. B. Krstić, M. G. Pavlović, and K. I. Popov, Chem. 1612

Eng. Sci. 63 (2008) $2824 . \quad 1613$

${ }^{61}$ D. G. Offin, P. R. Birkin, and T. G. Leighton, Electrochem. Commun. 9 (2007) 1062. 1614

${ }^{62}$ K. I. Popov, V. Radmilović, B. N. Grgur, and M. G. Pavlović, J. Serb. Chem. Soc. 591615 (1994) $47 . \quad 1616$

${ }^{63}$ L. Barton and J. O’M. Bockris, Proc. R. Soc. A268 (1962) 485.

${ }^{64}$ J. W. Diggle, A. R. Despić, and J. O’M. Bockris, J. Electrochem. Soc. 116 (1969) 1618 $\begin{array}{ll}1503 . & 1619\end{array}$

${ }^{65}$ E. Gileadi, Electrode Kinetics, VCH Publishers Inc., New York, (1993) 443.

${ }^{66}$ K. I. Popov, N. V. Krstajić, and M. I. Čekerevac, in: Modern Aspects of Electrochem- 1621 istry, Vol. 30, Ed. by R. E. White, B. E. Conway, and J. O’M. Bockris, Plenum Press, 1622 New York (1996) 261-311, and references therein. 1623

${ }^{67}$ N. D. Nikolić, G. Branković, M. G. Pavlović, and K. I. Popov, J. Electroanal. Chem. 1624 621 (2008) 13. 1625

${ }^{68}$ N. D. Nikolić, Lj. J. Pavlović, M. G. Pavlović, and K. I. Popov, J. Serb. Chem. Soc. 1626 72 (2007) 1369. 1627

${ }^{69}$ E. Budevski, G, Staikov, and W. J. Lorenz, Electrochemical Phase Formation and 1628 Growth, An Introduction to the Initial Stages of metal Deposition, VCH Weinheim, 1629 New York; Basel; Cambridge; Tokyo (1996) 163.

${ }^{70}$ M. Volmer and A. Weber, Z. Physik. Chem. 119 (1926) 277.

${ }^{71}$ H. Vogt and R. J. Balzer, Electrochim. Acta $\mathbf{5 0}(2005) 2073$. 
